\title{
WestVirginiaUniversity
}

THE RESEARCH REPOSITORY @ WVU

Graduate Theses, Dissertations, and Problem Reports

2021

\section{Quantifying the Impact of Load-Following on Gas-fired Power Plants}

\author{
Yifan Wang \\ WVU, yw0001@mix.wvu.edu
}

Follow this and additional works at: https://researchrepository.wvu.edu/etd

Part of the Process Control and Systems Commons

\section{Recommended Citation}

Wang, Yifan, "Quantifying the Impact of Load-Following on Gas-fired Power Plants" (2021). Graduate Theses, Dissertations, and Problem Reports. 8143.

https://researchrepository.wvu.edu/etd/8143

This Dissertation is protected by copyright and/or related rights. It has been brought to you by the The Research Repository @ WVU with permission from the rights-holder(s). You are free to use this Dissertation in any way that is permitted by the copyright and related rights legislation that applies to your use. For other uses you must obtain permission from the rights-holder(s) directly, unless additional rights are indicated by a Creative Commons license in the record and/ or on the work itself. This Dissertation has been accepted for inclusion in WVU Graduate Theses, Dissertations, and Problem Reports collection by an authorized administrator of The Research Repository @ WVU.

For more information, please contact researchrepository@mail.wvu.edu. 


\title{
Quantifying the Impact of Load-Following on Gas-fired Power Plants
}

\author{
Yifan Wang \\ Dissertation submitted to the \\ Benjamin M. Statler College of Engineering and Mineral Resources \\ at West Virginia University \\ in partial fulfillment of the requirements for the degree of \\ Doctor of Philosophy \\ in \\ Chemical Engineering
}

Debangsu Bhattacharyya, $\mathrm{PhD}$, Chair

Richard Turton, $\mathrm{PhD}$

Fernando V. Lima, $\mathrm{PhD}$

Xingbo Liu, $\mathrm{PhD}$

Stephen E. Zitney, PhD

Department of Chemical and Biomedical Engineering

Morgantown, West Virginia

2021

Keywords: natural gas, load-following, thermal-mechanical stress, equipment health, dynamic modeling, multi-objective optimization

Copyright 2021 Yifan Wang 


\section{Abstract \\ Quantifying the Impact of Load-Following on Gas-fired Power Plants

\author{
Yifan Wang
}

Due to rapid penetration of renewables into the grid, natural gas combined cycle (NGCC) power plants are being forced to cycle their loads more frequently and rapidly than for which they were designed. However, the impact of load-following operation on plant efficiency and equipment health are currently poorly understood. The objective of this work is to quantify the impact of loadfollowing on the gas-fired plants by developing high-fidelity multi-scale dynamic models.

There are four main tasks in this project. First, dynamic model of an NGCC power plant has been developed. The main components of the NGCC plants are the gas turbine (GT), heat recovery steam generator (HRSG), and steam turbine (ST). The second task focuses on one of the undesired phenomena known as 'spraying to saturation' being faced by the NGCC plants during loadfollowing, where the attemperator spray leads to saturation at the inlet of superheater and/or reheater causing damage and eventual failure of the superheater and/or reheater tubes due to twophase flow. Different configurations of NGCC plants and operation strategies that can not only eliminate 'spraying to saturation' but can maximize the plant efficiency have been developed and evaluated. The third task focuses on modeling the unprecedented damages to the boiler components due to rapid load-following, which is leading to higher operation and maintenance $(\mathrm{O \& M})$ costs. Stress and wear models have been developed by accounting for creep and fatigue damages in key HRSG components. Multiple locations at the component junctions have been monitored and the most stressed part has been identified as the constraint in the dynamic optimization of the load-following operation. A multi-objective dynamic optimization algorithm has been developed for maximizing plant efficiency and minimizing deviation from desired ramp rates while satisfying operational constraints such as those due to stress and wear. The fourth task focuses on developing reduced order models. Since the modeling domain of interest includes multiple time scales and multiple spatial scales, it can be computationally intractable to use the 
detailed models for optimization/scheduling/control. Therefore, reduced order dynamic models have been developed for the NGCC system including the health models so that they can be computationally tractable for being used in dynamic optimization while providing desired accuracy. 


\section{Acknowledgements}

I would like to express my deepest gratitude to Dr. Debangsu Bhattacharyya, my advisor and a great mentor during my PhD study at WVU. His knowledge and expertise are extremely valuable and helpful to me in understanding the dynamic modeling and optimization of the advance process and energy system. His support, patience, and mentorship are of great importance in my development as a young researcher. I would also like to extend my gratitude to Dr. Richard Turton as my co-advisor, and other committee members, Dr. Fernando V. Lima, Dr. Xingbo Liu and Dr. Stephen E. Zitney, for their insightful advices, guidances and supports in my research work.

I would like to thank U.S.-China Clean Energy Research Center and U.S. Department of Energy for funding my research. I sincerely thank all the members from Dr. Debangsu's research group, Dr. Yuan, Dr. Zhang, Dr. Huang, Dr. Morgan, Dr. Mevawala, Pushpitha, Paul, Anca, Gautham, Ryan, Eli, Katie, Parikshit, Vivek, Ana, Pavitra, Dr. Mihn, Vinayak and many others for sharing their knowledges and insights, and building a friendly and interesting research environment. Thanks also to my friends Xin, Rebecca, Lei, Xiao, Xinwei, Shuyun, Lingfeng, Liu, Jing, Xiaofei, Xuan, Haiyang, Yihan, Yibing for making the life at Morgantown a memorable one.

Most importantly, I would like to thank my family members for supporting me with love all these years. 


\section{Contents}

Abstract.

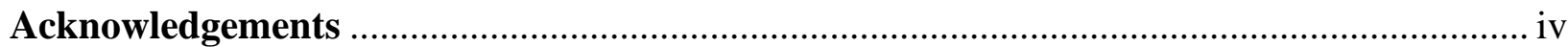

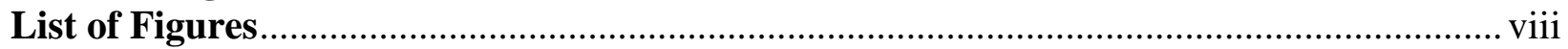

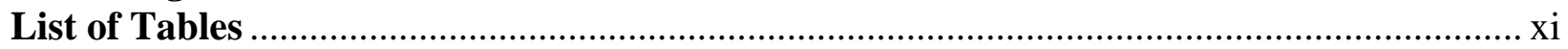

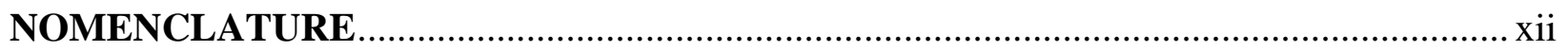

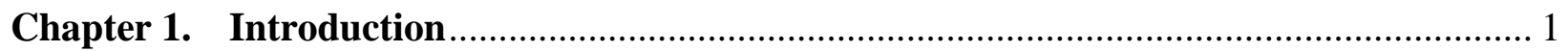

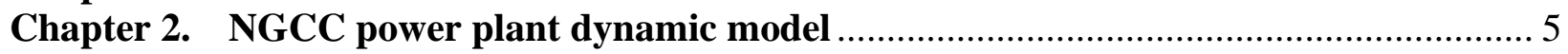

2.1. Literature review ............................................................................................ 5

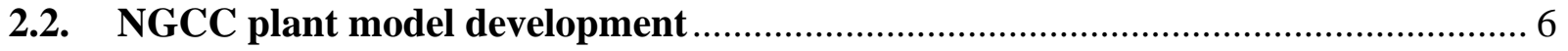

2.2.1 Gas turbine (GT) ...................................................................................... 7

2.2.2 Heat recovery steam generator (HRSG) ............................................................... 8

2.2.3 Steam turbine (ST) ................................................................................. 9

2.2.4 Regulatory and supervisory control layers....................................................... 13

2.3. Results and discussion.................................................................................... 14

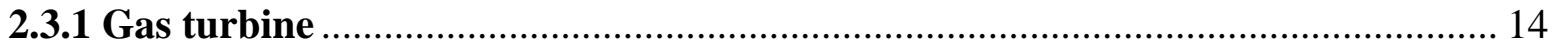

2.3.2 Heat recovery steam generator (HRSG) …….............................................. 15

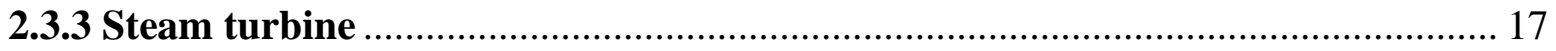

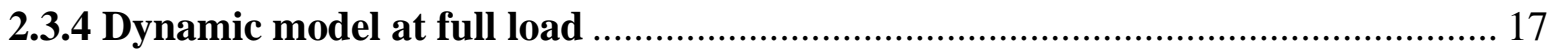

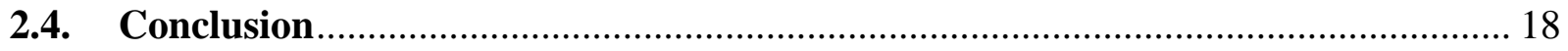

Chapter 3. Novel configurations of NGCC plant for load-following ................................... 19

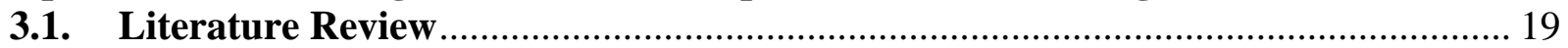

3.2. NGCC configurations and control strategies for load-following operation............. 20

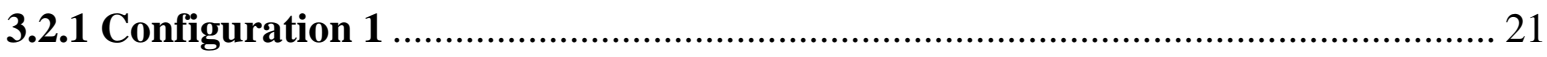

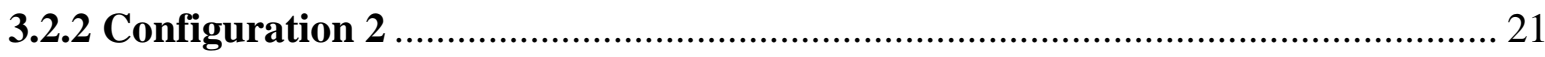

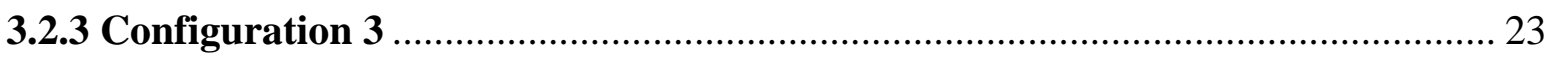

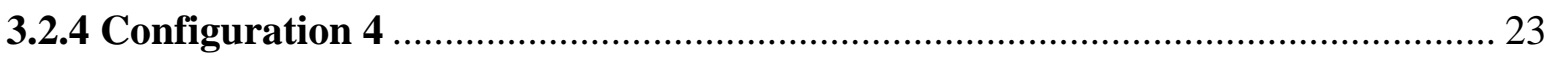

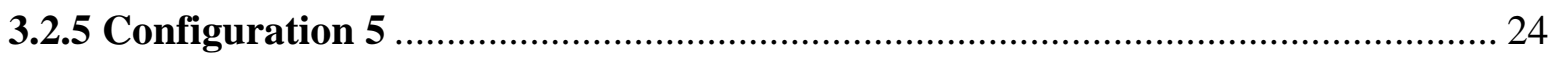

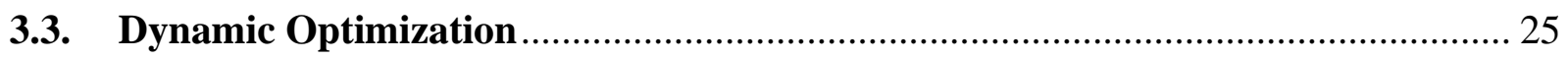

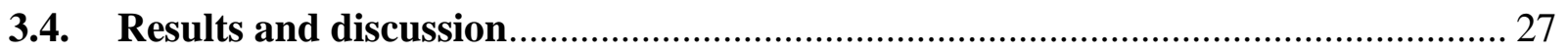

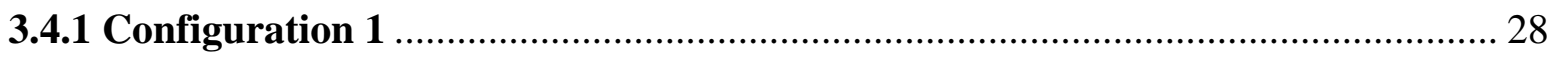

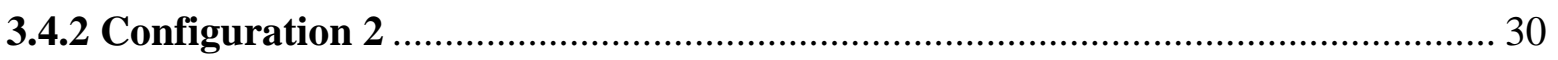

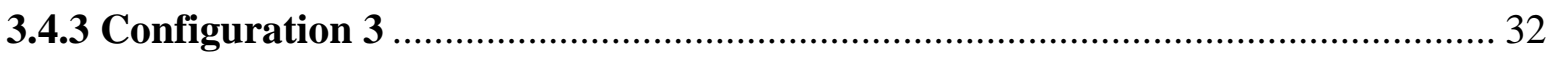

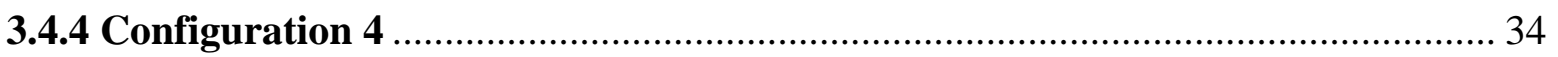

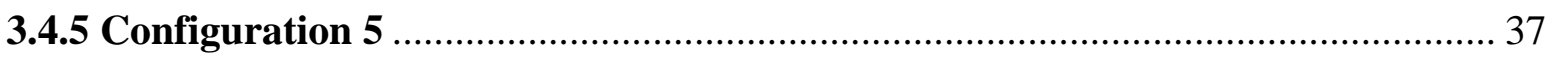

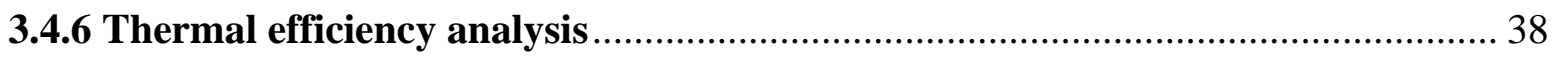


3.5. Conclusion

Chapter 4. Optimal load-following of NGCC plant with stress monitoring of highpressure boiler drum 42

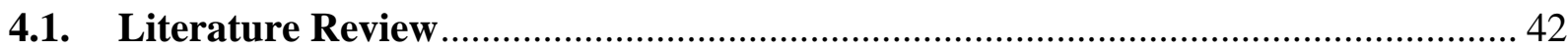

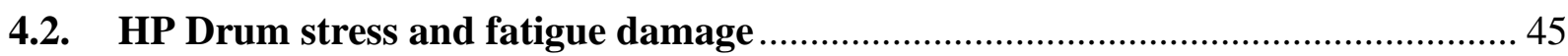

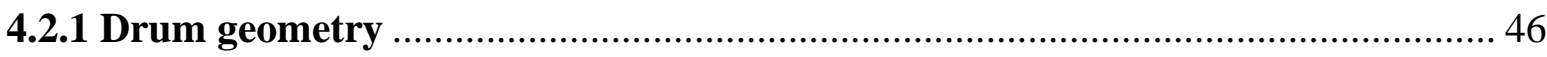

4.2.2 Temperature transient and thermo-mechanical stress evolution....................... 46

4.2.3 Simplified mechanical stress and thermal stress calculation ............................ 47

4.2.3 Stress concentration due to the component discontinuity ................................ 48

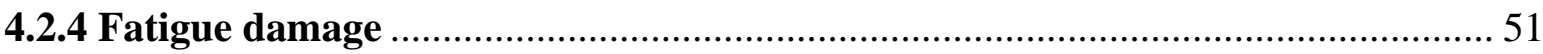

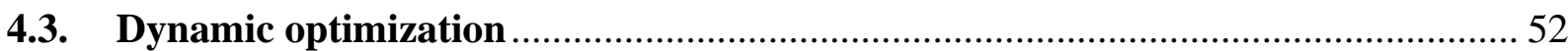

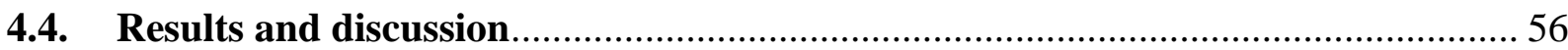

4.4.1 HP Drum stress transient under the load-following operation .......................... 56

4.4.2 Dynamic optimization under the load-following operation ............................... 60

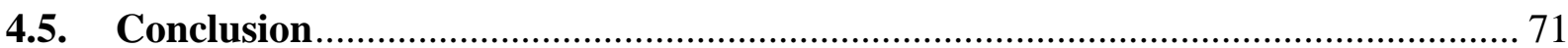

Chapter 5. Optimal load-following of NGCC plant with stress monitoring of both HP drum

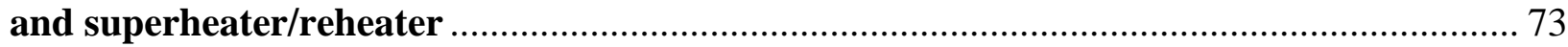

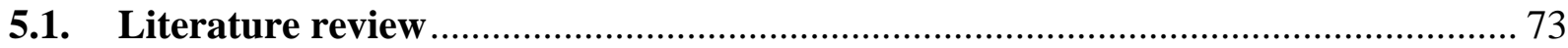

5.2. SH/RH geometry and stress monitoring location .......................................... 74

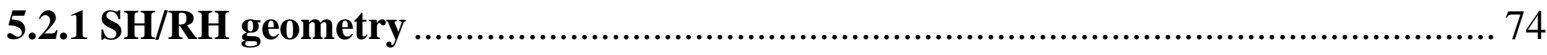

5.2.2 SH/RH junction stress monitoring under the load-following operation .............. 74

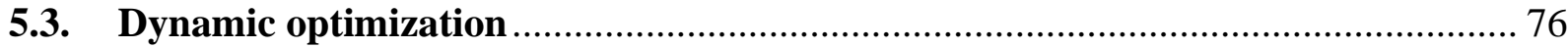

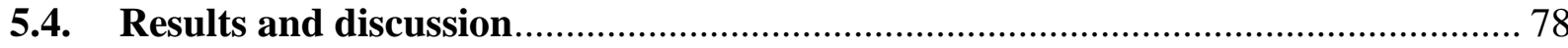

5.4.1. Optimal process under a constant average ramp rate neglecting stress

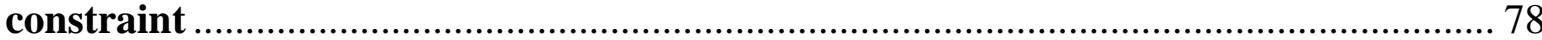

5.4.2. Optimal process when the drum stresses are limiting .................................. 81

5.4.3. Optimal operation when the SH stresses are limiting ................................ 85

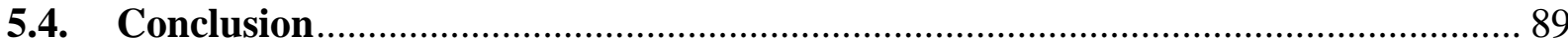

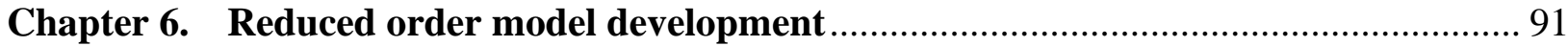

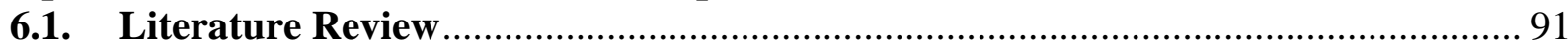

6.2. Linear reduced-order state-space model....................................................... 91

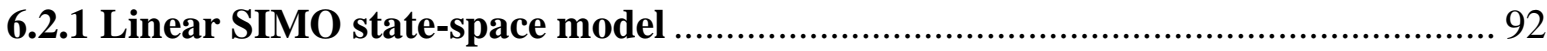

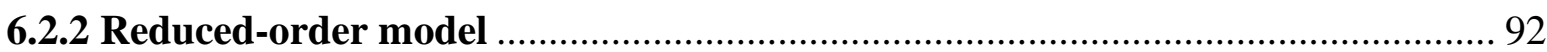

6.3. Linear transfer function model .................................................................... 96

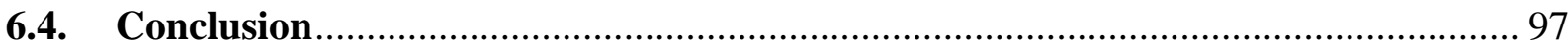

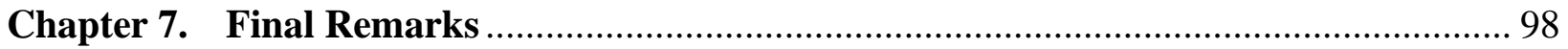




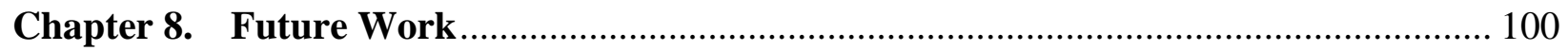

Appendix A: The thermo-hydraulic model of HRSG ................................................. 102

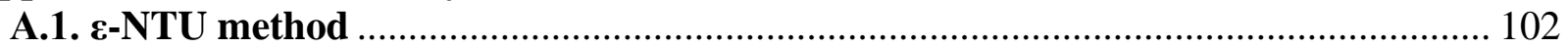

A.2. Heat transfer coefficients.......................................................................... 102

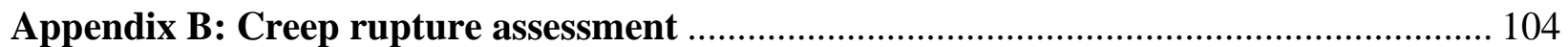

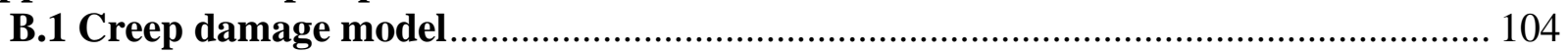

B.2. Creep rupture assessment using minimum commitment (MC) equation ............... 104

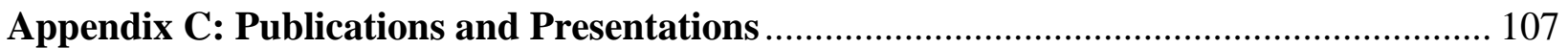

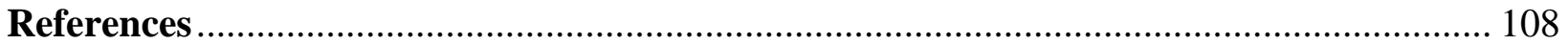




\section{List of Figures}

Figure 2. 1. Process flow diagram of NGCC power plant .................................................. 7 Figure 2. 2. Stage by stage model of steam turbine for moisture detection and correction (a) logicbased Algorithm1 (b) without logic-based Algorithm2 ................................................ 12 Figure 2. 3. GT thermal efficiency under off-design conditions ............................................ 14 Figure 2. 4. GT temperature and air/fuel mass flow ratio under off-design conditions (a) TET (b)

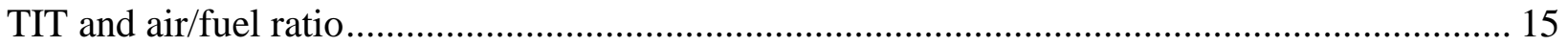

Figure 3. 1. Series configuration with single-stage attemperation 21

Figure 3. 2. Series configuration with two-stage attemperation for $\mathrm{HP} \mathrm{SH} 2$ and one-stage

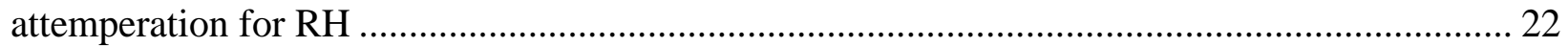

Figure 3. 3. Parallel configuration with single-stage attemperation ........................................ 23

Figure 3. 4. Parallel configuration with two-stage attemperation......................................... 24

Figure 3. 5. Parallel configuration including damper control with two-stage attemperation for HP

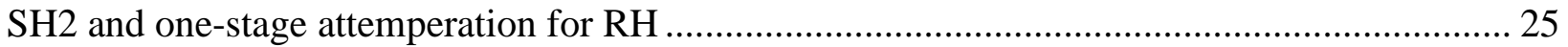
Figure 3. 6. Steam temperature transients under load-following operation using coordinated control for Configuration 1: (a1) main steam temperature, (a2) HP SH2 inlet temperature, (b1) reheat steam temperature, (b2) RH inlet temperature ......................................................... 28 Figure 3. 7. Comparison between coordinated control and dynamic optimization for Configuration 2 (a) thermal efficiency (b) spray flow at the SH ATT1 and RH ATT .................................. 30 Figure 3. 8. Steam temperature transients under load-following operation for Configuration 2: (a1) main steam temperature, (a2) HP SH2 inlet temperature, (b1) reheat steam temperature, (b2) RH

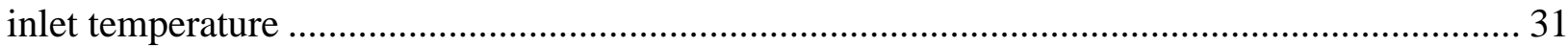

Figure 3. 9. Steam temperature transients under load-following operation using coordinated control for Configuration 3: (a1) main steam temperature (a2) HP SH2 inlet temperature (b1) reheat steam temperature (b2) RH inlet temperature ........................................................................ 33 Figure 3. 10. Comparison between coordinated control and dynamic optimization for Configuration 4 (a) thermal efficiency (b) spray flow at ATT1 (c) HP steam flow (d) IP steam flow 34

Figure 3. 11. Steam temperature transients under load-following operation for Configuration 4: (a1) Main steam temperature (a2) HP SH2 inlet temperature (b1) Reheat steam temperature (b2) RH inlet temperature ............................................................................................. 35 Figure 3. 12. Dynamic optimization for Configuration 5 (a) spray flow at SH ATT1 (b) IP steam

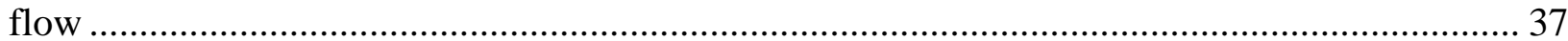

Figure 3. 13. Steam temperature transients under load-following operation for Configuration 5 (a1) main steam temperature, (a2) HP SH2 inlet temperature, (b1) reheat steam temperature, (b2) RH

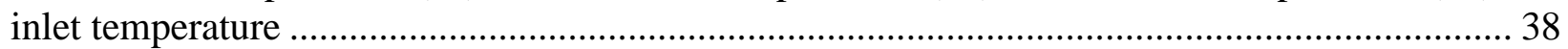

Figure 3. 14. Load-following operation of NGCC plant (a) thermal efficiency (b) power output39 Figure 4. 1. Parallel configuration with two-stage attemperation 45

Figure 4. 2. Schematic and approximation of cylindrical shell with a hole............................. 49 Figure 4. 3. Drum pressure and temperature transients under load-following operation: (a) pressure

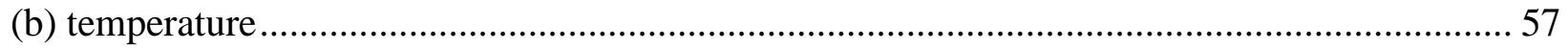

Figure 4. 4. Tangential stress transient on drum inner surface under load-following ................ 57 Figure 4. 5. Stress amplitude with respect to the drum wall thickness at Positions A and B ....... 58 Figure 4. 6. Transients of circumferential stress at drum/downcomer junction ....................... 59 
Figure 4. 7. Comparison between dynamic optimization and coordinated control system: (a) thermal efficiency (b) total spray flow at SH/RH ATT (c) HP steam flow from HP drum (d) HP drum pressure.

Figure 4. 8. Comparison of stress transient between dynamic optimization and conventional linear approach: (a) tangential stress at drum inner surface (b) circumferential stress at drum/downcomer junction at Position $B$ 62 Figure 4. 9. Comparison of linear and optimal profiles under different stress constraints for 5\% average ramp down in load per min: (a) power output (b) thermal efficiency (c) HP drum stress at drum/downcomer junction at Position $B$ 63 Figure 4. 10. Comparison of linear and optimal profiles under different stress constraints for 5\% average ramp up in load per min (a) Power output (b) Thermal efficiency (c) HP drum stress at drum/downcomer junction at Position B 65 Figure 4. 11. Effect of the stress upper bound on the minimum ramprate relaxation and time average thermal efficiency for a desired rate of $5 \%$ rampdown per minute 66 Figure 4. 12. Comparison of different ramp-down processes with the fixed/relaxed average ramp rate: (a) power output (b) thermal efficiency (c) HP drum stress at drum/downcomer junction at Position B. 67

Figure 4. 13. Effect of ramprate relaxation on time average efficiency for ramp down when stress upper bound of $165 \mathrm{MPa}$ and desired ramprate is $5 \%$ load change per min 69 Figure 4. 14. Effect of the stress lower bound on the minimum ramprate relaxation and time average thermal efficiency for a desired rate of $5 \%$ rampup per minute 69 Figure 4. 15. Comparison of different ramp-up processes with the fixed/relaxed average ramp rate: (a) power output (b) plant thermal efficiency (c) HP drum stress at drum/downcomer junction at

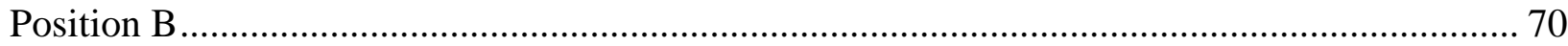
Figure 5. 1 Schematic of SH/RH header-tube junction 75

Figure 5. 2. Different locations for SH/RH head-tube junction stress monitoring .................... 75 Figure 5. 3. SH(A) inlet performance under the load-following (a) steam temperature (b) steam pressure (c) stress at Position A of junction(d) stress at Position B of junction.......................... 80 Figure 5. 4. $\mathrm{SH}(\mathrm{B})$ inlet performance under the load-following (a) steam temperature (b) steam pressure (c) stress at Position A of junction(d) stress at Position B of junction ......................... 81 Figure 5. 5. Linear and optimal profiles under different drum stress constraints for 5\% average ramp down in load per min: (a) power output, (b) $\mathrm{SH}$ (B) inlet steam temperature, (c) stress at $\mathrm{SH}(\mathrm{B})$ inlet junction Position B 82 Figure 5. 6. Comparison of linear and optimal profiles under different drum stress constraints for 5\% average ramp up in load per min: (a) power output, (b) SH(B) inlet steam temperature, (c)

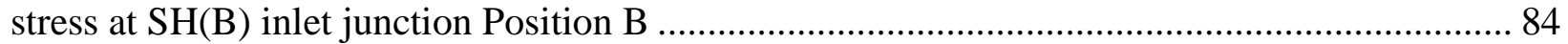
Figure 5. 7. Linear and optimal profiles under different equipment stress constraints for rampdown process: (a) power output (b) thermal efficiency (c) stress at HP drum junction Position B (d) stress at $\mathrm{SH}(\mathrm{B})$ inlet junction Position B 85

Figure 5. 8. Linear and optimal profiles under different equipment stress constraints for ramp-up process: (a) power output (b) thermal efficiency (c) stress at HP drum junction Position B (d) stress

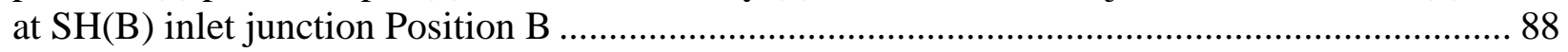

Figure 6. 1. Hankel singular values of the state-space model under full load condition 93

Figure 6. 2. Input variation for the ROM validation........................................................ 93 
Figure 6. 3. Output responses to the input variations for linear model generated at full load condition (a) total power output (b) GT power output (c) main steam temperature (d) reheat steam temperature 94

Figure 6. 4. Output responses to the input variations for linear model generated at 0.81 oad and 0.6load (a) total power output (b) GT power output (d) main steam temperature (e) reheat steam

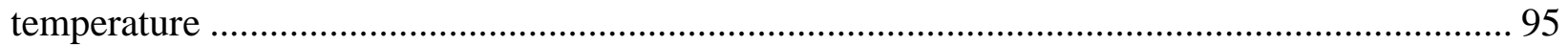

Figure 6. 5. Random signals of input for system identification.......................................... 96 Figure 6. 6. Comparison between model in Aspen Plus Dynamics and identified process model96 Figure B. 1. Creep-rupture database of Grade 91 steel

104

Figure B. 2. Different isothermal curves and 95\% confidence bounds for creep-rupture database 106 


\section{List of Tables}

Table 2. 1 Estimated coefficients for the dimensionless GT performance curves..................... 14

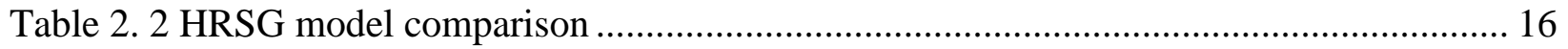

Table 2. 3. Operating parameters and the surface area of the three-pressure HRSG ................. 16

Table 2. 4. Computational times of different ST algorithms for load-following operation.......... 17

Table 2. 5. Comparison between the model results and NETL baseline Case B31A................. 18

Table 3. 1. Key operating conditions and performance measures for variation in HP SH2 area ratio at $40 \%$ load for Configuration 2

Table 3. 2. Key operating conditions and performance measures for variation in HP SH2 and RH

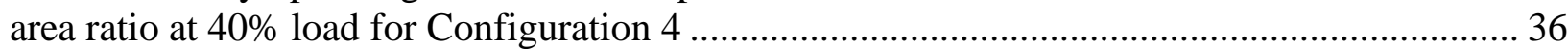

Table 3. 3. Summary of different configurations for load-following operation ........................ 39

Table 3. 4. Performances of different configurations at $40 \%$ load ....................................... 40

Table 4. 1. HP Drum geometry and material 46

Table 4. 2. Relation of stress concentration factors at different positions ................................ 50

Table 4. 3. Fatigue damage estimation at drum/downcomer junction ..................................... 59

Table 4. 4. Plant average efficiency under different ramp-down processes with the fixed average

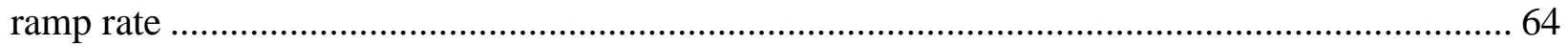

Table 4. 5. Plant average efficiency under different ramp-up processes with the fixed average ramp

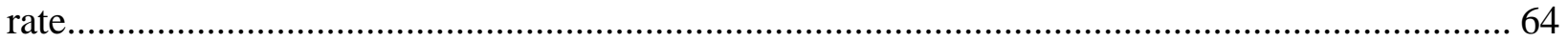

Table 4. 6. Plant average efficiency under different ramp-down processes with the fixed/relaxed

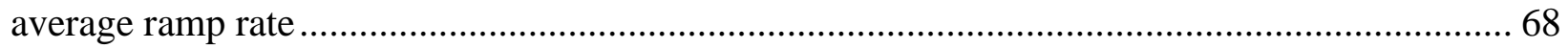

Table 5. 1. HP SH/IP RH geometry and material $\quad 74$

Table 5. 2. Stress at SH/RH header-tube junction under load-following ................................ 79

Table 5. 3. Maximum and minimum Stress and stress amplitude at SH inlet header-tube junction

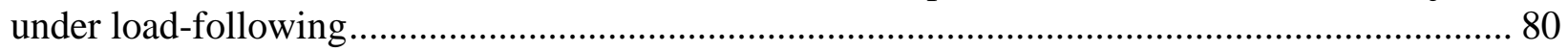

Table 5. 4. SH inlet header-tube junction stress under different ramp-down processes .............. 83

Table 5. 5. SH inlet header-tube junction stress under different ramp-up processes................... 84

Table 5. 6. Comparison of linear and optimal ramp-down profiles under different equipment stress

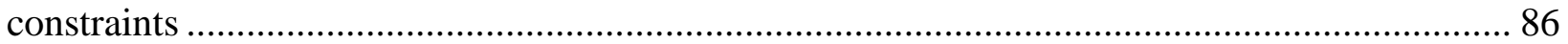

Table 5. 7. Comparison of linear and optimal ramp-up profiles under different equipment stress constraints 89

Table B. 1. Coefficients of MC equation for Grade91 105

Table B. 2. 95\% confidence intervals for coefficients of MC equation 105 


\section{NOMENCLATURE}

$A_{f} \quad$ fin surface area $\left(\mathrm{m}^{2}\right)$

$A_{t} \quad$ bare tube surface area $\left(\mathrm{m}^{2}\right)$

$A_{t o t} \quad$ finned tube surface area $\left(\mathrm{m}^{2}\right)$

$C_{\text {flow }}$ nozzle coefficient

$C$ heat capacity rate

$D_{f} \quad$ fatigue damage

$d \quad$ drum/tube inner diameter ( $\mathrm{mm}$ )

$d_{m} \quad$ drum mean diameter (mm)

$E \quad$ weld joint efficiency

$E_{m} \quad$ Young's modulus (N/mm²)

$f \quad$ friction factor of tube

$F_{a} \quad$ arrangement factor of tube banks

$F_{m} \quad$ mass flowrate $(\mathrm{kg} / \mathrm{hr})$

$F \quad$ correction factor

$h \quad$ heat transfer coefficient $\left(\mathrm{W} / \mathrm{m}^{2} \mathrm{~K}\right)$

$H \quad$ enthalpy $(\mathrm{J} / \mathrm{kg})$

$\dot{H} \quad$ isentropic head of turbine (m)

$k$ thermal conductivity (W/m K)

$k_{i s} \quad$ stage head coefficient

$L H V$ lower heating value $(\mathrm{MJ} / \mathrm{kg})$

$M A S$ maximum allowable stress of material (MPa)

$N \quad$ the number of cycling

$n \quad$ number of tube passes

$N_{A} \quad$ maximum allowable cycle number

nf normalized heat flux correction factor

$N_{s} \quad$ specific shaft speed

$N T U$ number of transfer units

$\mathrm{Nu} \quad$ Nusselt number

$P \quad$ pressure (bar)

$p_{l} \quad$ longitudinal tube pitch (m)

$\mathrm{Pr} \quad$ Prandtl number 


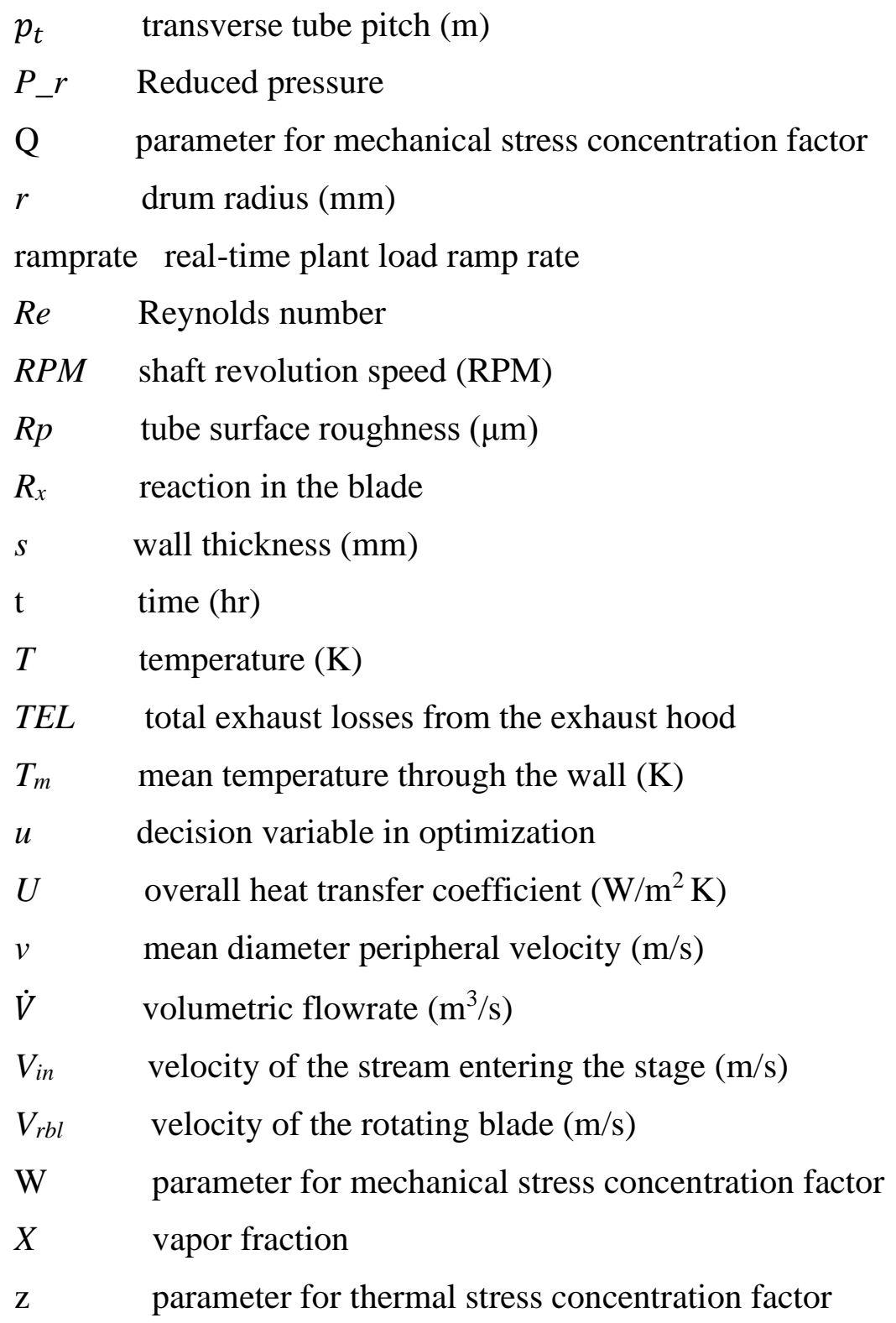

\section{Greek Symbols}

$\varepsilon \quad$ heat exchanger effectiveness

$\rho$ density $\left(\mathrm{kg} / \mathrm{m}^{3}\right)$

$\eta \quad$ isentropic efficiency

$\eta_{0} \quad$ surface efficiency of the finned tube

$\eta_{f} \quad$ fin efficiency

$\eta_{\text {st }} \quad$ stage efficiency at $3000 \mathrm{RPM}$

$\Delta \eta_{\omega} \quad$ efficiency penalty for operating at RPM higher than 3000 


$\begin{array}{ll}m & \text { mechanical stress } \\ \text { max } & \text { maximum } \\ \text { min } & \text { minimum } \\ M S & \text { main steam } \\ N c B & \text { nucleate boiling } \\ N G & \text { natural gas } \\ \text { out } & \text { outer surface/ outlet condition } \\ P F & \text { pressure correction } \\ r & \text { radial direction } \\ R H & \text { reheater } \\ R S & \text { reheat steam } \\ S H & \text { superheater } \\ s p & \text { setpoint } \\ t & \text { thermal stress/tube side } \\ t h & \text { thermal efficiency } \\ \text { TP } & \text { two-phase } \\ U E E P & \text { the used-energy end-point enthalpy } \\ \text { upper } & \text { upper bound } \\ z & \text { axial direction } \\ \theta & \text { tangential direction } \\ \varphi & \text { circumferential direction } \\ & \end{array}$




\section{Chapter 1. Introduction}

In recent years, an increasing amount of electricity in the U.S. has been generated from renewable sources. According to the United States Energy Information Administration (U.S. EIA, 2020), renewable energy sources accounted for about 17\% of the total U.S. electricity generation in 2019. In addition, the share of the renewable sources in the electric grid is expected to continue to grow in the foreseeable future. Due to intermittency of the renewable energy sources, conventional fossil-fueled power plants are being forced to cycle their load more frequently and rapidly than for which they were designed.

Besides the coal-fired power plants, natural gas combined cycle (NGCC) power plants are also being subjected to load-following. Due to higher efficiency, lower emissions, and lower capital cost of NGCC power plants, natural gas is leading the fossil-fuel based power generation, accounting for about $38 \%$ of the U.S. generation capacity in 2019 (U.S. EIA, 2020). In addition, NGCC plants show the high operational flexibility and rapid load-following capability. They would be playing a key role in fulfilling the fluctuating grid demand.

Even though cycling operation may be unavoidable for many NGCC power plants, the impacts of load-following on plant efficiency and equipment health are currently poorly understood. With this motivation, high-fidelity multi-scale dynamic models are developed to assess and quantify the impacts of load-following on the gas-fired power plants.

Specifically, this project includes four main tasks.

\section{Specific Goal \#1: Dynamic modeling of an NGCC power plant}

Compared to the vast amount of literature on dynamic modeling of pulverized coal-fired power plants (Lawal et al., 2012; Oko and Wang, 2014; Starkloff, et al., 2015; Hentschel et al., 2017; Yan et al., 2020), the body of literature on detailed dynamic modeling of NGCC plants is much lower. In addition, most of these studies are mainly focused on the specific components of NGCC plant (e.g. Heat recovery stream generator). There are a few works in the open literature on dynamic modeling of a complete combined cycle power plant. More details are discussed in Section 2.1. 
For an NGCC plant, while there are various designs of the boiler for the desired heat duty at the nominal condition, the dynamics of the boiler can be very different depending on a specific design. In other words, the plant dynamics strongly depend on the specific design.

The contributions of Task 1 are as follows. The boiler is optimally designed based on the operating conditions outlined in NETL baseline Case B31A (Zoelle et al., 2015). Then a plant-wide dynamic model of the NGCC plant is developed with detailed equipment level sub-models to capture the plant load-following behavior. The NGCC dynamic model includes a model of the gas turbine (GT) for estimating its performance under off-design conditions, a thermo-hydraulic model for the heat recovery steam generator (HRSG), and a model of the steam turbine (ST) with moisture detection and variable adaptation capability.

Specific Goal \#2: Modeling and evaluating novel NGCC configurations and optimizing their operation for avoiding spraying to saturation

Under the load-following, the main steam and reheat steam temperature should be well maintained to avoid the ST damage or efficiency loss. At low load, the higher exhaust gas temperature from the GT and the lower steam flowrate may lead to a higher final steam and reheat steam temperature exceeding the maximum design steam temperature to the ST. Excessive spray is required at attemperators before the inlet of the superheater/reheater for steam temperature control. That would lead to two-phase flow through the superheater/reheater typically denoted in the utility industry as 'spraying to saturation' (Moelling et al., 2015; Sorge et al., 2017). Since superheater and reheater are not typically designed for two-phase flow, this undesired phenomenon should be avoided. More details are shown in Section 3.1.

Damage in superheater/reheater tubes as a result of 'spraying to saturation' has been reported by the utilities and the recent literature (Moelling et al., 2015; Sorge et al., 2017; Liese and Zitney, 2018). However, to the best of our knowledge, there has been no study on this issue in the open literature using a mathematical model especially for mitigating this undesired phenomenon.

The contributions of Task 2 are as follows. Several novel configurations are proposed for controlling the main steam and reheat steam temperatures while avoiding 'spraying to saturation' during fast load-following by considering different final high-pressure superheater (HP SH2)/ reheater $(\mathrm{RH})$ arrangements (in series or in parallel) and attemperation strategies (single-stage, two-stage, and damper-assisted attemperation). Load-following operation is studied under two 
operational strategies- the industry-standard coordinated control strategy and dynamic optimization. Dynamic optimization is formulated to maximize the plant efficiency while satisfying the operational constraints and state transition constraints.

Specific Goal \#3: Equipment damage model and optimal load-following of NGCC plant with stress monitoring

Damage of the boiler components caused by rapid load-following is difficult to measure or identify real-time. Typically, simplified expressions for cycling cost have been used as a measure of damage due to load-following operation in unit commitment models (Troy et al., 2012; Rodilla et al., 2013; Van den Bergh and Delarue, 2015). However, a damage model that can be executed real time for equipment health analysis and optimal load-following operation is desired and for reducing the adverse impact of load-following.

In an HRSG, the thick-walled HP drum is one of the most vulnerable components. It is mainly subject to the fatigue damage. Load-following leads to cyclic variation in steam pressure and temperature affecting the stress profiles in the HP drum. Moreover, the stress concentration due to the discontinuity in the drum such as those due to drum-downcomer junctions can intensify the stress amplitude under the load-following operation.

Superheaters $(\mathrm{SH})$ and reheaters $(\mathrm{RH})$, as the other vulnerable components, are subject to both creep and fatigue damage due to the high operating temperature and the large inlet stream temperature variation caused by the large amount of spray at the inlet attemperator under the loadfollowing. When the final main steam and reheat steam temperatures are well-maintained and overheating is avoided, the creep damage on the SH/RH caused by load-following is not significant. However, if the attemperator spray at the inlet of SH/RH is high, then it can lead to large thermal stress and fatigue damage on SH/RH. Also, the SH/RH header-tube junctions can experience high stress amplitude and fatigue damage during load-following operation.

Monitoring of stress evolution in the critical components can be useful not only for optimal operation of NGCC power plants but also for improving their reliability and reducing the operating and maintenance $(\mathrm{O} \& \mathrm{M})$ costs. For assessing component damage, it is desired to develop a model that is computationally inexpensive and can be used for model-based dynamic optimization. In this work, available international standards and literature are leveraged for computing creep and fatigue damages of boiler components. 
The contributions of Task 3 are as follows. Fatigue/creep damage of boiler components is estimated by developing a detailed plant model that can compute through-wall temperature transients and thermo-mechanical stress evolutions in the critical components (i.e. HP drum, superheater and reheater). EN Standard 12952-3 with consideration of additional positions at junctions is used to monitor locations that can be more vulnerable to fatigue damage. Optimal load-following operation with stress constraint is obtained by solving a dynamic multi-objective optimization problem.

\section{Specific Goal \#4: Reduced order dynamic model development}

There is scarcity of literature on reduced order dynamic modeling of NGCC plants especially when damage models are considered. In the high-fidelity model, the equipment stress is calculated based on the transient information of certain state variables. While in the reduced order model, it is hard to capture the state variable transient for stress estimation. The contributions of Task 4 are as follows. A state-space dynamic reduced order model (ROM) for the NGCC plant is generated. Then a liner hybrid ROM for reasonable analysis of the equipment health with affordable computational cost is developed for dynamic optimal dispatch of energy systems (Kim et al., 2020).

The nonlinear NGCC plant model in Aspen Plus Dynamic can be linearized at the different load conditions by using control design interface (CDI) tool to generate a large-scale full-order linear state space model. The balanced truncation method is used for reducing the order of the linear fullstate model to a reduced order state-space model with a lower computational cost. This reduced order model shows a good prediction in power output and steam temperature.

Since the state-space model may not accurately capture the transients in through-wall temperature profile thus can lead to inaccuracies in the evaluation of thermal stress, the simple input-output transfer function model is also developed to provide the thermal stress transients under the loadfollowing. The hybrid linear reduced order model is computationally tractable for being used in the optimal scheduling. 


\section{Chapter 2. NGCC power plant dynamic model}

\subsection{Literature review}

Dynamic behavior of NGCC plants and advanced control techniques for load-following operation can be simulated and investigated using a high-fidelity dynamic model. Even though there are a number of studies in the open literature on dynamic modeling and control of NGCC plants, most of them are only focused on the specific component, such as the GT or ST or HRSG, while other components of NGCC plant are considered as a boundary or fairly simple models are used for those components.

Pletl (2005) developed a dynamic model of a single-pressure once-through heat recovery steam generator (HRSG) model and demonstrated the importance of thermal inertia in the HRSG model on accurate prediction of the boiler response. Alobaid et al $(2008,2009)$ developed dynamic models of a subcritical drum-type HRSG and a supercritical once-through HRSG using the Advanced Process Simulation Software (Apros $\left.{ }^{\circledR}\right)$. In addition, a transient simulation of the startup of a subcritical HRSG was conducted by Alobaid et al (2014) using Aspen Plus Dynamics® (APD). However, GT model was not included in these works and the exhaust temperature and mass flow from GT were applied as dynamic boundary conditions. Horkeby (2012) developed a dynamic model of an HRSG to evaluate the performance of different control strategies, but simple models of the GT and ST were considered. Rieger (2009) evaluated various control concepts for a once-through HRSG for rapid load changes from full load to $38 \%$ and vice versa. They observed that the ramp rates can be improved through efficient control design. The studies noted before are mainly focused on the HRSG, while other components of NGCC plant, such as the gas turbine (GT) and steam turbine (ST) are considered as a boundary or fairly simple models are used for those components.

However, there are considerable variabilities in the GT and ST performances under off-design operation. Development of mathematical models for the behavior of the ST under off-design conditions has been the focus of a number of studies. The Stodola equation is widely used for the pressure-flow calculation (Cooke, 1983). A nonlinear mathematical model was developed by Chaibakhsh and Ghaffari (2008) to study the transient dynamics of an ST. High-pressure (HP), intermediate-pressure (IP) and low-pressure (LP) sections were considered separately in the model. However, the turbine efficiency was assumed to be constant. A model of an ST with partial 
arc admission was developed by Liese (2014). Separate models were developed for the first stage and last stage, while the intermediate stages were considered to have constant efficiency. A stageby-stage approach was proposed by Lozza (1990) to estimate the ST efficiency based on the operating conditions, and other key design parameters.

There are a few works in the open literature on dynamic modeling of a complete combined cycle power plant using detailed models of the GT, ST, and HRSG that can be used for studying the offdesign transient behavior of the NGCC plants. Benato et al. $(2015,2016)$ developed a dynamic model of a combined cycle plant to evaluate the transient behavior during load variations and estimate the lifetime reduction of most stressed components. A dynamic model of an NGCC plant with post-combustion $\mathrm{CO}_{2}$ capture (PCC) system was developed by Montañés et al. (2017). The dynamic interaction between NGCC and PCC units was analyzed and different control structures for the PCC plant were evaluated.

While there are various designs of the heat exchangers like HRSG for the desired heat duty, dynamics of the HRSG can be very different (Jiang et al., 2018). Since HRSGs can be designed for the same heat duty but different objective functions, such as minimizing the total area or maximizing compactness (Franco and Giannini, 2006), their dynamics strongly depend on the specific design. Hence, first the HRSG is optimally designed and then it is used to develop a plantwide dynamic model of an NGCC plant to assess the impact of load-following operation.

In this chapter, a high-fidelity plant-wide dynamic model of an NGCC power plant is developed with detailed equipment level sub-models. A model of the gas turbine (GT) for estimating its performance under off-design conditions, a thermo-hydraulic model for the heat recovery steam generator (HRSG), and a model of the steam turbine (ST) with moisture detection and correction capability are included in the NGCC plant model. It was observed that the steady-state results from the dynamic model at full load shows a great agreement with the NETL baseline Case B31A (Zoelle et al., 2015). Also, the off-design behavior of NGCC plant can be simulated using the dynamic model.

\subsection{NGCC plant model development}

A nominal 641 MWe gross NGCC power plant is modeled based on the baseline Case B31A conducted by the National Energy Technology Laboratory (NETL) (Zoelle et al., 2015). The 
steady-state model is developed using Aspen Plus ${ }^{\circledR}$ and Aspen Custom Modeler ${ }^{\circledR}$ (ACM), and then converted to the dynamic model, which is simulated using Aspen Plus Dynamics ${ }^{\circledR}$ (APD).

As shown in Figure 2.1, the exhaust heat from the GT is recovered in a triple-pressure HRSG with reheat. The condensate from the condenser first passes through the 2-stage pre-heater (PRE HRT) and deaerator. Then HP, IP and LP steams are generated by sending boiler feed water (BFW) through a corresponding economizer (ECO), evaporator (EVA) and superheater (SH), respectively. The heating sections can be arranged in series or in parallel for heat recovery. Correspondingly, a triple-pressure ST is used for power generation. The main steam leaving the HP ST, combined with IP steam, goes through the RH to produce reheat steam for the IP ST. The attemperators are used to maintain the main steam and reheat steam temperature by spraying BFW at the inlets of the HP SH2 and RH. The total steam from the LP ST is sent back to the condenser thus completing the water cycle.

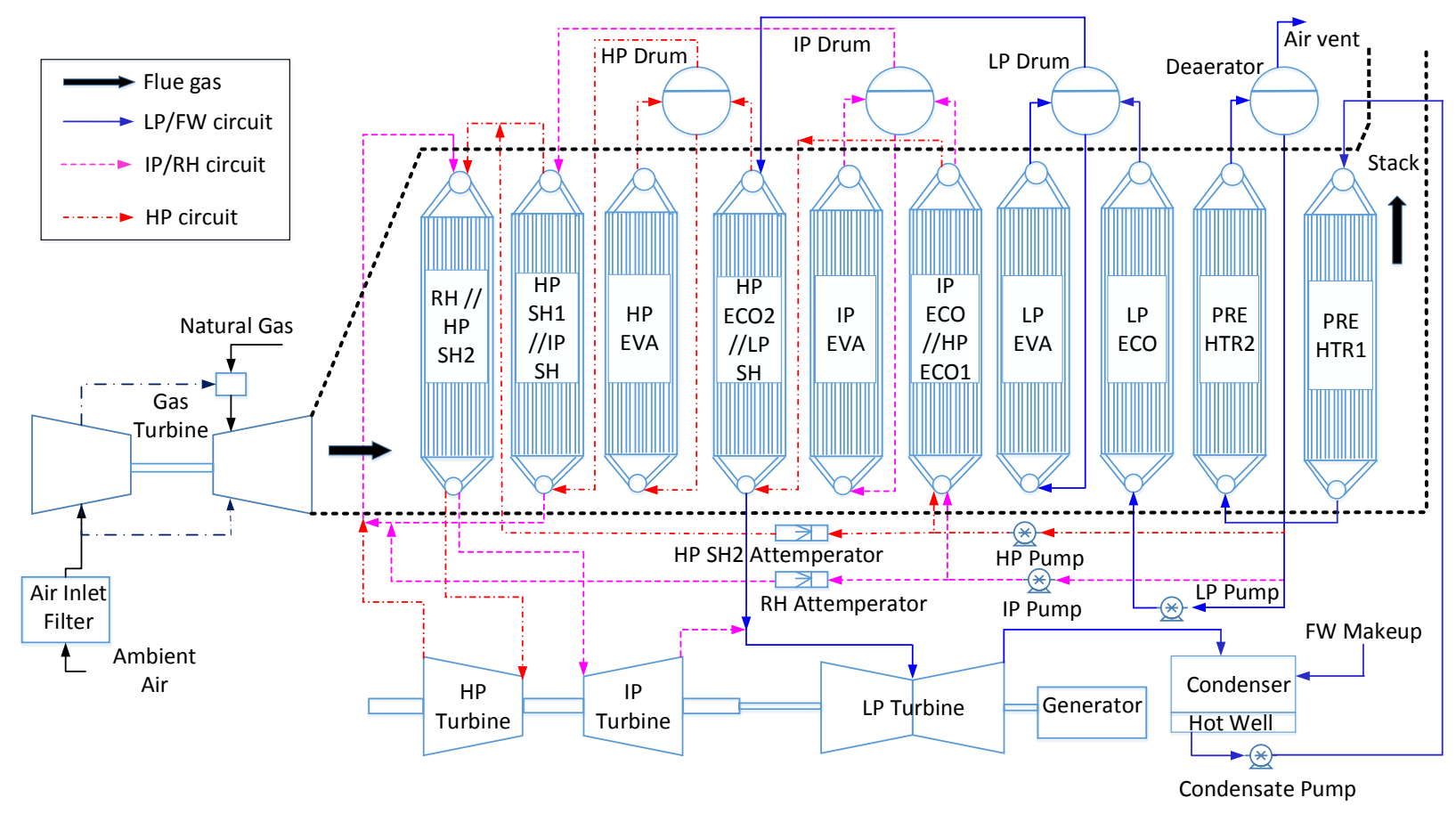

Figure 2. 1. Process flow diagram of NGCC power plant

\subsubsection{Gas turbine (GT)}

Due to the fast response of the GT in comparison to the water/steam cycle, shaft and thermal dynamics of the GT are neglected. Dimensionless performance curves are used to model the 
dimensionless head and isentropic efficiency versus dimensionless flow under standard conditions as shown in Equations 2.1-2.5.

$$
\begin{gathered}
\dot{H}_{D}=\frac{\dot{H}}{\dot{H}_{T}} \\
\eta_{D}=\frac{\eta}{\eta_{T}} \\
\dot{V}_{D}=\frac{\dot{V}}{\dot{V}_{T}} \\
\dot{H}_{D}=a_{1} \dot{V}_{D}^{2}+a_{2} \dot{V}_{D}+a_{3} \\
\eta_{D}=b_{1} \dot{V}_{D}^{2}+b_{2} \dot{V}_{D}+b_{3}
\end{gathered}
$$

where $\dot{H}$ is the head, $\eta$ is the isentropic efficiency, and $\dot{V}$ is the volumetric flowrate under standard conditions. The subscripts ' $D$ ' and ' $T$ ' represent dimensionless ratio and nominal condition, respectively. Coefficients $a$ and $b$ are regressed using the literature data (Jordal et al. 2012).

\subsubsection{Heat recovery steam generator (HRSG)}

A triple-pressure HRSG with reheat is used for steam generation as shown in Figure 2.1. In order to capture the load-following behavior, a thermo-hydraulic model is developed to size all the heating sections in the HRSG with due considerations of their geometry, configuration, and other design parameters.

For each heating section, finned tube heat exchangers in a staggered arrangement are modeled. Exchangers with several tube passes and overall counter-flow is modeled using the $\varepsilon$-NTU method, while each single pass is considered to be in a crossflow arrangement with the flue gas side mixed and water/steam side unmixed. In addition, pressure drop on the tube side is also considered.

The heat transfer coefficient for the gas side is calculated using the following correlation (Khan et al., 2006)

$$
N u_{D}=0.35 F_{a} R_{D}^{0.57} \operatorname{Pr}^{0.31}
$$

where $N u_{D}$ and $R e_{D}$ denote Nusselt number and Reynolds number based on the tube diameter, respectively. $\mathrm{Pr}$ denotes the Prandtl number and $\mathrm{Fa}$ is an arrangement factor related to the tube pitch.

The heat transfer coefficients for the water/steam vary based on the phase. The Gnielinski correlation (1976) is used for the liquid phase: 


$$
N u=\frac{(f / 8)(R e-1000) P r}{1+12.7 \sqrt{f / 8}\left(\operatorname{Pr}^{2 / 3}-1\right)}
$$

where $f$ denotes the friction factor for smooth tubes.

The Dittus-Boelter correlation (1930) is used for the vapor (steam) phase:

$$
N u=0.023 \operatorname{Re}^{0.8} \operatorname{Pr}^{0.4}
$$

For the evaporator, boiler circulation ratios vary depending on pressure levels (Ganapathy, 2013). The convective heat transfer coefficient under boiling condition is given by (Collier and Thome, 2006):

$$
h_{F B}=\left[\left(h_{N C B} F_{N C B}\right)^{3}+\left(h_{f} F_{T P}\right)^{3}\right]^{1 / 3}
$$

where $h_{N c B}$ is normalized nucleate pool boiling coefficient; $h_{f}$ is the liquid heat transfer coefficient calculated by Gnielinski correlation; $F_{N c B}$ is a nucleate boiling correction factor, including the effects of pressure, heat flux, tube diameter, and surface roughness; $F_{T P}$ is two-phase multiplier related to the steam quality.

The overall heat transfer coefficient is calculated as:

$$
U=\left[\frac{A_{t}}{h_{g} A_{t o t} \eta_{0}}+\frac{s}{k}+\frac{1}{h_{t}}\right]^{-1}
$$

where $\eta_{0}$ is the overall surface efficiency of the finned tube, $s$ is tube thickness, $k$ is thermal conductivity of tube. $h_{g}$ and $h_{t}$ are gas side and tube side heat transfer coefficient, respectively. $A_{t}$ and $A_{t o t}$ are bare tube and finned tube surface area, respectively.

Besides the surface area of each heating section, the wall thickness and component material for specific equipment, such as HP drum and high temperature SH/RH, are determined to calculate the thermo-mechanical stress evolution. More details will be discussed in the following chapter.

\subsubsection{Steam turbine (ST)}

Similar to the GT model, the shaft and thermal dynamics of the ST are neglected as the ST response is much faster than the water/steam cycle. In an ST model, an impulse-type stage is used as the governing stage while other stages typically have a 50\% reaction, and the final stage operates under a choked flow condition with a large variation in the amount of reaction from blade root to tip (Liese, 2014). Hence, three separate ST models are considered to capture the off-design behavior of the ST, i.e., leading (governing) stage, intermediate stages, and final stage. The turbine models 
are developed in ACM. These custom models are then compiled into library blocks and used in APD.

\section{Leading/Governing Stage}

Model of the leading stage is developed based on the work of Liese (2014). In the model, the nozzle flow equation is used to calculate the pressure-flow relationship:

$$
F_{m}=C_{\text {flow }} \frac{P_{\text {in }}}{\sqrt{T_{\text {in }}}} \sqrt{\frac{\gamma}{\gamma-1}\left[\left(\frac{P_{\text {out }}}{P_{\text {in }}}\right)^{\frac{2}{\gamma}}-\left(\frac{P_{\text {out }}}{P_{\text {in }}}\right)^{\frac{\gamma+1}{\gamma}}\right]}
$$

where $F_{m}$ is the mass flowrate, $\gamma$ is heat capacity ratio, $C_{\text {flow }}$ is the nozzle coefficient and determined according to the nominal condition.

The stage efficiency coefficient $\eta_{\text {is }}$ is calculated as:

$$
\begin{gathered}
\eta_{i s}=2 \eta_{T}\left(\frac{V_{r b l}}{V_{i n}}\right)\left[\left(\sqrt{1-R_{x}}-\frac{V_{r b l}}{V_{\text {in }}}\right)+\sqrt{\left(\sqrt{1-R_{x}}-\frac{V_{r b l}}{V_{\text {in }}}\right)^{2}+R_{x}}\right] \\
V_{\text {in }}=44.72 \sqrt{\left(1-R_{x}\right)\left(H_{\text {in }}-H_{\text {is,out }}\right)}
\end{gathered}
$$

where $\eta_{T}$ is the efficiency under nominal condition, $R_{x}$ is reaction in the blade and assumed to $1 \%$ for the leading stage, $V_{r b l}$ is the velocity of the rotating blade and determined according to the nominal condition, $V_{i n}$ is the velocity of the stream entering the stage and related with the specific enthalpy $H$.

\section{Intermediate Stages}

A model of the intermediate stage is developed according to the stage-by-stage approach (Lozza, 1990), which is uses the basis of the thermodynamic stage rather than the true stage.

For each stage, the isentropic enthalpy drop $\Delta H_{i s}$ is related to the mean diameter peripheral velocity $v$ and the specific shaft speed $N_{s}$.

$$
\begin{gathered}
\Delta H_{i s}=\frac{k_{i s} v^{2}}{2} \\
k_{i s}=2.20+8.88 \exp \left(-42.83 N_{s}\right) \\
N_{s}=\left(\frac{R P M}{60}\right) \frac{\sqrt{\dot{V}_{i s, \text { out }}}}{\Delta H_{\text {is }}^{0.75}}
\end{gathered}
$$

where $k_{i s}$ is the stage head coefficient and obtained under the nominal operating condition, $\dot{V}_{\text {is,out }}$ is the volume flowrate at stage outlet under the isentropic condition, RPM is the revolution speed. 
The isentropic efficiency $\eta_{i s}$ is also calculated from the specific speed $N_{s}$ with the correction terms considering the different revolution speeds and the possible presence of moisture.

$$
\begin{gathered}
\eta_{i s}=\eta_{s t}\left(1-\Delta \eta_{\omega}\right)-0.87(1-X) \\
\eta_{s t}=0.0072\left(\ln N_{s}\right)^{3}+0.0196\left(\ln N_{s}\right)^{2}-0.0103 \ln N_{s}+0.8777 \\
\Delta \eta_{\omega}=-0.0049\left(\ln N_{s}\right)^{3}-0.0309\left(\ln N_{s}\right)^{2}-0.0598 \ln N_{s}-0.0222
\end{gathered}
$$

where $\eta_{s t}$ is the stage efficiency at $3000 \mathrm{RPM}, \Delta \eta_{\omega}$ is the efficiency penalty for operating at $R P M$ higher than $3000, X$ is the steam vapor content, averaged between the inlet and outlet stage conditions.

For the 641 MWe NGCC power plant in this work, the HP, IP, and LP sections comprise three, eleven, and seven thermodynamic stages, respectively.

\section{Final Stage}

A model of the final stage is also developed on the basis of the work of Liese (2014). The Stodola equation is considered to define the pressure ratio to flow rate relationship:

$$
F_{m}=C_{\text {flow }} \frac{P_{\text {in }}}{\sqrt{T_{\text {in }}}} \sqrt{\left[1-\left(\frac{P_{\text {out }}}{P_{\text {in }}}\right)^{2}\right]}
$$

Due to the existence of condensation in the last stage, a moisture correction term is included in the calculations of the end-line end-point enthalpy $H_{E L E P}$ and the used-energy end-point enthalpy $H_{U E E P}$. Then the efficiency is calculated based on the real enthalpy drop.

$$
\begin{gathered}
H_{E L E P}=H_{\text {in }}+\left(H_{\text {is }, \text { out }}-H_{\text {in }}\right) \eta_{\text {dry }} X(1-0.65(1-X)) \\
H_{U E E P}=H_{E L E P}+T E L \cdot \eta_{d r y} X(1-0.65(1-X)) \\
\eta_{\text {is }}=\frac{H_{\text {in }}-H_{U E E P}}{H_{\text {in }}-H_{\text {is out }}}
\end{gathered}
$$

where $\eta_{d r y}$ is dry efficiency and assumed to be $87 \%$ and TEL is the total exhaust losses from the exhaust hood.

\section{Methodology for Moisture Detection}

The existence of moisture in the last few stages of the LP section significantly affects the ST efficiency and the actual power production as shown in Equation 2.17. Under low-load operation, condensation may take place on the stages that are non-condensing under nominal condition. Therefore, for any stage, simultaneous moisture detection and adaptation of the system of equations based on the presence or absence of moisture are required. 


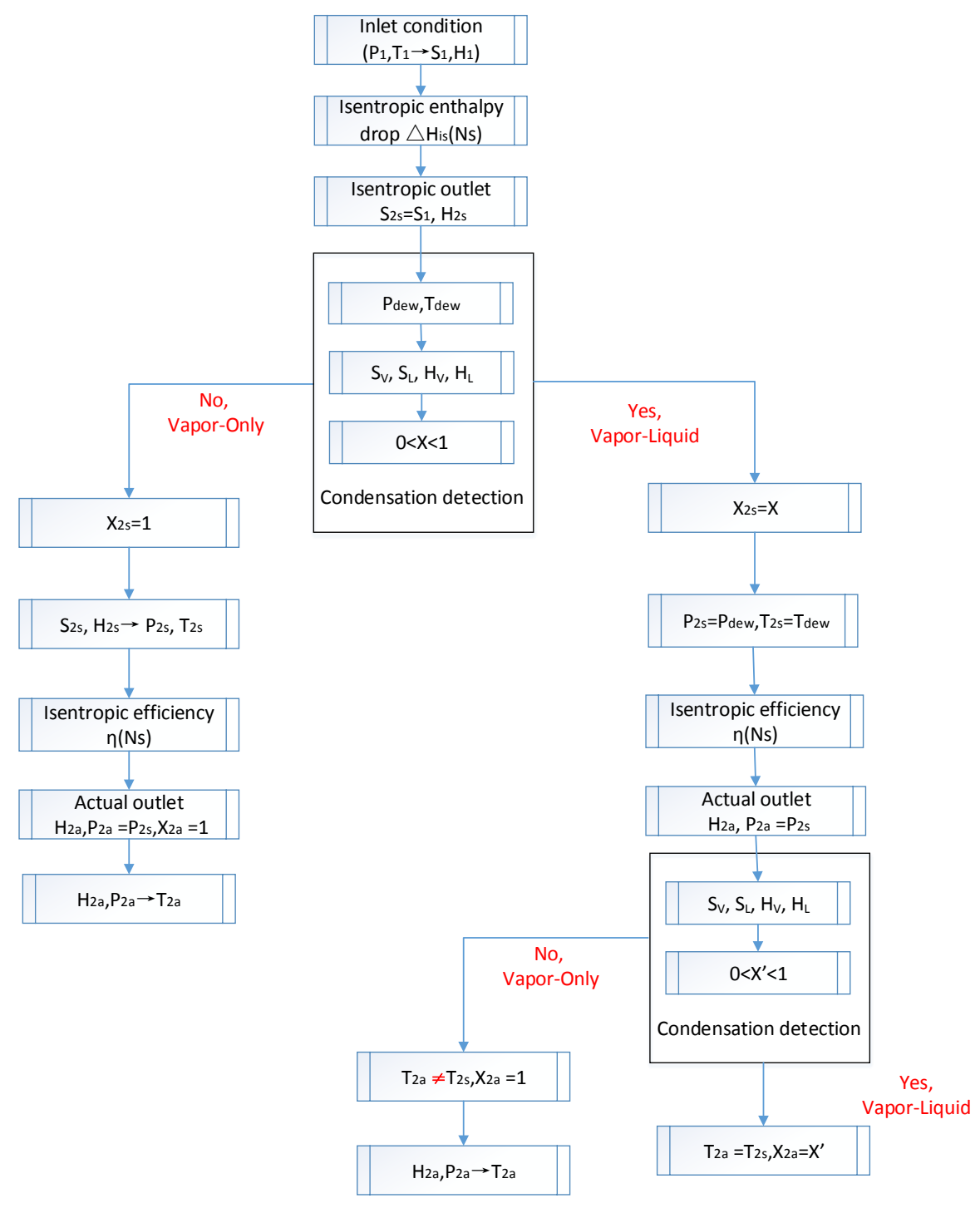

(a)

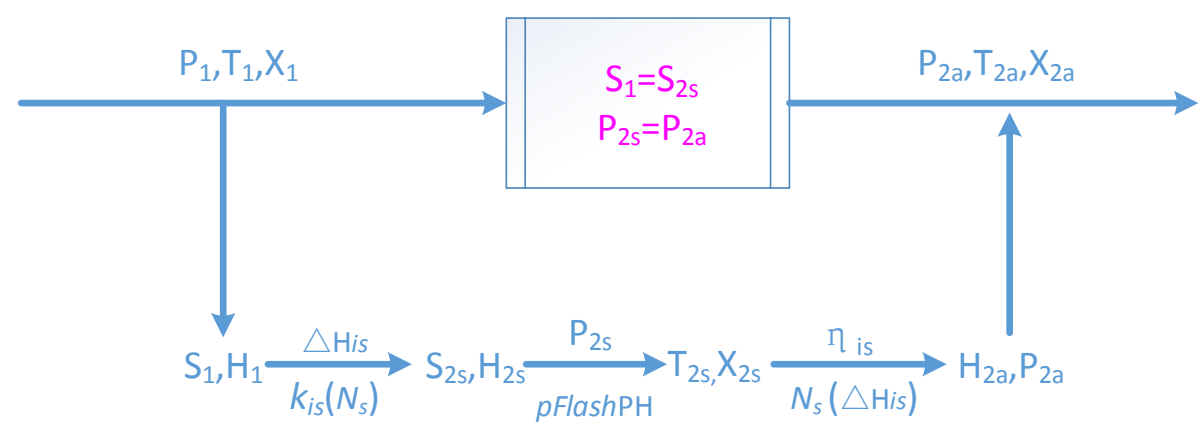

(b)

Figure 2. 2. Stage by stage model of steam turbine for moisture detection and correction (a) logic-based Algorithm1 (b) without logic-based Algorithm2 
For each stage, the isentropic enthalpy drop $\Delta H_{i s}$ is calculated using Equation 2.14. Based on the inlet condition and isentropic enthalpy drop $\Delta H_{i s}$, the corresponding isentropic outlet condition is determined with the moisture detection. Then the isentropic efficiency is calculated based on the isentropic outlet condition as shown in Equations 2.16-2.19, and the actual outlet condition is also determined simultaneously with the moisture detection.

The strategy of moisture detection and model adaptation is implemented by two different approaches. The first approach is logic-based as shown in Figure 2.2(a). Moisture is detected based on the dew point calculation. If moisture is present at the outlet of a stage, the steam temperature is fixed at its saturation temperature for a given pressure and the moisture fraction becomes the calculated variable. Even though this approach is easy to implement, it leads to a change in the problem structure due to a change in the variables. So, it may cause difficulties in convergence.

Another approach without the logic-based structure is proposed and shown in Figure2. 2(b) (Sarda et al., 2018). Since pressure and enthalpy can fully define the system for both the presence and absence of condensation, they are considered as the calculated variables for the stage-by-stage model rather than pressure and temperature (non-condensing) or pressure and vapor fraction (condensing). Then, Aspen Properties calls, which are external function calls, are used to obtain the vapor fraction and temperature given the pressure and enthalpy. The key advantage of this approach is that the set of calculated variables remain the same irrespective of moisture formation.

\subsubsection{Regulatory and supervisory control layers}

While the primary task of the regulatory control layer is plant stabilization, it is also used as the degrees of freedom (i.e., the set points of the controllers at the regulatory control layer are used as manipulated variables) by the supervisory control layer during nominal as well as load-following operation. Therefore, the regulatory control layer plays a critical role in achieving the control objective of the supervisory layer. The regulatory layer includes several flowrate controllers such as the BFW flow controllers to HP, IP, and LP drums, makeup flow controller, fuel gas flow controller, and air flow controller, as well as pressure controllers. In addition, during fast load transients, liquid inventory control can be challenging especially because of the cascading effect in the NGCC process. Liquid inventories for the LP, IP and HP drums, deaerator, and surface condenser hotwell are controlled. Vapor phase inventories are maintained by operating the HP, IP, and LP steam drums at their respective desired pressures. 
The supervisory layer is similar to the industry-standard coordinated control system that includes feedforward-augmented cascaded feedback controllers along with function approximation and constraints (Sarda et al., 2018). Satisfying the load demand is the primary task of the supervisory layer with due consideration of other process and operational constraints. It is also essential to maintain the main steam and reheat steam temperatures at their desired set points during loadfollowing operation. If these temperatures are lower than their set points, it will lead to an efficiency loss. On the other hand, if these temperatures are above their set points, equipment damage can take place. Therefore, these steam temperatures should be maintained at or near their set points during low-load operation and during transients.

\subsection{Results and discussion}

\subsubsection{Gas turbine}

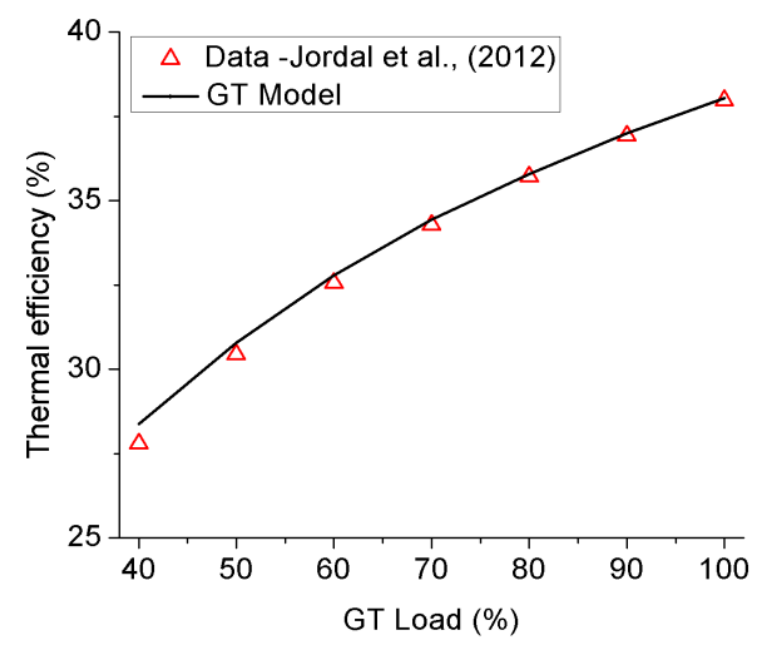

Figure 2. 3. GT thermal efficiency under off-design conditions

Coefficients for Equations 2.4-2.5 are estimated using the data from the work of Jordal et al (2012). Table 2.1 shows the coefficients and Figure 2.3 shows the resulting fit for the GT thermal efficiency calculated on the basis of fuel LHV.

Table 2. 1 Estimated coefficients for the dimensionless GT performance curves

\begin{tabular}{|c|c|c|c|c|c|c|}
\hline $\begin{array}{c}\text { Coefficients for the } \\
\text { GT curves }\end{array}$ & a1 & a2 & a3 & b1 & b2 & b3 \\
\hline Results & -0.2108 & 0.4828 & 0.7277 & -0.4426 & 0.8875 & 0.5466 \\
\hline
\end{tabular}


The GT efficiency decreases with the load decrease and this results in an increase in the turbine exhaust temperature (TET) as shown in Figure 2.4(a). In the GT, the air flow rate is controlled by closing or opening the inlet guide vane (IGV). The IGV helps to manipulate the air/fuel mass flow rate ratio, so that turbine inlet temperature (TIT) is maintained to achieve a relatively higher GT efficiency at part load condition (Apan-Ortiz et al., 2018). As shown in Figure 2.4(b), under the relatively high load conditions ( $100 \%$ to $80 \%$ load), the air/fuel ratio remains essentially constant, but as the load decreases below $80 \%$, the air/fuel ratio increases and leads to a decrease in the TIT. Figure 2.4(a) shows that at low load the TET increases relatively more slowly as the TIT is reduced.

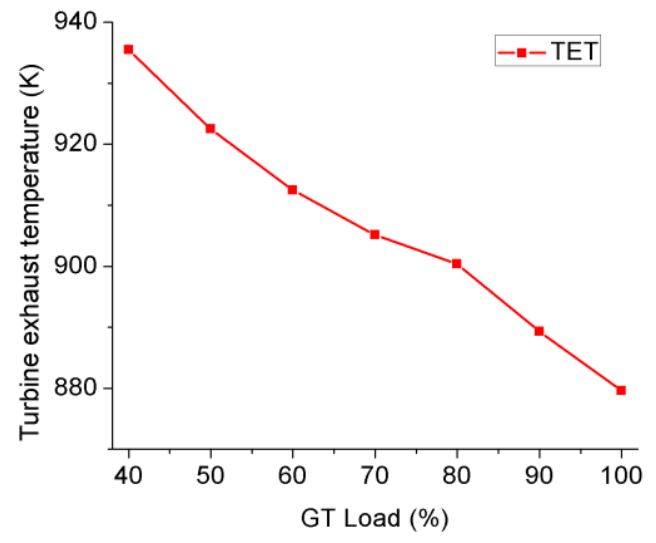

(a)

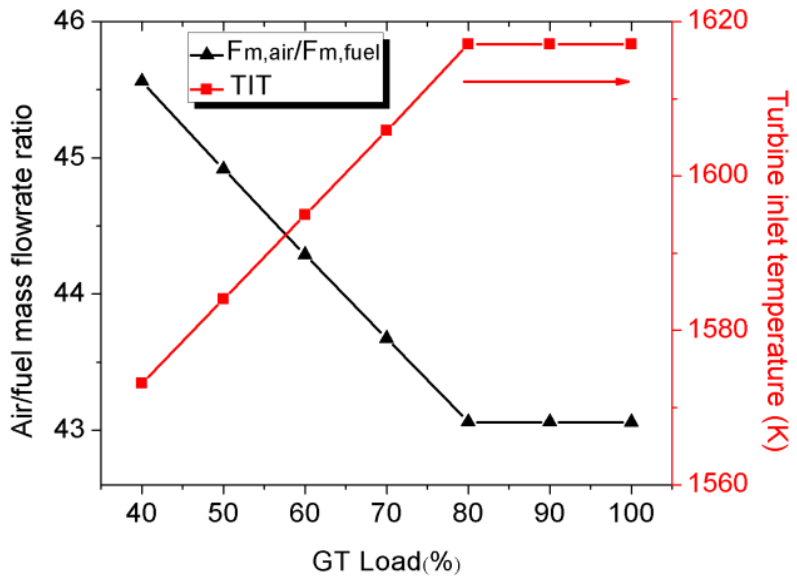

(b)

Figure 2. 4. GT temperature and air/fuel mass flow ratio under off-design conditions (a) TET (b) TIT and air/fuel ratio

\subsubsection{Heat recovery steam generator (HRSG)}

Results from the thermo-hydraulic model of the HRSG are compared with the work of Franco and Giannini (2006). They have developed a detailed model of a three-pressure HRSG and have used it for an optimal design of the HRSG. Since the number of tube passes and circulation ratio (CR) are not provided in their work, these parameters were estimated to minimize the error in area. Table 2.2 compares the results from Franco and Giannini (2006) with the results obtained using the model developed in this work. 
Table 2. 2 HRSG model comparison

\begin{tabular}{|c|c|c|c|c|c|}
\hline Components & $\begin{array}{c}\text { Heat Duty } \\
(\mathrm{MW})\end{array}$ & $\begin{array}{c}\text { Estimated } \\
\text { Parameters }\end{array}$ & $\begin{array}{c}\text { Area from } \\
\text { Literature }(\text { Zoelle } \\
\text { et al., 2015) }\left(\mathrm{m}^{2}\right)\end{array}$ & Area(m $\left.{ }^{2}\right)$ & $\begin{array}{c}\text { Error } \\
(\%)\end{array}$ \\
\hline ECO LP & 26.24 & Pass=6 & 17,893 & 18,259 & 2.05 \\
\hline EVA LP & 28.39 & Pass=1,CR=30 & 18,454 & 18,733 & 1.51 \\
\hline SH LP & 1.95 & Pass=1 & 1,789 & 1,834 & 2.53 \\
\hline ECO IP & 8.59 & Pass=1 & 8,947 & 9,161 & 2.39 \\
\hline EVA IP & 24.86 & Pass=1,CR=20 & 17,893 & 18,734 & 4.70 \\
\hline SH IP & 3.16 & Pass=1 & 2,936 & 3,239 & 10.32 \\
\hline ECO HP & 10.5 & Pass $=2$ & 5,704 & 6,010 & 5.37 \\
\hline EVA HP & 26.29 & Pass $=1, \mathrm{CR}=4$ & 14,763 & 13,816 & 6.42 \\
\hline SH HP & 21.86 & Pass $=1$ & 20,224 & 21,924 & 8.41 \\
\hline
\end{tabular}

Table 2. 3. Operating parameters and the surface area of the three-pressure HRSG

\begin{tabular}{|c|c|c|c|c|c|c|c|}
\hline \multicolumn{2}{|c|}{ Heating Section } & $\begin{array}{c}\text { Flue Gas } \\
\text { Inlet (K) }\end{array}$ & $\begin{array}{c}\text { Flue Gas } \\
\text { Outlet (K) }\end{array}$ & $\begin{array}{c}\text { Water/Steam } \\
\text { Inlet (K) }\end{array}$ & $\begin{array}{c}\text { Water/Steam } \\
\text { Outlet (K) }\end{array}$ & $\begin{array}{c}\text { Heat Duty } \\
(\mathrm{MW})\end{array}$ & $\begin{array}{c}\text { Area } \\
\left(\mathrm{m}^{2}\right)\end{array}$ \\
\hline \multirow{2}{*}{ PRE } & HTR 1 & 429.1 & 376.4 & 311.3 & 395.4 & 57.80 & 21,895 \\
\cline { 2 - 9 } & HTR 2 & 445.9 & 429.1 & 395.4 & 421.9 & 18.52 & 11,234 \\
\hline \multirow{4}{*}{ LP } & ECO & 446.9 & 445.9 & 422.0 & 428.7 & 1.10 & 827 \\
\cline { 2 - 9 } & EVA & 518.0 & 446.9 & 427.6 & 427.6 & 79.11 & 34,983 \\
\cline { 2 - 9 } & SH & 648.4 & 551.1 & 427.6 & 552.5 & 10.23 & 11,052 \\
\hline \multirow{4}{*}{ IP } & ECO & 549.5 & 518.7 & 423.6 & 534.0 & 0.68 & 847 \\
\cline { 2 - 9 } & EVA & 551.6 & 549.5 & 530.3 & 530.3 & 2.40 & 1,765 \\
\cline { 2 - 9 } & SH & 799.1 & 725.6 & 530.3 & 760.9 & 0.89 & 1,170 \\
\cline { 2 - 9 } & RH & 879.6 & 799.0 & 630.3 & 842.4 & 61.55 & 20,100 \\
\hline \multirow{4}{*}{ HP } & ECO1 & 549.5 & 518.0 & 425.5 & 490.4 & 34.67 & 7,471 \\
\cline { 2 - 9 } & ECO2 & 648.4 & 551.6 & 490.4 & 633.1 & 100.26 & 44,467 \\
\cline { 2 - 9 } & EVA & 725.4 & 648.4 & 632.5 & 632.5 & 89.79 & 29,295 \\
\cline { 2 - 9 } & SH1 & 799.1 & 725.4 & 632.5 & 750.0 & 86.60 & 21,104 \\
\cline { 2 - 9 } & SH2 & 879.6 & 799.3 & 746.1 & 841.7 & 35.59 & 15,800 \\
\hline
\end{tabular}


The thermo-hydraulic model is then used to design the components for the nominal $641 \mathrm{MWe}$ gross NGCC power plant since the size information is not available in the NETL baseline studies (Zoelle et al., 2015). Results are shown in Table 2.3. It should be noted that as opposed to many industrial configurations, this plant has the 2-stage preheater (PRE HTR) before the economizer resulting in a low duty of the LP economizer (LP ECO) duty. Also, the low IP steam flowrate in this configuration leads to the low heat duties of the heating sections that are solely used for generation of the superheated IP steam (Zoelle et al., 2015).

\subsubsection{Steam turbine}

The ST models using different algorithms for moisture detection and model adaptation are implemented under load-following operation described in Chapter 3. Both algorithms give the same solutions for all the load-following studies conducted in APD. Performances of Configuration 1 and 3 are for the coordinated control system, and those of Configuration 2, 4 and 5 are for dynamic optimization. Computational times of different ST algorithms are presented in Table 2.4.

It shows that the logic-based Algorithm1 is solved in lesser time. The possible reason is that the external Aspen Property call in Algorithm2 takes a longer time to calculate the vapor fraction and temperature given the pressure and enthalpy. While Algorithm 1 could converge all cases considered here, authors believe that Algorithm 2 has better convergence properties especially when there are rapid occurrences of moisture appearing/vanishing in some LP stages.

Table 2. 4. Computational times of different ST algorithms for load-following operation

\begin{tabular}{|c|c|c|c|c|c|}
\hline Configuration No. & 1 & 2 & 3 & 4 & 5 \\
\hline Algorithm1 & $4 \min 57 \mathrm{~s}$ & $5 \min 32 \mathrm{~s}$ & $7 \min 28 \mathrm{~s}$ & $6 \min 10 \mathrm{~s}$ & $13 \min 6 \mathrm{~s}$ \\
\hline Algorithm2 & $7 \min 13 \mathrm{~s}$ & $7 \min 6 \mathrm{~s}$ & $11 \min 32 \mathrm{~s}$ & $8 \min 39 \mathrm{~s}$ & $21 \min 32 \mathrm{~s}$ \\
\hline
\end{tabular}

\subsubsection{Dynamic model at full load}

The steady-state results from the Aspen Plus Dynamics model at full load are compared with the NETL baseline Case B31A (Zoelle et al., 2015) in Table 2.5. The great agreement is shown here. 
Table 2. 5. Comparison between the model results and NETL baseline Case B31A

\begin{tabular}{|c|c|c|c|c|}
\hline \multicolumn{2}{|c|}{} & $\begin{array}{c}\text { NETL Baseline Case } \\
\text { B31A (Zoelle et al., 2015) }\end{array}$ & $\begin{array}{c}\text { Model } \\
\text { Results }\end{array}$ & $\begin{array}{c}\mid \text { Error| } \\
(\%)\end{array}$ \\
\hline \multirow{3}{*}{$\begin{array}{c}\text { HP SH } \\
\text { Outlet }\end{array}$} & Mass flow(kg/hr) & $439,079.23$ & $440,400.22$ & 0.30 \\
\cline { 2 - 5 } & Temperature(K) & 838.71 & 838.71 & - \\
\cline { 2 - 5 } & Pressure(bar) & 166.51 & 166.70 & 0.12 \\
\hline \multirow{2}{*}{$\begin{array}{c}\text { IP RH } \\
\text { Outlet }\end{array}$} & Mass flow(kg/hr) & $444,504.65$ & $446,037.91$ & 0.34 \\
\cline { 2 - 5 } & Temperature(K) & 838.71 & 838.71 & - \\
\cline { 2 - 5 } $\begin{array}{c}\text { LP SH } \\
\text { Outlet }\end{array}$ & Pressure(bar) & 41.92 & 41.52 & 0.96 \\
\cline { 2 - 5 } & Mass flow(kg/hr) & $137,131.41$ & $136,123.20$ & 0.74 \\
\cline { 2 - 5 } & Temperature(K) & 553.71 & 552.51 & 0.22 \\
\hline \multirow{3}{*}{$\begin{array}{c}\text { Power } \\
\text { Generation }\end{array}$} & Pressure(bar) & 5.10 & 5.10 & - \\
\cline { 2 - 5 } & GT Power (MWe) & 219 & 218.61 & 0.18 \\
\cline { 2 - 5 } & Total Power (MWe) & 422 & 422.39 & 0.09 \\
\hline
\end{tabular}

\subsection{Conclusion}

For an NGCC plant, while there are various designs of the boiler for the desired heat duty at the nominal condition, the dynamics of the boiler would be very different. In this study, the boiler is optimally designed based on the NETL baseline Case B31A (Zoelle et al., 2015). Then a plantwide dynamic model of the NGCC plant is developed with detailed equipment level sub-models to capture the plant load-following behavior.

A model of the gas turbine (GT) is developed for estimating its performance under off-design conditions. A thermo-hydraulic model is used for the optimal design of heating sections in the heat recovery steam generator (HRSG). A model of the steam turbine (ST) is developed with moisture detection and correction capability. It was observed that the steady-state results from the dynamic model at full load shows a great agreement with the NETL baseline Case B31A (Zoelle et al., 2015). Also, the off-design behavior of NGCC plant can be simulated using the dynamic model. 


\section{Chapter 3. Novel configurations of NGCC plant for load-following}

\subsection{Literature Review}

Under the load-following operation of power plants, the main steam temperature to the ST is tightly controlled (Sarda et al., 2018). A lower main steam temperature not only results in lower plant efficiency but can also lead to undesired moisture formation in intermediate ST stages where steam condensation is not expected and/or higher amount of moisture formation in last stage or last few stages than what those stages are designed for. Larger number of water droplets can cause considerable damage to the turbine blades. If the steam temperature is higher than the design, then severe damage of the ST blades can occur (JianPing et al., 2003). Therefore, a tight control of the main steam temperature is desired.

At low-load operation, the temperature of the exhaust gas from the GT increases as the GT efficiency decreases. In addition, the steam flowrate generated from the evaporator (EVA) decreases. These two effects can lead to a higher final steam and reheat steam temperature exceeding the maximum design steam temperature to the ST. Typically, the final/reheat steam temperature is controlled by an attemperator, which is a device where boiler feedwater (BFW) is sprayed to the steam to reduce its temperature. For single-stage superheater/reheater, attemperation is provided before the inlet of the superheater/reheater. For designs with two or more stages of superheaters/reheaters, additional attemperation is provided before the inlet of the intermediate stage(s).

In order to maintain the steam temperature at its design value at the outlet of the final high-pressure superheater (HP SH2)/reheater (RH) under off-design conditions, excessive spray may be required at one or more attemperators (Liese and Zitney, 2018), leading to a two-phase flow through the superheater/reheater typically denoted in the utility industry as 'spraying to saturation' (Moelling et al., 2015; Sorge et al., 2017). Since superheater and reheater are not typically designed for twophase flow, free water, if present, can flow as a slug along with the steam at a high velocity. This free water can hit the pipe wall, especially when it changes direction, creating a loud hammering noise as well as large stress on the pipe. This phenomenon is called 'water hammer', which can lead to considerable damage in tubes eventually leading to failure of tubes. 
To the best of our knowledge, there has been no study on this issue in the open literature using a mathematical model especially for mitigating this undesired phenomenon. A mathematical model can be helpful in understanding the operating conditions that lead to this undesired problem and in studying the impact of various configurations and control strategies to avoid this issue.

In this chapter, several novel configurations are proposed for controlling the main steam and reheat steam temperatures while avoiding 'spraying to saturation' during fast load-following by considering different final high-pressure superheater (HP SH2)/ reheater (RH) arrangements (in series or in parallel) and attemperation strategies (single-stage, two-stage, and damper-assisted attemperation). Load-following operation is studied under two operational strategies- the industrystandard coordinated control strategy and dynamic optimization. Dynamic optimization is used to maximize the plant efficiency while satisfying the operational constraints and state transition constraints. It was observed that while more than one configuration can avoid spraying to saturation and maintain the steam temperatures within their limits even during very fast load transients, their efficiency can greatly vary and that dynamic optimization, when feasible, can lead to superior efficiency than the coordinated control system. (Wang et al., 2020).

\subsection{NGCC configurations and control strategies for load-following operation}

As shown in Figure 2.1, the final superheater (HP SH2) and reheaeter (RH) are located at the front end of the HRSG. Actually, they can be arranged in series or in parallel.

Under the steady-state operation at the nominal condition, these two arrangements would show no difference in the power generation if the HP SH2 and RH are appropriately designed such that their respective heat duties would remain the same irrespective of their arrangement. However, their required surface area would vary due to the differences in the flue gas side conditions. In a series structure, since the RH is located behind the HP SH2, it has much larger surface area because of the lower inlet temperature of the flue gas. As a result, their respective volumes also change depending on the arrangement. Therefore, these two arrangements show considerable differences in their heat duties and temperature transients under load-following operation especially under part load operations.

Five configurations are proposed in this work. In addition to details of each of the configuration, this section also provides details of the coordinated control system specific to each configuration. It should be noted that the coordinated control system implemented in the power plants is very 
involved and can vary considerably from plant to plant. In this work, since the focus is on steam temperature control with constraints on dew point, only the coordinated control system that is specific to the steam temperature control corresponding to each of the configurations considered here will be discussed. Therefore, any reference to 'coordinated control' in the subsequent text would denote only the supervisory control layer specific to steam temperature control (i.e. in the subsequent text the term 'coordinated control' does not include other supervisory/regulatory controllers discussed in Section 2.2.4).

\subsubsection{Configuration 1}

Configuration 1, shown in Figure 3.1, is a series configuration with single-stage attemperation. The flue gas first goes through the HP SH2 followed by the RH. For single-stage attemperation, only one attemperator each located at the inlet of the HP SH2 and RH is used. Here as part of the coordinated control, a cascaded control system is considered where two PID controllers are used for the main and reheat steam temperature control. These controllers manipulate the set points of respective attemperator spray flow controllers.

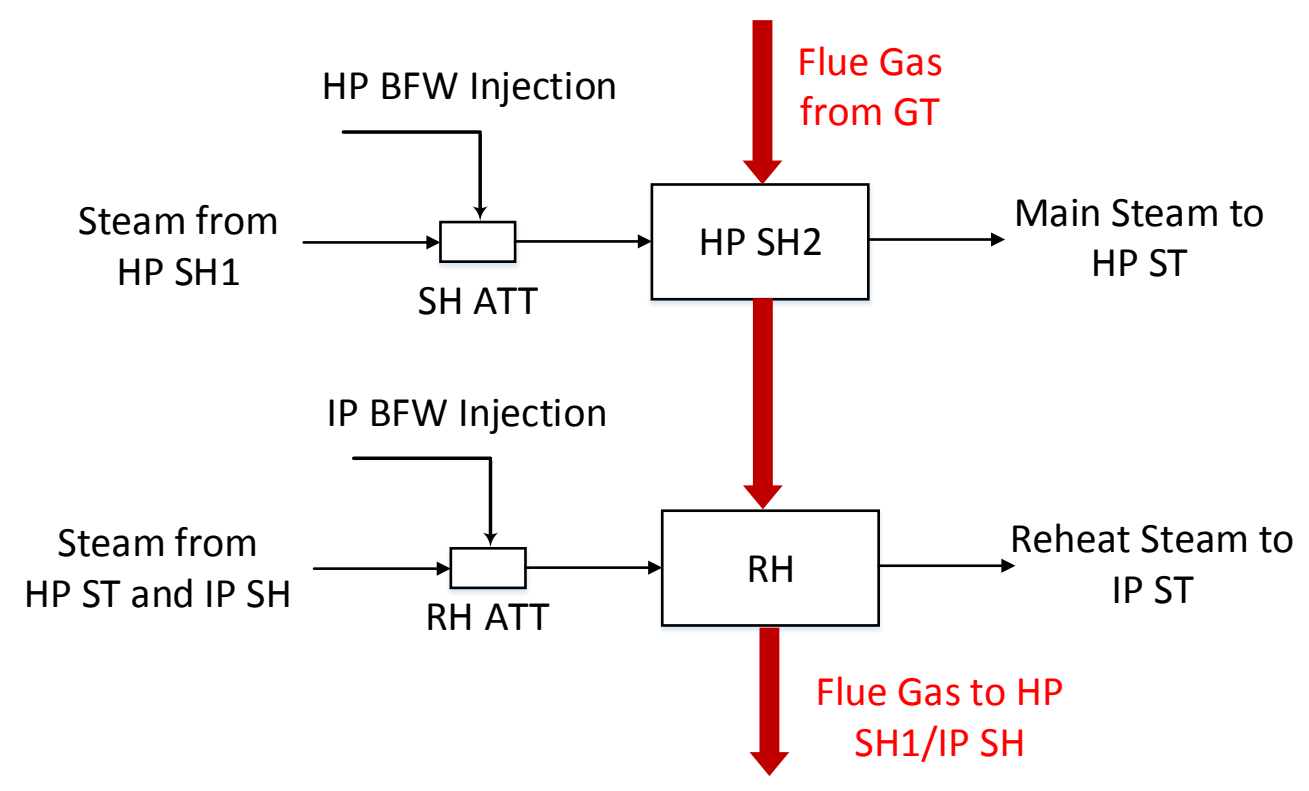

Figure 3. 1. Series configuration with single-stage attemperation

\subsubsection{Configuration 2}

In Configuration 2, the final superheater is divided into two sections HP SH2 (A) and HP SH2 (B) with an additional attemperation between the sections as shown in Figure 3.2. In this configuration, 
the ratio of the sizes of divided sections of $\mathrm{HP} \mathrm{SH} 2$ is an additional degree of freedom while keeping the total surface area of HP SH2 the same as Configuration 1.

During load-following operation, the two-stage attemperation provides additional flexibility in maintaining the steam temperature. Here, as part of the coordinated control, a cascaded control system is considered to control the main steam temperature where a PID controller manipulates the set point of the spray flow controller for the second attemperator (SH ATT2) that is located immediately before HP SH2 (B). Another cascaded PID controller manipulates the set point of the spray flow controller for the first attemperator (SH ATT1) that is located immediately before HP SH2 (A) to ensure that the opening of the spray flow control valve for SH ATT2 remains in the desired range. This strategy is widely used in the industry as part of the coordinated control system for similar configuration (Sarda et al., 2018). For the reheat steam temperature control, another cascaded control system is considered where a PID controller manipulates the setpoint of the spray flow controller for the reheat attemperator.

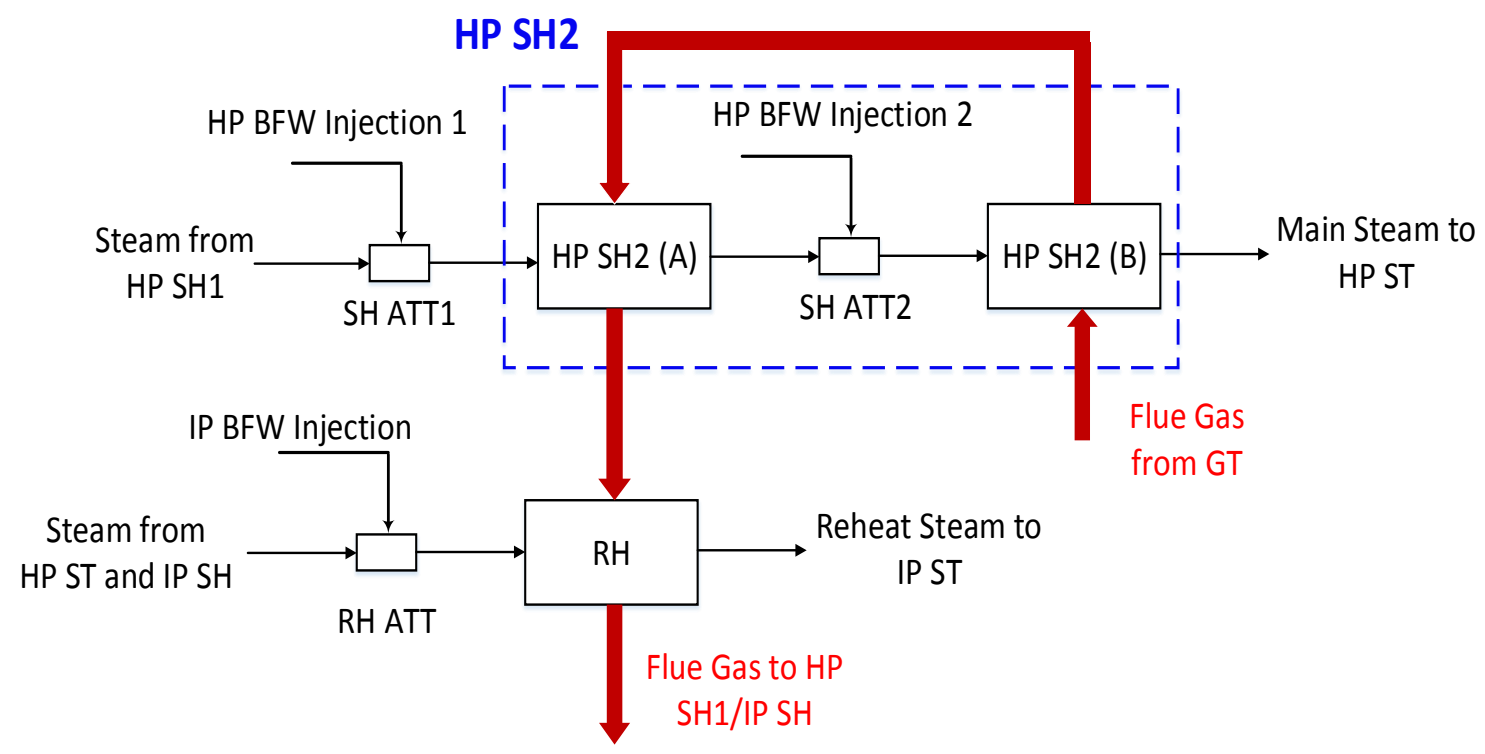

Figure 3. 2. Series configuration with two-stage attemperation for HP SH2 and onestage attemperation for RH

Since the RH is located downstream of the HP SH2 in the flue gas path, HP ATT1 does not only assist SH ATT2 to maintain the main steam temperature but can affect the reheat attemperator (RH ATT) that is located immediately before the RH for reheat steam temperature control. If the RH ATT spray flowrate at part-load condition is low, the higher steam temperature profile leads to 
lower heat exchange in the $\mathrm{RH}$ and a higher temperature of flue gas feeding to the downstream HP EVA for HP steam generation, which leads to a higher thermal efficiency. Therefore, the SH ATT1 spray flowrate can be optimized to maximize the thermal efficiency while both main steam and reheat temperature are maintained with acceptable deviation from their respective setpoints. Since the conventional coordinated control may not be adequate to maximize thermal efficiency while achieving steam temperature control, dynamic optimization can exploit this opportunity as discussed later.

\subsubsection{Configuration 3}

Configuration 3 is a parallel configuration with single-stage attemperation for both superheater and reheater. In this configuration, the RH is located in parallel with the HP SH2 at the front end of the HRSG. For single-stage attemperation, only one attemperator is used and located at the inlet of each heating section as shown in Figure 3.3. The split flue gas flow through each section cannot be manipulated during load-following operation and therefore depends on the nominal design and pressure drop through each section. For this configuration, the coordinated control system is similar to Configuration 1.

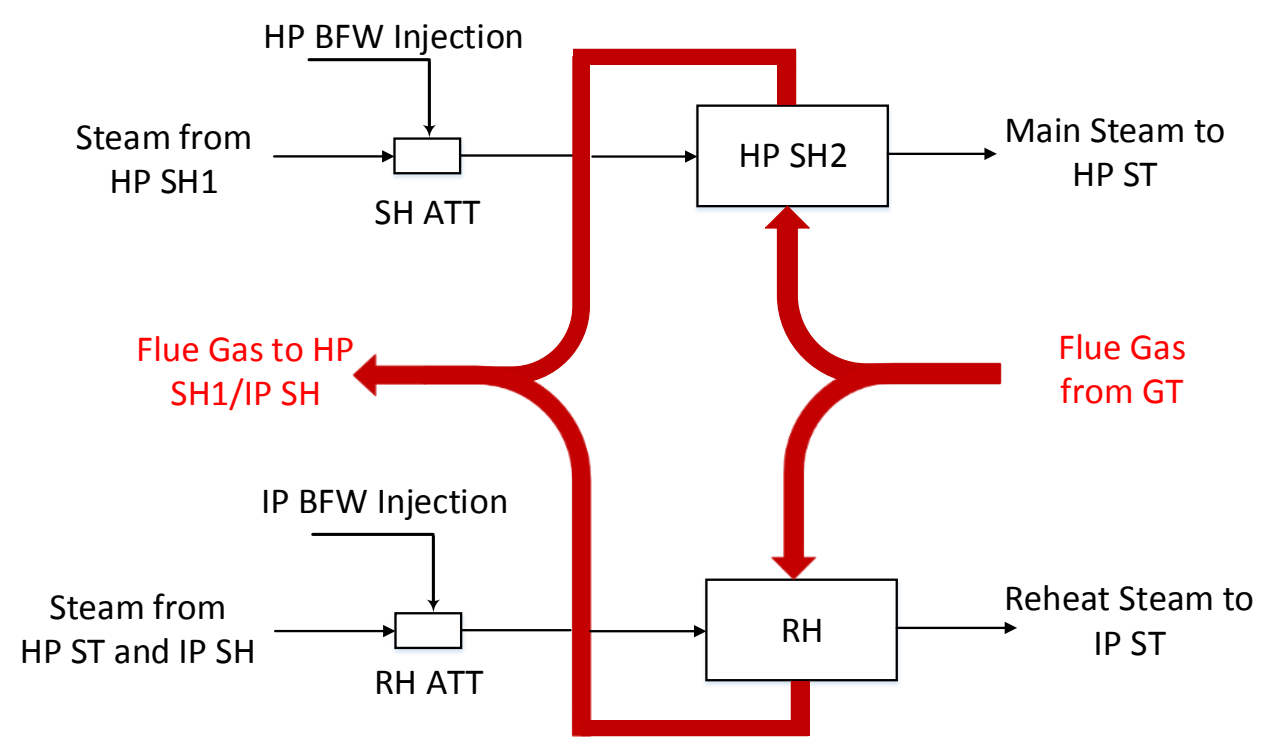

Figure 3. 3. Parallel configuration with single-stage attemperation

\subsubsection{Configuration 4}

In Configuration 4, both the HP SH2 and RH are divided into two sections with two-stage attemperation as shown in Figure 3.4. The ratios of the sizes of divided sections of the HP SH2 
and $\mathrm{RH}$ are additional degrees of freedom while keeping their respective total surface areas the same as Configuration 3.

Here, the coordinated control system for both main and reheat steam temperature control is similar to that for the main steam temperature control in Configuration 2, i.e. the second attemperator (SH ATT2 or RH ATT2) spray flowrate is used to control the steam temperature whereas the first attemperator (SH ATT1 or RH ATT1) spray flowrate is manipulated to ensure that the opening of the spray flow control valve for the second attemperator remains in the desired range.

Similar to Configuration 2, HP ATT1 and RH ATT1 do not only assist ATT2 to maintain the main /reheat steam temperature but can affect the steam flowrate generated at each pressure level and consequently affect the thermal efficiency. If the ATT1 spray flowrate at part-load condition is low, more exhaust heat is recovered in the HP EVA for HP steam generation, and it leads to a higher thermal efficiency. However, one possible issue is that not enough IP steam can be produced due to less heat available for the IP EVA, which results in a dry IP steam circuit.

Therefore, the ATT1 spray flowrate to both the SH and RH sections can be optimized to maximize the thermal efficiency while ensuring that steam flowrate at each pressure level remains higher than the lower bound (10\% of the nominal condition).

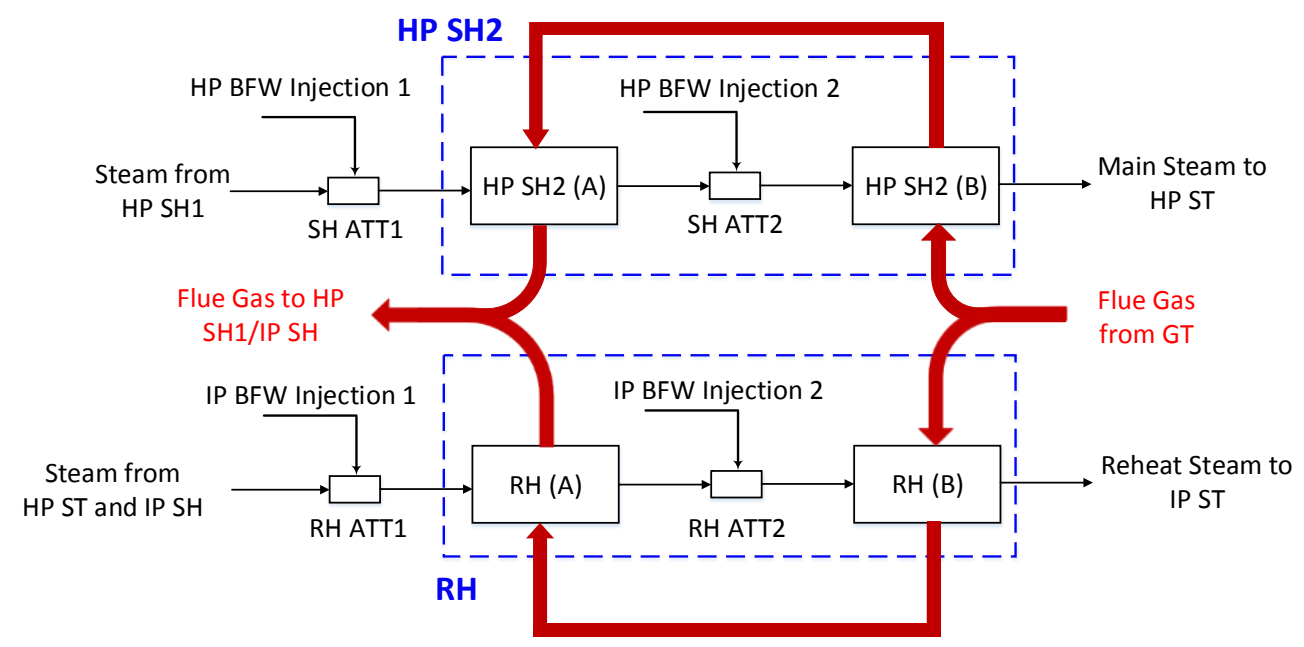

Figure 3. 4. Parallel configuration with two-stage attemperation

\subsubsection{Configuration 5}

Configuration 5, as shown in Figure 3.5, also considers the HP SH2 and RH are arranged in parallel but the flue gas split between them can be adjusted by a damper. Here as part of the coordinated 
control, a split-range control strategy is considered for the RH temperature control. During the load-following operation, the reheat steam temperature is first controlled by manipulating the opening of the damper that regulates the flue gas flowrate to the RH. When the opening of the damper reaches its limit, the split-range controller manipulates the RH ATT spray like Configuration 3. Due to the damper, less flue gas flowrate goes through the RH and almost no spray is required for reheat steam temperature control even at low load. Thus, a two-stage attemperation does not help to improve the efficiency as there is no more degrees of freedom. Therefore, only one stage attemperation for the RH is considered. Since a two-stage attemperation is considered for the HP SH2, the coordinated control system for the main steam temperature control is similar to Configuration 4. Also, the SH ATT1 spray flowrate can be optimized to maximize the thermal efficiency while satisfying the constraints of the steam temperature and dew point, and that the steam flowrate at each pressure level remains higher than the lower bound.

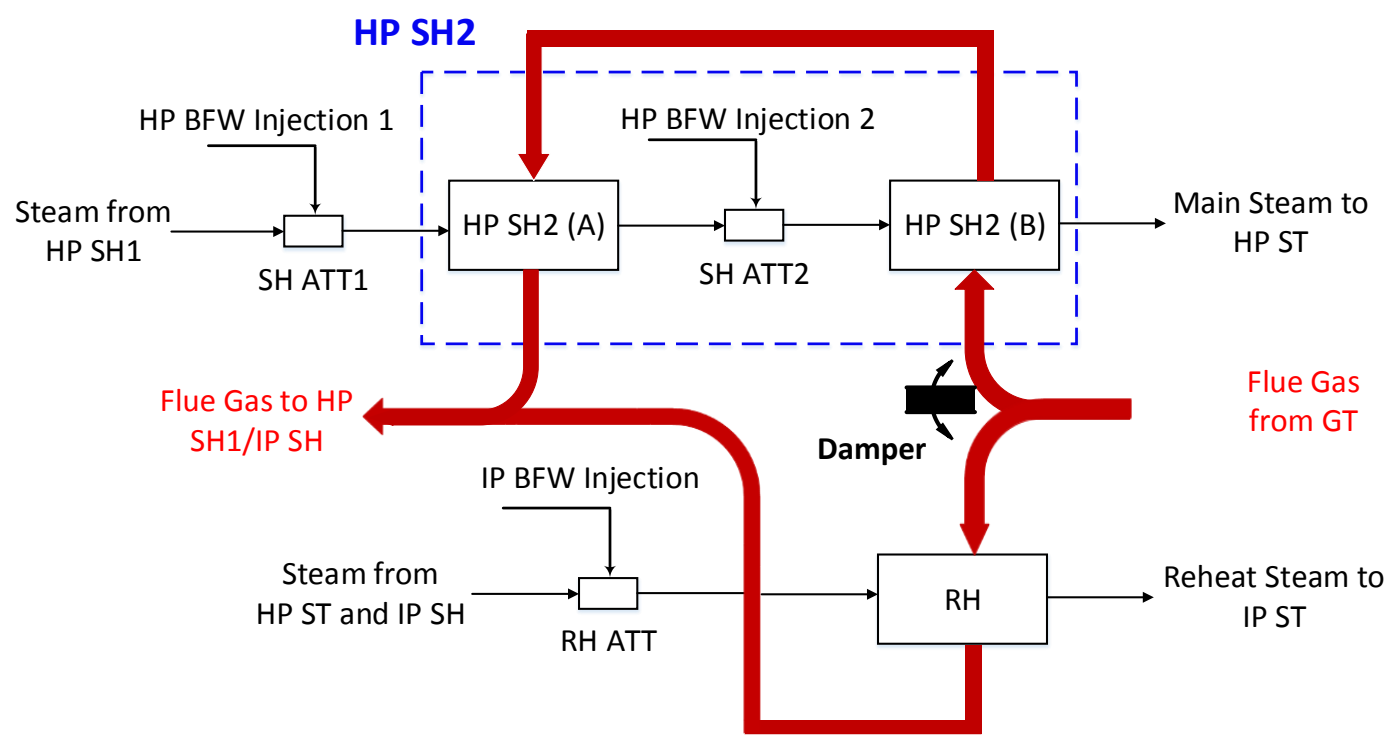

Figure 3. 5. Parallel configuration including damper control with two-stage attemperation for HP SH2 and one-stage attemperation for RH

\subsection{Dynamic Optimization}

The dynamic models for different configurations can be used to implement the load-following operation. For the specific configuration, it was observed that there are several degrees of freedom that can be used for maximizing the thermal efficiency under off-design conditions while satisfying the constraints of maintaining the main/reheat steam temperature without reaching saturation 
downstream of any of the attemperators while maintaining the flowrate of steam generated at each pressure level above the lower bound.

The dynamic optimization problem is shown in Equation 3.1. It should be noted that here dynamic optimization is used only for optimal operation and therefore design parameters are not included. Two bound constraints are considered to ensure that the main/reheat steam temperature is maintained with certain bounds. Two inequalities are considered to ensure that the steam temperature remains above the corresponding dew point at the inlet of the respective SH/RH stage. In the dynamic optimization problem, only the coordinated control layer (in the sense as discussed in the beginning of Section 3.2) is removed and the setpoints of respective attemperator spray flow controllers and the damper opening (only for Configuration 5) are considered as the decision variables. Neither other supervisory/regulatory controllers discussed in Section 2.2.4 nor the attemperator spray flow controllers are removed. While one might remove all controllers in the dynamic optimization and consider the manipulated variables as the decision variables, that approach is not pursued here since the focus of the paper is on steam temperature control and the proposed approach makes solution of the dynamic optimization problem computationally tractable in APD.

$$
\begin{gathered}
\max _{u} \quad \eta_{t h}=\frac{\text { power output }}{F_{m, N G} \times L H V} \\
\text { s.t. } f(x, y, u) \leq 0 \quad x, y, u \in R^{n} \\
T_{s p, M S}-\Delta T_{M S} \leq T_{M S} \leq T_{s p, M S}+\Delta T_{M S} \\
T_{s p, R S}-\Delta T_{R S} \leq T_{R S} \leq T_{s p, R S}+\Delta T_{R S} \\
T_{S H, i} \geq T_{\text {dew }, S H, i}+\Delta T_{\text {dew }, S H} \\
T_{R H, i} \geq T_{\text {dew }, R H, i}+\Delta T_{\text {dew }, R H} \\
F_{m_{j}} \geq F_{m_{\text {lower }, j}}
\end{gathered}
$$

where $\eta_{t h}$ is the thermal efficiency of power plant, defined as the ratio of the power output over the product of natural gas mass flowrate $F_{m, N G}$ and its lower heating value $L H V . f(x, y, u) \leq 0$ denote the process model equalities and inequalities where $x, y$, and $u$ denote state/algebraic variables, output and decision variables, respectively. $T$ is the steam temperature, $\triangle T$ is the allowable temperature deviation /difference, and $F_{m}$ is the steam flow rate. The subscripts ' $s p$ ', 'dew', and 'lower' denote setpoint, dew point and lower bound, respectively; ' $M S$ ' and ' $R S$ ' represent main steam and reheat 
steam, respectively; ' $S H$ ' and ' $R H$ ' denote superheater and reheater inlet steams, respectively; $i$ represents $\mathrm{SH} / \mathrm{RH}$ stages, and $j$ denotes HP or IP or LP steam.

In APD, FEASOPT, which uses a feasible path SQP algorithm, is used. As the decision variables are the attemperator spray flowrates and damper opening (only for Configuration 5) for each discrete instant of time over the entire time span of simulation ( $3 \mathrm{hr}$ for all cases considered here), the computational time increases considerably as the number of attemperator sprays increases (such as four attemperator sprays in Configuration 4 compared to two sprays in Configuration 3). Therefore, the number of discrete instants of time for optimization is adjusted to obtain solution from dynamic optimization within reasonable time (typically within a day).

A good initial guess is critical for convergence of the dynamic optimization problem. Typically, results obtained from the coordinated control system are used as the initial guess for dynamic optimization. It should be noted that different feasible initial guesses can be generated and used by changing the tuning parameters of the coordinated control system. For the different initial guesses that are evaluated, variation in the optimal transient profile of each decision variable is minor and within numerical tolerance.

\subsection{Results and discussion}

Transient responses of the steam temperature and thermal efficiency under off-design conditions for the five configurations discussed earlier are presented here. Results from the dynamic optimizations are compared with the results obtained by using the coordinated control when the dynamic optimization problem converges. When the dynamic optimization problem fails to converge, only the results from the coordinated control are shown. These specifics are discussed in more details under each configuration. In the coordinated control system, a constraint is used that does not allow further increase in the attemperator flowrate once the saturation condition is reached. This constraint-augmented coordinated control is contrary to standard industry practice that leads to spraying to saturation but certainly avoids excessive increases in steam/tube temperature. The extent of temperature excursions is investigated when such a constraint for the coordinated control system is to be exercised. The results presented below are generated by simulating a ramp decrease in the load from $100 \%$ to $40 \%$ at a ramp rate of $5 \%$ load per min initiated at $1 \mathrm{hr}$. In other words, the gross power output is decreased from 641 to $256 \mathrm{MWe}$ over a period of $12 \mathrm{~min}$. 


\subsubsection{Configuration 1}

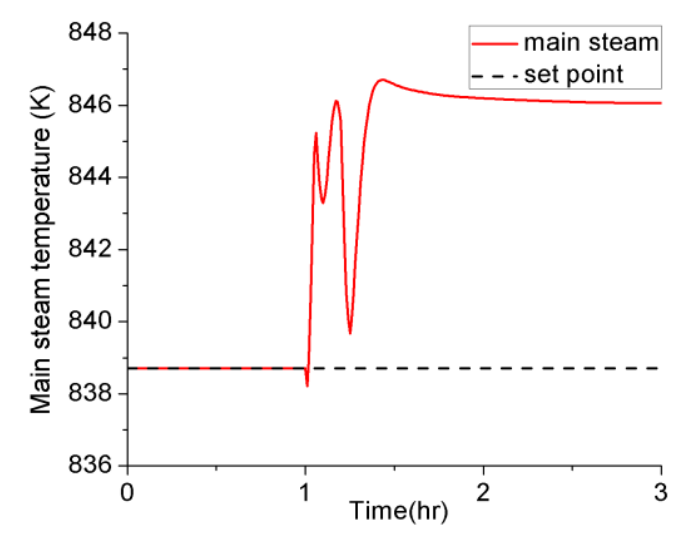

(a1)

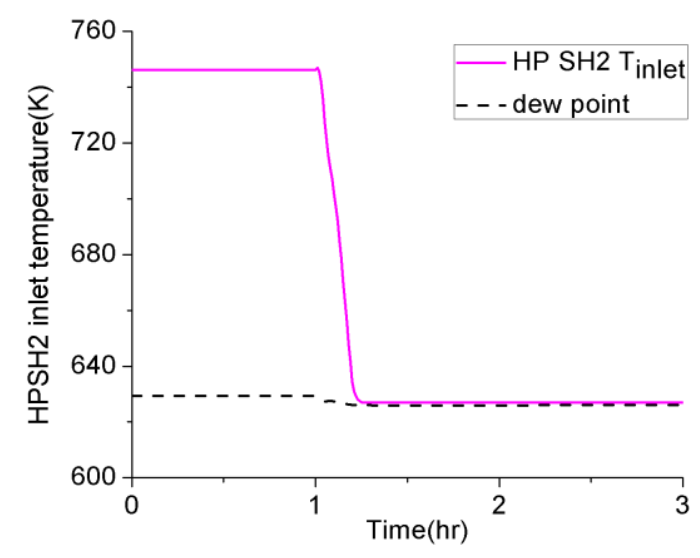

(a2)

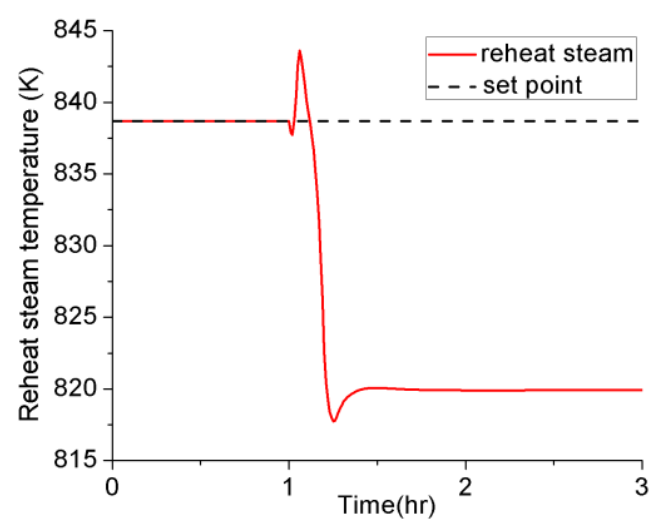

(b1)

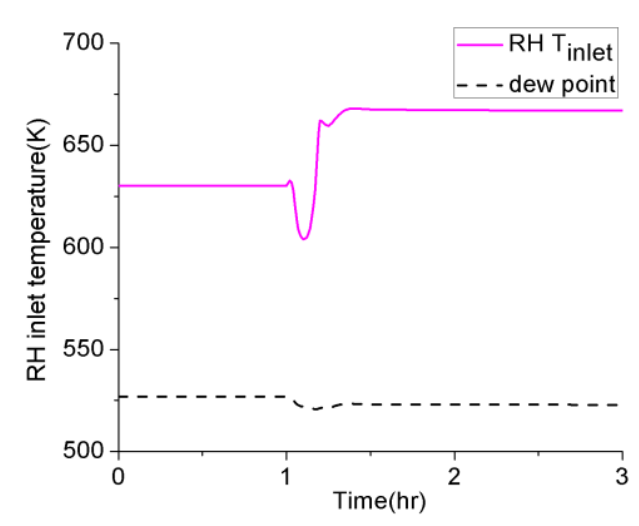

(b2)

Figure 3. 6. Steam temperature transients under load-following operation using coordinated control for Configuration 1: (a1) main steam temperature, (a2) HP SH2 inlet temperature, (b1) reheat steam temperature, (b2) RH inlet temperature

In Configuration 1, only HP SH2 is located at the front end of the HRSG. For this configuration, there is no feasible solution for the dynamic optimization problem as the inequality/bound constraints related to dew point and main/reheat steam temperature as given in Equation 3.1 could not be satisfied simultaneously. If the bound constraints in Equation 3.1 are relaxed considerably, then the dynamic optimization problem becomes feasible. In the coordinated control mode, while 
there are dew point constraints, there is no constraint on main/reheat steam temperature. Therefore, results could be generated when coordinated control is used. These results are presented below.

With the higher GT exhaust temperature and lower steam flowrate, the main steam temperature first rises as load decreases as shown in Figure 3.6 (a1). When more feedwater is sprayed into the $\mathrm{HP}$ SH2 attemperator, the temperature starts decreasing. Eventually, the SH steam inlet temperature reaches its saturation condition as seen in Figure 3.6 (a2). As the spray water is not increased any further, the main steam temperature rises again and an excursion (about $7 \mathrm{~K}$ ) from its desired setpoint is shown in Figure 3.6 (a1).

On the other hand, the reheat steam temperature first rises then decreases below the setpoint as shown in Figure 3.6 (b1). Therefore, spray water to the RH attemperator is completely stopped by the corresponding temperature controller. This results in an increase in the RH steam inlet temperature that is much above the corresponding dew point as shown in Figure 3.6 (b2). In this configuration, the reheat steam cannot be heated to the desired temperature. That is because as high attemperator spray is used at the HP SH2 attemperator for the main steam temperature control, the steam inlet temperature to HP SH2 becomes lower by more than $115 \mathrm{~K}$ compared to the nominal value as shown in Figure 3.6 (a2). The overall higher driving force results in higher heat exchange in HP SH2. Therefore, the temperature of flue gas from HP SH2 to RH becomes much lower than its nominal value resulting in a reheat steam temperature that is about $20 \mathrm{~K}$ lower than the desired value.

The deviation in the main/reheat steam temperature using the coordinated control provides valuable insight into the infeasibility of the dynamic optimization problem for this configuration. The results show that when the dew point constraint on the main steam temperature is reached, HP SH2 attemperator flowrate cannot be increased any further (i.e. HP SH2 attemperator flowrate reaches its upper limit) thus losing a degree of freedom in the dynamic optimization problem. In addition, as noted above, even when the RH attemperator spray is completely stopped, RH temperature is considerably lower than its set point. Thus, for the dynamic optimization problem, the RH attemperator spray flow would reach its lower limit thus losing a degree of freedom. Since both decision variables hit their upper/lower limits, steam temperature constraints could not be satisfied. 


\subsubsection{Configuration 2}

For this configuration, solution of the dynamic optimization problem is feasible, so results from dynamic optimization are compared with the results from coordinated control system (CCS).

Figure 3.7 (a) shows that higher thermal efficiency could be obtained by using dynamic optimization compared to the coordinated control system. Figure 3.7 (b) shows that more spray at SH ATT1 is used under dynamic optimization. That leads to less spray at RH ATT for reheat steam temperature control, and the RH ATT spray reaches its lower limit at part-load condition. Less spray results in a higher steam inlet temperature and lower driving force for heat exchange in RH. Therefore, more exhaust heat is recovered in HP EVA for HP steam generation leading to more power generation and higher efficiency.

Steam temperature transients for Configuration 2 under dynamic optimization are shown in Figure 3.8. Figures 3.8 (a1) and 3.8 (b1) show that during load-following operation, both main steam and reheat steam temperatures can be maintained at their respective set points with a small deviation. Furthermore, Figures 3.8 (a2) and 3.8 (b2) show that a saturation condition is neither reached at the inlet of HP SH2 nor at the inlet of RH.

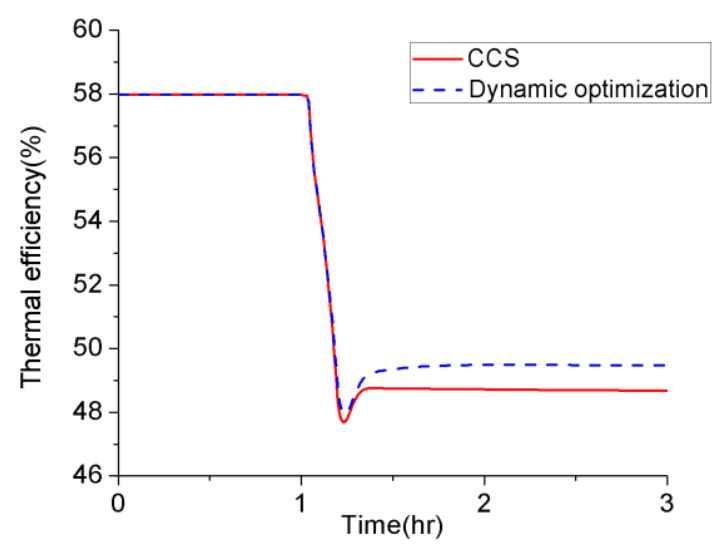

(a)

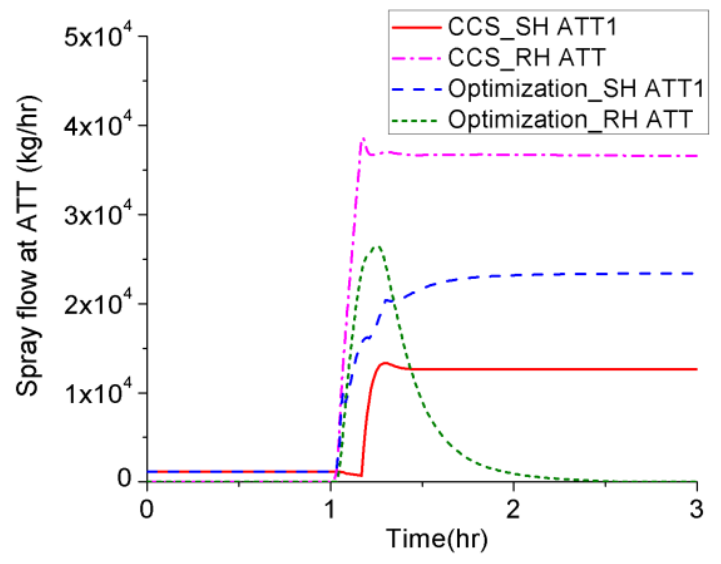

(b)

Figure 3. 7. Comparison between coordinated control and dynamic optimization for Configuration 2 (a) thermal efficiency (b) spray flow at the SH ATT1 and RH ATT 


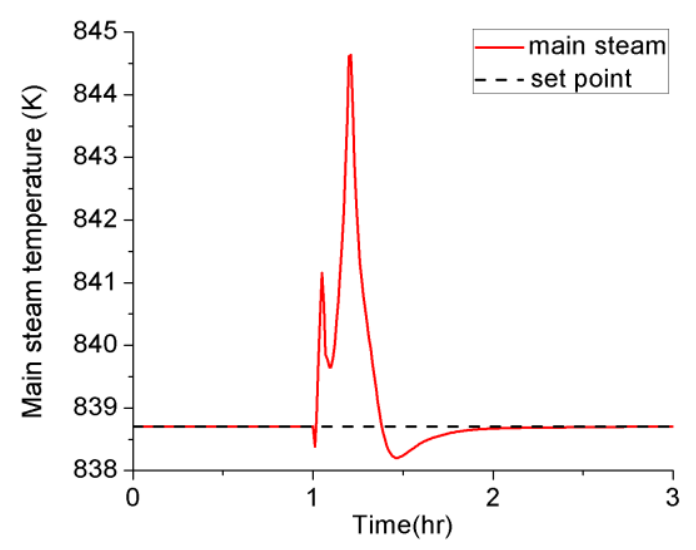

(a1)

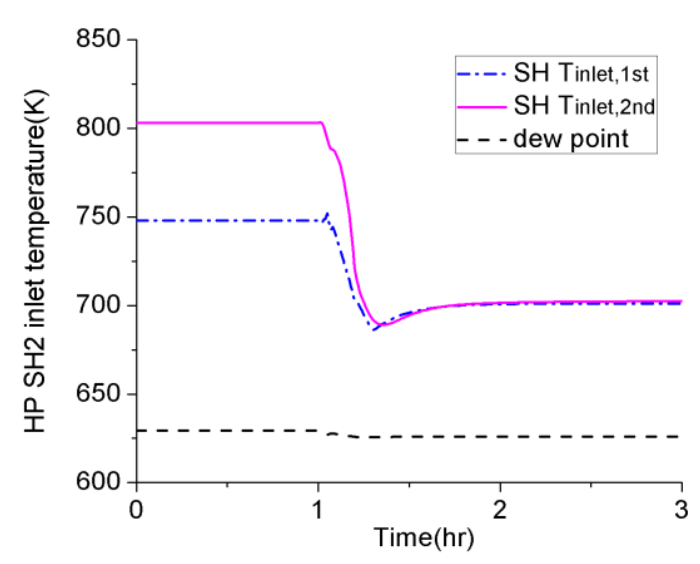

(a2)

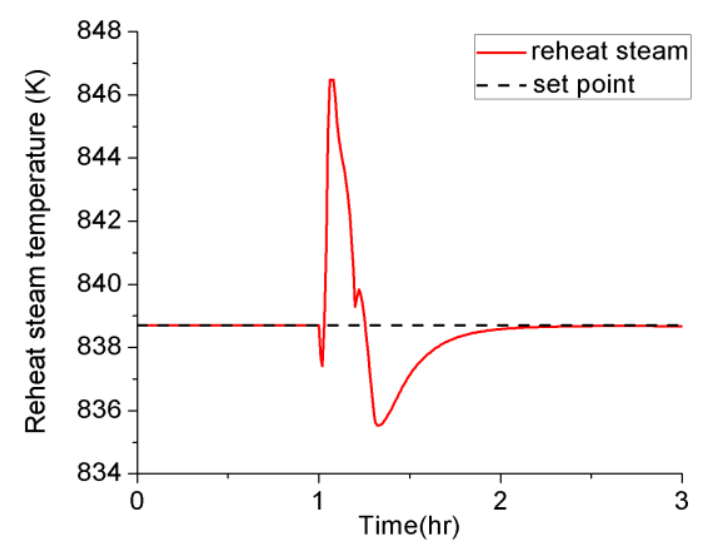

(b1)

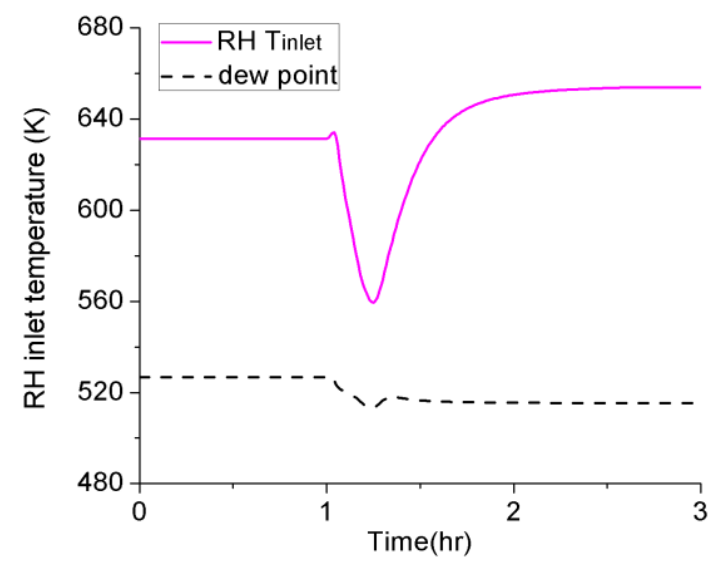

(b2)

Figure 3. 8. Steam temperature transients under load-following operation for Configuration 2: (a1) main steam temperature, (a2) HP SH2 inlet temperature, (b1) reheat steam temperature, (b2) RH inlet temperature

The results of dynamic optimization for Configuration 2 shown in Figure 3.8 are obtained with the HP SH 2 (A) accounting for $50 \%$ of the total area.

Since the HP SH2 has two sections in Configuration 2, a sensitivity study is conducted to evaluate the impact of the area ratio of the two sections. Obviously at full load, the change in the ratio is not expected to show any difference in thermal efficiency or the steam temperature control performance. At part load, the RH ATT spray is at its lower limit under dynamic optimization. 
Only the SH ATT1 and SH ATT2 are activated for the steam temperature control. Table 3.1 shows the key operating conditions and performance measures at $40 \%$ load for Configuration 2. It was observed that there is practically no difference regardless of the area ratio. While a larger HP SH2 (A) requires the less spray at SH ATT2 for main steam temperature control, more spray is used at SH ATT1. The total spray flowrate practically does not change. Consequently, the total heat duty of HP SH2 and RH and power generation do not get affected as the ratio is changed. To avoid carryover of free water to the turbine, there will be an upper limit of HP SH2 (A) to ensure that there is sufficient residence time. Determination of this maximum limit will need to consider the mass transfer rate with due consideration of the actual layout and configuration of the HP SH2 (B). Since such a kinetic model is not considered here, the upper limit of HP SH2 (A) is specified to be $90 \%$ of the total area. The lower limiting of HP SH2 (A) is $30 \%$ of the total area, at which a zero spray flowrate at SH ATT1 is reached. If the HP SH2 (A) area is less than the lower bound, the reheat steam temperature would be lower than the setpoint even if there is no spray at RH ATT.

Table 3. 1. Key operating conditions and performance measures for variation in HP $\mathrm{SH} 2$ area ratio at $\mathbf{4 0 \%}$ load for Configuration 2

\begin{tabular}{|c|c|c|c|c|}
\hline \multicolumn{2}{|c|}{ Area Ratio of HP SH2(A) to total area } & $50 \%$ & $70 \%$ & $90 \%$ \\
\hline \multirow{3}{*}{ HPSH2 section } & Spray at ATT1 (kg/hr) & 22,870 & 39,824 & 50,452 \\
\cline { 2 - 5 } & Spray at ATT2 (kg/hr) & 39,144 & 22,175 & 11,538 \\
\cline { 2 - 5 } & Total Spray (kg/hr) & 62,014 & 61,999 & 61,990 \\
\cline { 2 - 5 } & Total duty (MW) & 62.59 & 62.59 & 62.60 \\
\hline \multirow{3}{*}{ RH section } & Total duty (MW) & 34.44 & 34.44 & 34.44 \\
\hline \multirow{3}{*}{ Power generation } & GT (MWe) & 135.94 & 135.94 & 135.94 \\
\cline { 2 - 5 } & ST(MWe) & 120.06 & 120.06 & 120.06 \\
\cline { 2 - 5 } & Total (MWe) & 256 & 256 & 256 \\
\cline { 2 - 5 } & Efficiency (\%) & 49.44 & 49.44 & 49.44 \\
\hline
\end{tabular}

\subsubsection{Configuration 3}

Similar to Configuration1, convergence of the dynamic optimization problem is infeasible for Configuration 3. Therefore, only results obtained using the coordinated control system is presented. 


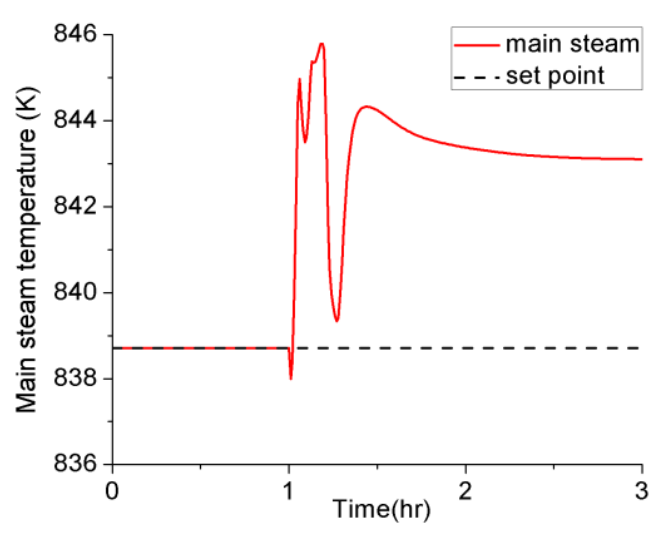

(a1)

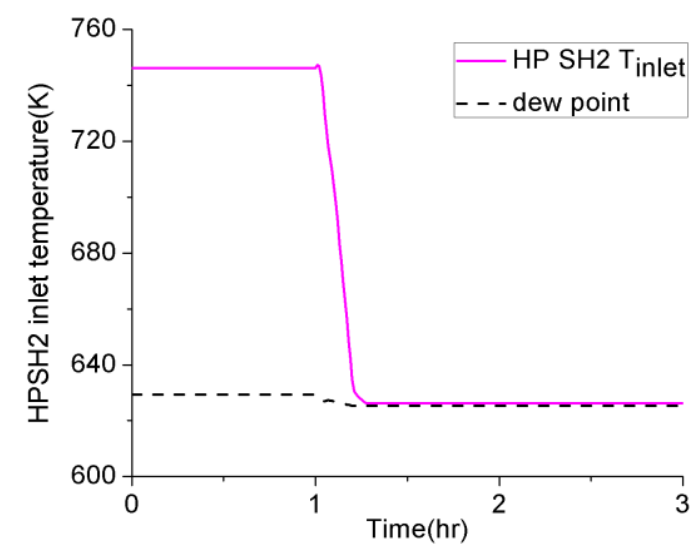

(a2)

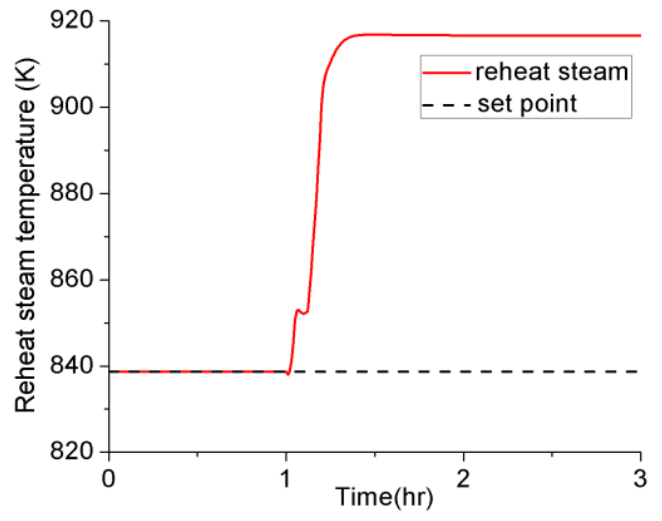

(b1)

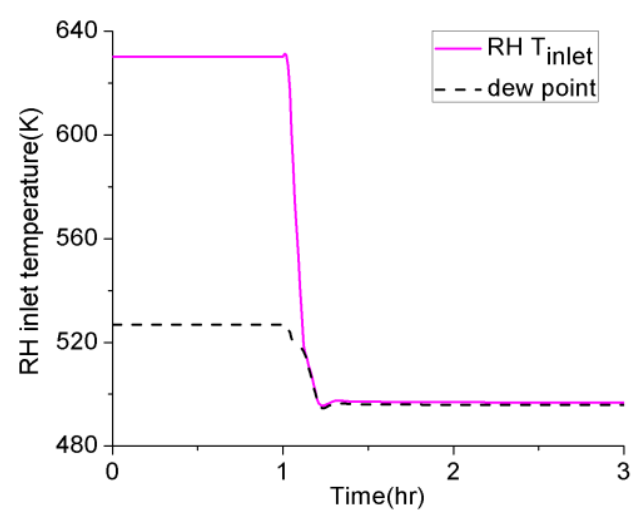

(b2)

Figure 3. 9. Steam temperature transients under load-following operation using coordinated control for Configuration 3: (a1) main steam temperature (a2) HP SH2 inlet temperature (b1) reheat steam temperature (b2) RH inlet temperature

Figures 3.9 (a1) and 3.9 (b1) show that during the load-following operation, considerable excursions of main steam temperature (about $5 \mathrm{~K}$ ) and reheat steam temperature (about $80 \mathrm{~K}$ ) from their setpoints occur. These excursions happen as both SH and RH steam inlet temperatures reach saturation conditions, shown in Figures 3.9 (a2) and 3.9 (b2), respectively. The reheat steam temperature response is in stark contrast to Configuration 1, where the reheat steam temperature finally falls below its setpoint. Similar to Configuration 1, the results provide valuable insight into 
the infeasibility of dynamic optimization problem. The results show that when the dew point constraints are satisfied, satisfying the constraints on main/reheat steam temperature is infeasible.

\subsubsection{Configuration 4}

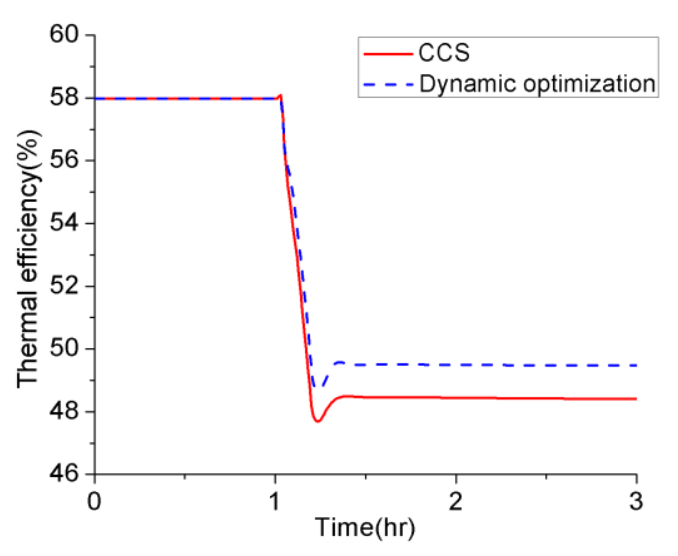

(a)

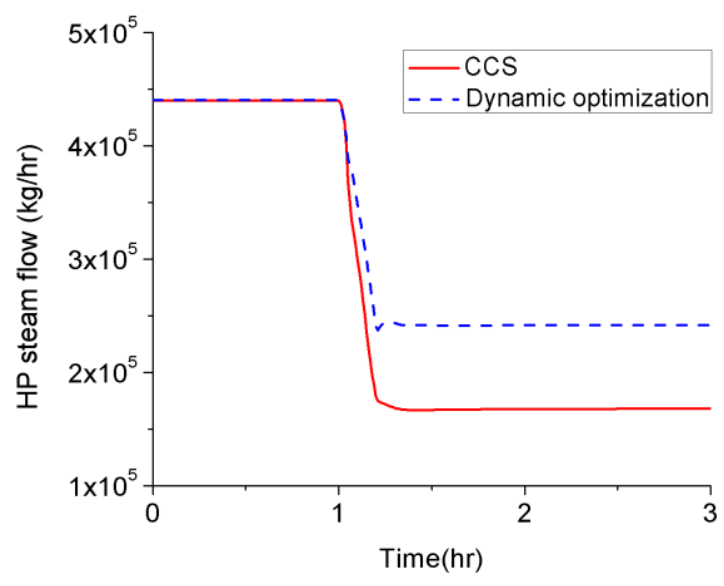

(c)

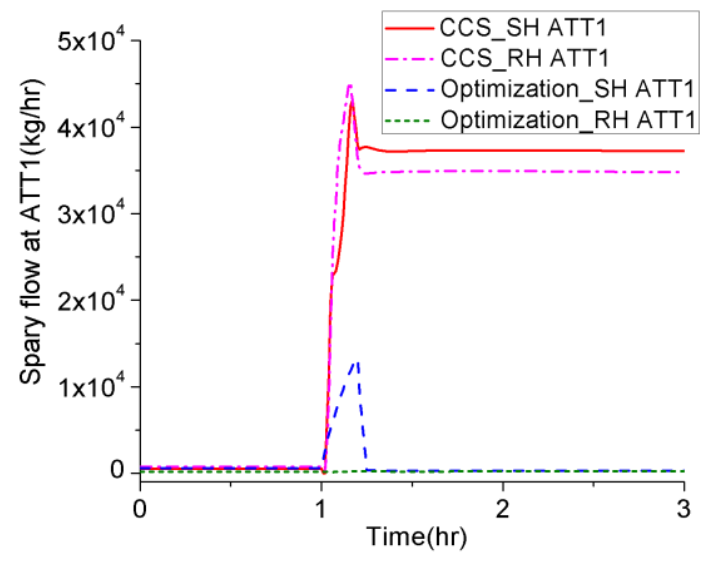

(b)

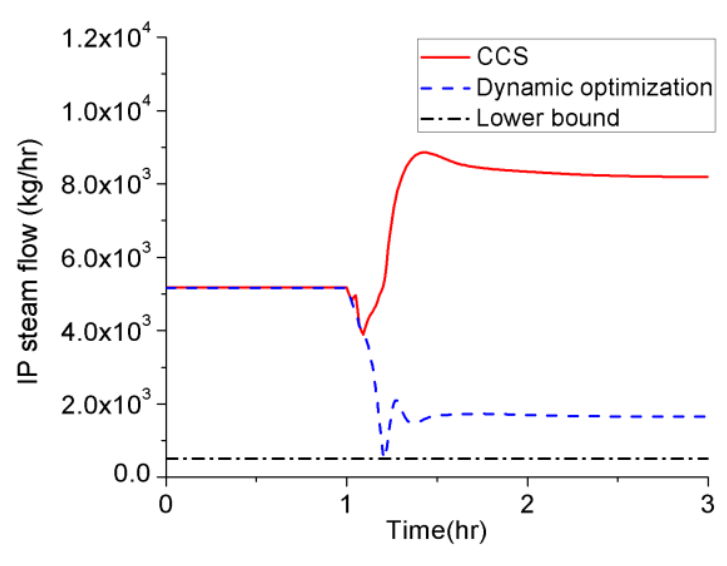

(d)

Figure 3. 10. Comparison between coordinated control and dynamic optimization for Configuration 4 (a) thermal efficiency (b) spray flow at ATT1 (c) HP steam flow (d) IP steam flow

Similar to Configuration 2, solution of the dynamic optimization problem is feasible for Configuration 4, so results from dynamic optimization are compared with the results from coordinated control. 
As we can see from Figure 3.10 (a-c), thermal efficiency is higher for dynamic optimization. That is because less spray at ATT1 leads to more HP steam generation in the HP EVA and therefore results in higher thermal efficiency. On the other hand, Figure 3.10 (d) indicates that the IP steam flow would decrease as more exhaust heat is absorbed by the HP flow. This study shows that during the load transient, a low limit on the spray flowrate at the HP ATT1 is required to keep the IP steam flow higher than the lower bound.

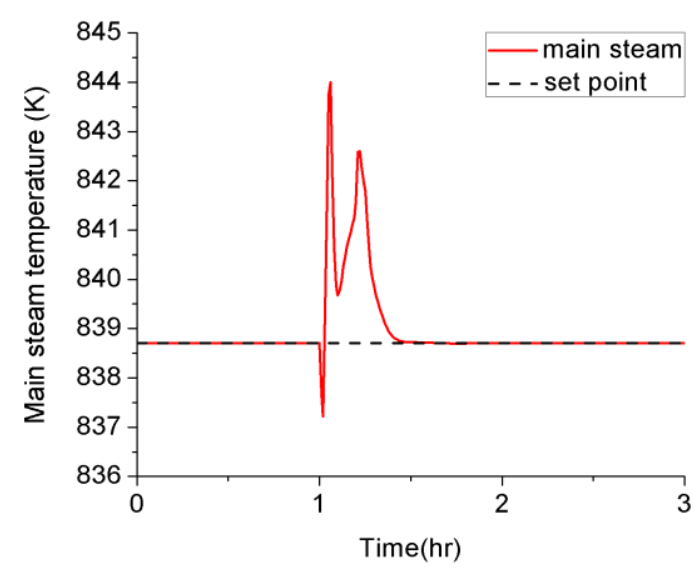

(a1)

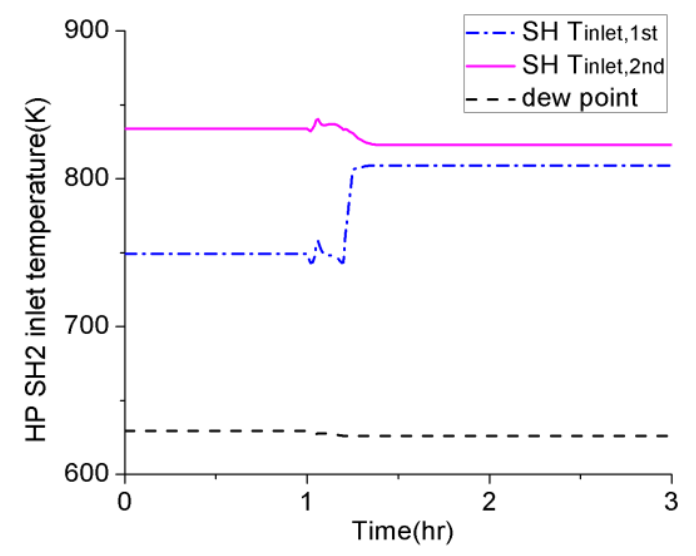

(a2)

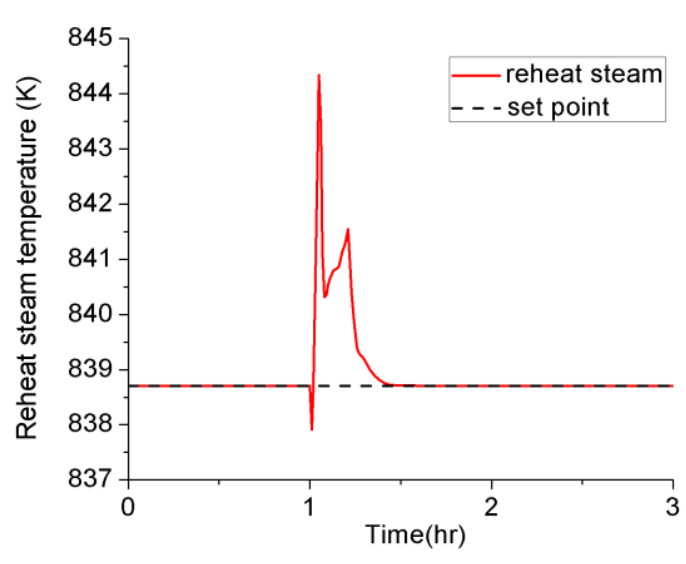

(b1)

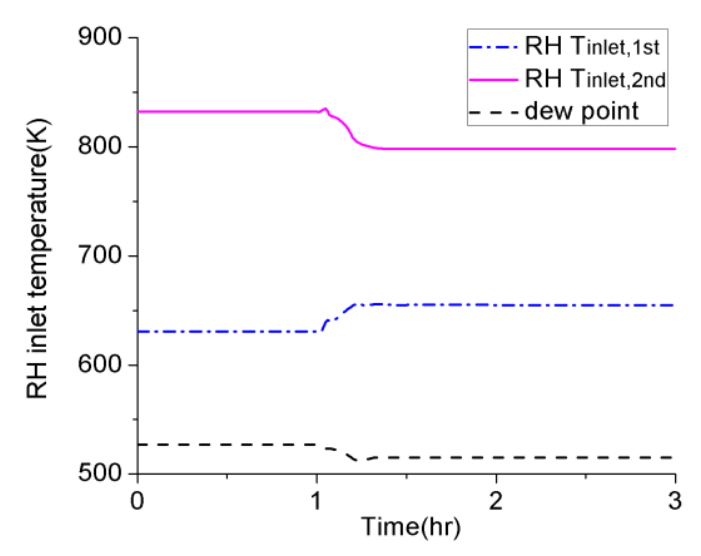

(b2)

Figure 3. 11. Steam temperature transients under load-following operation for Configuration 4: (a1) Main steam temperature (a2) HP SH2 inlet temperature (b1) Reheat steam temperature (b2) RH inlet temperature 
The steam temperature transient performance for Configuration 4 under dynamic optimization is shown in Figure 3.11. Both main steam and reheat steam temperature are maintained with a small deviation. In addition, saturation condition can be avoided at the inlets. Since only a lower spray flowrate is used at the ATT1, the inlet temperature of Section A rises during the transient.

The results of dynamic optimization for Configuration 4 shown above are obtained with Section A accounting for $90 \%$ of the total area.

Similar to Configuration 2, a sensitivity study is done to understand the impact of the area ratio on the efficiency. At part load, the ATT1 spray is at its lower limit under dynamic optimization. Only the SH ATT2 and RH ATT2 are activated for the steam temperature control. Table 3.2 shows the key operating conditions and performance measures at $40 \%$ load for Configuration 4 . Opposed to Configuration 2, it can be observed that the area ratio does affect the efficiency with the highest efficiency being obtained when the Section A area ratio is the highest.

Table 3. 2. Key operating conditions and performance measures for variation in HP SH2 and RH area ratio at $40 \%$ load for Configuration 4

\begin{tabular}{|c|c|c|c|c|}
\hline \multicolumn{2}{|c|}{ Area Ratio of HPSH2(A) and RH(A) } & $50 \%$ & $70 \%$ & $90 \%$ \\
\hline \multirow{2}{*}{ HPSH2 section } & Total duty (MW) & 43.51 & 32.23 & 24.34 \\
\cline { 2 - 5 } & Total Spray (kg/hr) & 34,396 & 24,770 & 19,235 \\
\hline \multirow{2}{*}{ RH section } & Total duty (MW) & 74.64 & 59.49 & 50.22 \\
\cline { 2 - 5 } & Total Spray (kg/hr) & 60,146 & 37,203 & 22862 \\
\hline \multirow{3}{*}{ Power generation } & GT (MWe) & 140.62 & 137.49 & 135.73 \\
\cline { 2 - 5 } & ST(MWe) & 115.38 & 118.51 & 120.27 \\
\cline { 2 - 5 } & Total (MWe) & 256 & 256 & 256 \\
\cline { 2 - 5 } & Efficiency (\%) & 48.46 & 49.11 & 49.48 \\
\hline
\end{tabular}

It can be observed that the larger section A of HP SH2/RH requires less spray for main/reheat steam temperature control and less heat is transferred in HP SH2 or RH as seen in Table 3.2, which in turn improves the thermal efficiency by generating more steam in the steam cycle for power production. Thus, a larger Section A leads to higher efficiency. The upper bound on Section A 
area is assumed to be $90 \%$ of the total area to avoid free water carryover into the turbine. The lower bound on Section A area is around $45 \%$ of the total area.

\subsubsection{Configuration 5}

For brevity, only the results from dynamic optimization are shown here. During the load following operation, a minimum spray flowrate at the SH ATT1 is required to maintain the IP steam flow above the lower bound as shown in Figure 3.12.

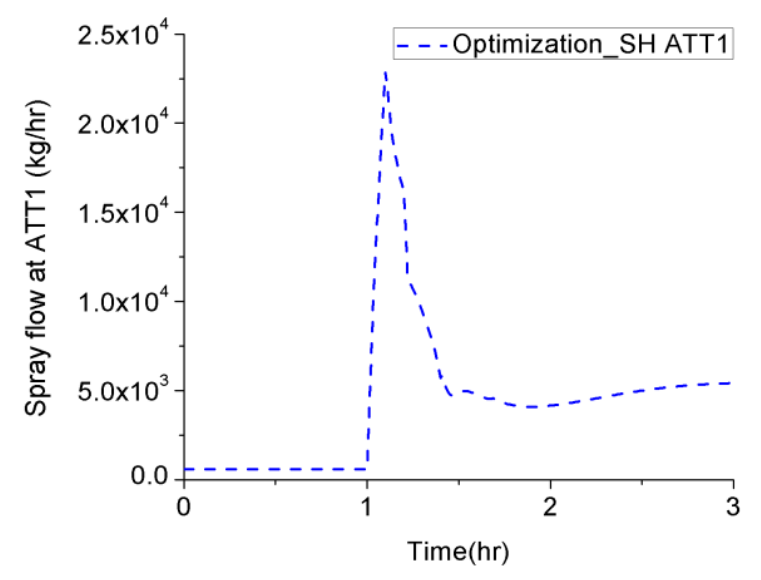

(a)

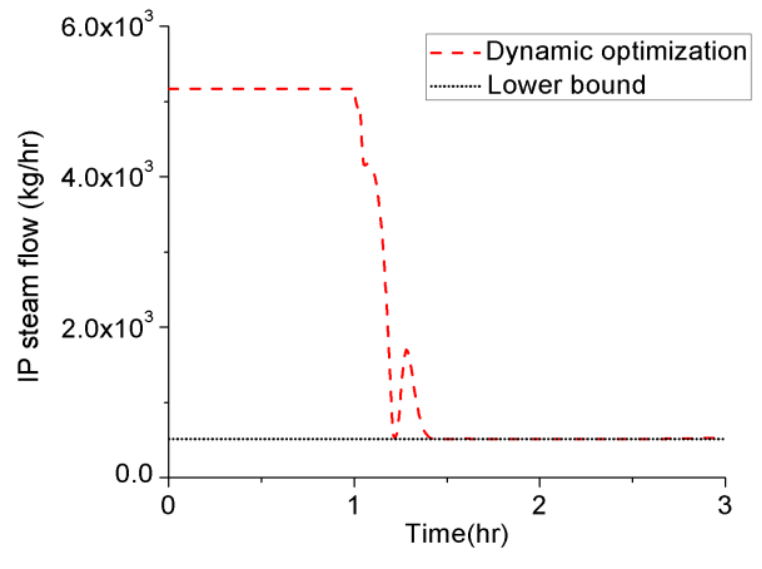

(b)

Figure 3. 12. Dynamic optimization for Configuration 5 (a) spray flow at SH ATT1 (b) IP steam flow

Figure 3.13 shows that both main steam and reheat steam temperature could be maintained with small deviation. Furthermore, the saturation can be avoided at the inlets.

Similar to Configuration 4, larger Section A improves the thermal efficiency. Therefore, section A of HP SH2 area is set to $90 \%$ of the total area for all studies presented here for Configuration 5. 


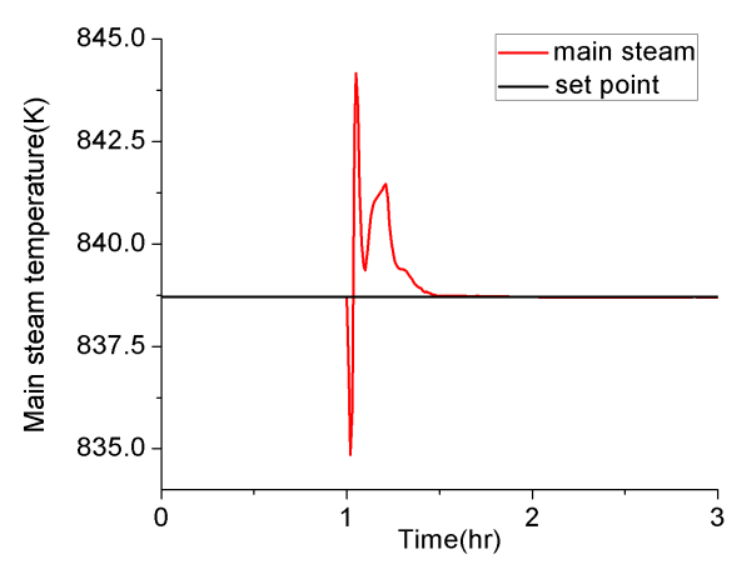

(a1)

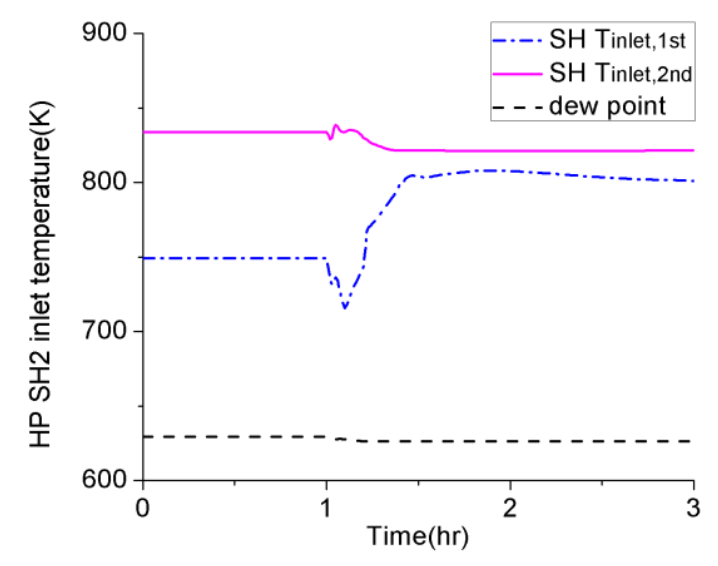

(a2)

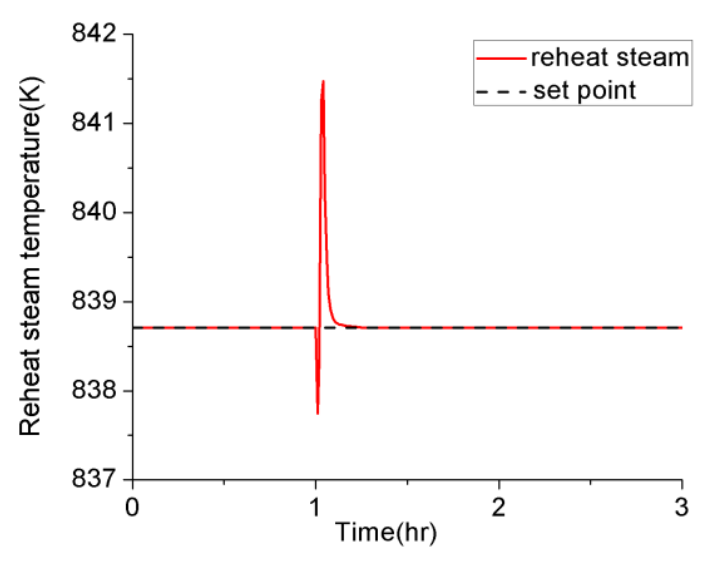

(b1)

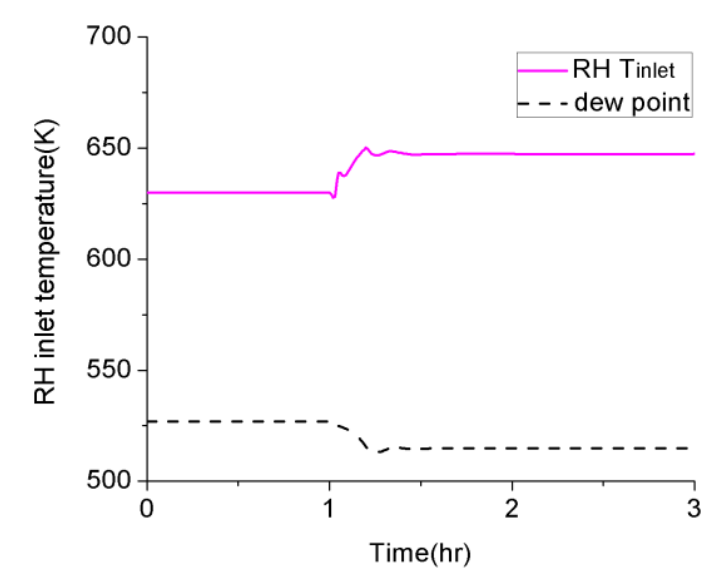

(b2)

Figure 3. 13. Steam temperature transients under load-following operation for Configuration 5 (a1) main steam temperature, (a2) HP SH2 inlet temperature, (b1) reheat steam temperature, (b2) RH inlet temperature

\subsubsection{Thermal efficiency analysis}

As discussed above, Configuration 1 and Configuration 3 with single-stage attemperation cannot maintain the steam temperature as the load decreases without spraying to saturation. Therefore, solution of the dynamic optimization is infeasible for those configurations. In the discussion and results presented in this section, thermal efficiency presented for Configuration 1 and 3 is for operation under the coordinated control system while thermal efficiency presented for 
Configuration 2, 4, and 5 is what is obtained using the dynamic optimization problem. Table 3.3 shows that while Configuration 2, 4, and 5 each can satisfy the dew point and steam temperature constraints, their efficiencies are different.

Table 3. 3. Summary of different configurations for load-following operation

\begin{tabular}{|c|c|c|c|c|c|}
\hline Configuration No. & 1 & 2 & 3 & 4 & 5 \\
\hline HP SH2/RH Structure & In series & In series & In parallel & In parallel & In parallel \\
\hline Attemperation & 1-stage & 2-stage & 1-stage & 2-stage & 2-stage/damper \\
\hline Constraints violation & Yes & No & Yes & No & No \\
\hline Thermal efficiency at 40\% load (\%) & 49.39 & 49.44 & 48.52 & 49.48 & 49.73 \\
\hline
\end{tabular}

As shown in Figure 3.14 (a), the plant efficiency decreases with the decrease in the load for all three feasible configurations. Configuration 5 provides the highest efficiency. The thermal efficiency transients show an undershoot during the load transient. Figure 3.14 (b) shows the power transients for all three configurations could track the load setpoint very well, where the fast response of the GT plays a key role.

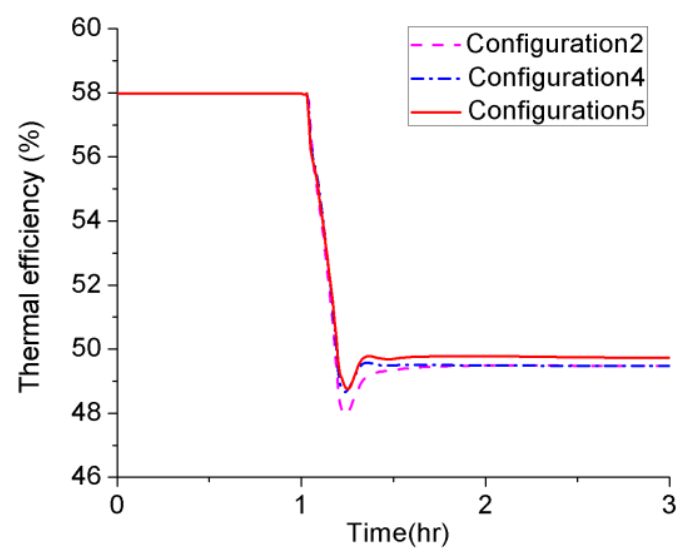

(a)

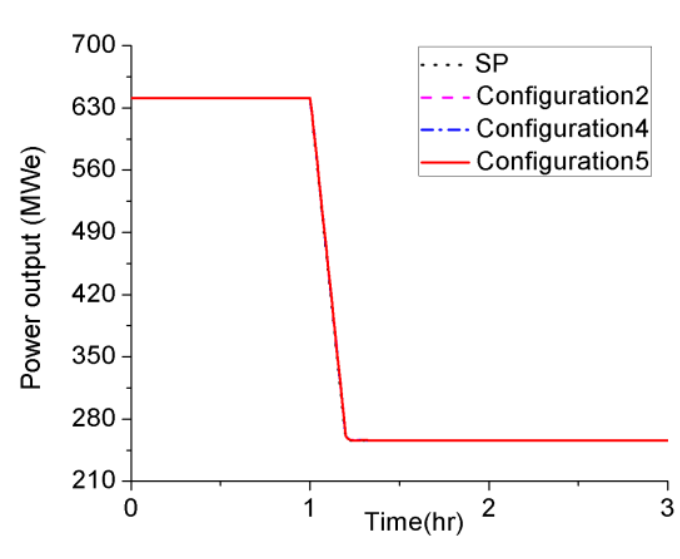

(b)

Figure 3. 14. Load-following operation of NGCC plant (a) thermal efficiency (b) power output

Table 3.4 shows that in Configuration 5, the least spray is used and the least exhaust heat is recovered by HP SH2 and RH. Consequently, higher amount of main steam is generated resulting 
in higher ST power and lower GT power compared to Configuration 2 and 4. Obviously, the lowest amount of natural gas is consumed in Configuration 5 leading to the highest efficiency.

Configuration 2 and 4 show similar efficiencies even though more main steam is generated in Configuration 2. That is because main steam is the sum of the HP steam generated in HP EVA and the attemperator spray flow to the HP SH2. More main steam is generated in Configuration 2 due to the higher attemperator spray at the HP SH2 albeit at the expense of higher amount of natural gas firing.

Table 3. 4. Performances of different configurations at $40 \%$ load

\begin{tabular}{|c|c|c|c|c|}
\hline \multicolumn{2}{|c|}{ Configuration No. } & 2 & 4 & 5 \\
\hline \multirow{3}{*}{ RH section } & Total Duty (MW) & 34.44 & 50.22 & 35.43 \\
\cline { 2 - 5 } & Total Spray (kg/hr) & 0 & 22,862 & 0 \\
\hline \multirow{2}{*}{$\begin{array}{c}\text { HP SH2 } \\
\text { section }\end{array}$} & Total Duty (MW) & 62.59 & 24.34 & 31.63 \\
\cline { 2 - 5 } & Total Spray (kg/hr) & 62,014 & 19,235 & 30,985 \\
\hline \multirow{3}{*}{$\begin{array}{c}\text { Operating } \\
\text { variables }\end{array}$} & Ratio of RH flue gas & 1 (In sequence) & 0.60 & 0.21 \\
\cline { 2 - 5 } & HP steam (kg/hr) & 208,514 & 241,632 & 252,227 \\
\cline { 2 - 5 } & Main steam (kg/hr) & 270,528 & 260,867 & 283,212 \\
\cline { 2 - 5 } & Natural gas (kg/hr) & 39,407 & 39,376 & 39,177 \\
\hline \multirow{3}{*}{$\begin{array}{c}\text { Power } \\
\text { generation }\end{array}$} & GT (MWe) & 135.94 & 135.73 & 133.54 \\
\cline { 2 - 5 } & Gross power (MWe) & 120.06 & 120.27 & 122.46 \\
\cline { 2 - 5 } & Thermal Efficiency (\%) & 49.44 & 256 & 256 \\
\hline
\end{tabular}

\subsection{Conclusion}

For load-following operation, five configurations of the NGCC plant with different HP SH2/RH arrangements and attemperation strategies are proposed, and their performances are evaluated by decreasing the load from $100 \%$ to $40 \%$ at a ramp rate of $5 \%$ load per min.

It was observed that the 1-stage attemperation, such as Configurations 1 and 3, leads to saturation and cannot maintain the steam temperature irrespective of whether $\mathrm{HP} \mathrm{SH} 2$ and $\mathrm{RH}$ are arranged in series or in parallel. However, the configurations with 2-stage attemperation, such as Configurations 2, 4, and 5, can maintain the main/reheat steam temperature at its set point without leading to saturation. Configuration 5 with the least spray has the highest efficiency at low-load 
operation. In Configuration 5, the least amount of heat is transferred in HP SH2 and RH sections, leading to generation of more HP steam and thus improving the thermal efficiency. The area ratio of HP SH2 (A) to the total area may or may not impact the efficiency depending on a particular configuration. In case of Configuration 2, the area ratio does not have any impact, but for Configurations 4 and 5, the highest efficiency is obtained when the area ratio is set to its maximum limit of $90 \%$. It was also observed that while the conventional coordinated control can satisfy operational constraints depending on a specific configuration, there is an efficiency penalty in comparison to the optimal profile. In summary, this study shows that an appropriate configuration of the HRSG in an NGCC plant with optimal design and operational strategy can not only help to avoid spraying to saturation and other operational constraints but also help to maximize the efficiency during load-following operation of NGCC plants. 


\section{Chapter 4. Optimal load-following of NGCC plant with stress monitoring of high-pressure boiler drum}

\subsection{Literature Review}

Impacts of load-following on plant health is currently poorly understood. Electric Power Research Institute (EPRI) utilized multivariate regression models to analyze the data from 158 operating units, but no clear correlation was found between the plant cycling operation and cycling-induced cost (Gray, 2001; Platt, 2002). It indicates that the equipment life expenditure due to cycling is unit dependent. The constructive details of plant (such as equipment materials, joint types, and component geometries) and operating patterns of plant (such as ramp rates, load ranges and holding periods) are required to estimate the long-term wear and tear costs. Intertek APTECH developed the COSTCOM software to estimate the cycling-related damage and quantify the corresponding O\&M costs by employing a combination of the top-down approach (depending on damage models and statistical regression) and bottom-up approach (relying on real-time monitoring data and plant surveys) (Lefton, 2004; Lefton and Hilleman, 2011). Intertek APTECH has analyzed hundreds of generating units and found that the costs of cycling of the conventional fossil-fired power plants are varied within a wide potential range depending on unit types and operating history and design features. It has been reported that these costs are often highly underestimated by the operators (Lefton and Hilleman, 2011; Lefton et al., 2006).

Besides the plant efficiency loss, load-following also leads to larger thermal and mechanical stresses, and more wear-and-tear on the plant equipment compared to the base-loaded operation. The damage caused by the load-following operation on the equipment items, especially the static equipment such as the components of the heat recovery steam generator (HRSG), is difficult to identify and quantify without inspection during plant shutdown. Even during plant shutdown, it can be intractable to inspect all possible locations. Quite often this damage gets reflected during plant operations leading to plant shutdown, thus raising the plant equivalent forced outage rate (EFOR) and/or operation and maintenance (O\&M) cost. Monitoring of stress evolution in the critical components during load-following operation can be useful for optimal operation of NGCC power plants.

In an NGCC plant, the thick-walled HP drum is one of the most vulnerable components that can suffer from the fatigue damage due to the load-following operation. One way of computing the 
fatigue damage is through development of detailed finite element method (FEM) model of stress distribution in the drum (Taler et al., 2018; González-Gómez et al., 2019). However, FEM models are computationally expensive and therefore dynamic optimization of the plant operation using the FEM model coupled with the plant-wide model is not computationally tractable.

Another approach is to use the available international standards for assessing drum fatigue damage and to enhance them, if needed, for higher accuracy for vulnerable, critical section(s) of the drum. For example, standards such as EN 12952-3 and (2011) and German boiler regulation TRD 301 (2001) are widely accepted and provide useful and computationally tractable approaches to assess fatigue damage due to stresses caused by pressure and thermal gradients. While both standards noted above are similar, EN 12952-3 is less conservative than TRD 301. The main improvement in EN 12952-3 compared to TRD 301 is in the determination of stress concentration factors and consideration of cumulative damage.

Benato et al. $(2015,2016)$ proposed a comprehensive plant component lifetime estimation procedure. Drum stress transient and fatigue damage are evaluated using EN 13445 under varying plant load. However, EN 13455 does not account for the effect of thermo-mechanical stress concentration at the locations of component discontinuity such as the drum-downcomer junctions. Fontaine and Golopin (2007) compared standard EN12952-3 and TDR 301for HRSG cumulative damage assessment and HRSG cyclic lifetime estimation. EN12952-3 appears to be less conservative than TRD 301, and more representative of the underlying physics. Hübel et al. (2017) incorporated the component stress constraint into an optimization approach for coal-fired power plant start-up. The thermo-mechanical stress was calculated considering the notch effect using EN12952-3. Taler et al. (2015, 2018) and González-Gómez et al. (2019) used both EN12952-3 and FEM to calculate the drum stress at the drum-downcomer junctions. They observed that other than the specific location at the drum-downcomer junctions that EN12952-3 already accounts for, there can be additional locations at the drum-downcomer junctions where stress concentration should be evaluated during the start-up process. In this chapter, the fatigue damage is estimated based on drum thermal-mechanical stress calculated using EN12952-3 with detailed drum design. Multiple locations at the drum-downcomer junctions are assessed and the most stressed part is used as the constraint in the dynamic optimization problem. 
For optimizing the load-following operation of NGCC plants, it is desired that the fatigue damage of the drum be accounted for. Kim et al. (2000) investigated the thermal stress evolution in the drum of a single-pressure HRSG to optimize the cold start-up procedure by manipulating the flue gas bypass flow. Rua et al. (2020) developed a model predictive control approach while considering the drum stress as a constraint control for flexible operation of an NGCC plant. With the proposed control methodology, the NGCC plant could respond to step changes in load without exceeding the maximum stress limit of the drum. Kim et al. (2000) presented an optimization framework for scheduling coal-fired and natural gas-fired power plants integrated with secondary batteries and renewable energy sources where the drum stress was used as a constraint. However, the plant and equipment models used in that work are reduced order models, thus only stress magnitude given by von Mises stress is considered. In fact, for computing fatigue damage, stress amplitude, i.e., not only the magnitude but also the directionality (i.e. tensile or compressive) should be considered.

In this chapter, optimal load-following operation including both ramping-up and -down the plant load is investigated. Depending on whether the plant is ramping-up or-down, operating conditions of the NGCC plant can differ considerably and therefore stress characteristics of the drum can also differ considerably. During the load-following operation, while it is desired that the drum stresses do not exceed certain limit, it is also desired that the plant efficiency is maximized during the transient operation. For trajectory optimization, a dynamic optimization approach is proposed for maximizing efficiency during load-following operation of the NGCC plant while ensuring that the stress limit is not exceeded and constraints such as spraying to saturation are not attained. The optimizer also ensures that the main and reheat steam temperatures are constrained. If the desired ramp rate is high, satisfying the constraints noted above may be infeasible. Therefore, relaxation of ramprate (i.e. deviation of actual ramprate from the desired ramprate, while ensuring that the actual ramprate is less than or equal to desired ramprate) is considered as a degrees-of-freedom to satisfy the constraints. However, since the optimizer seeks to maximize efficiency, it can lead to a solution, especially while ramping down, where relaxation of ramprate is higher than it is required for satisfying the constraints. Thus, for power plants where such larger relaxations are not admissible, it would be desired to minimize the relaxation while maximizing the plant efficiency. This leads to a multi-objective dynamic optimization problem. A lexicographic approach is proposed to solve this problem. In the lexicographic approach, the objectives are ordered 
depending on their importance. Minimizing the relaxation is the more important objective so that the plant can follow the desired load as close as possible without violating the stress and other constraints.

\subsection{HP Drum stress and fatigue damage}

In Chapter 3, five configurations are modeled for the SH/RH sections. It was observed that Configuration 4 with two-stage attemperation and parallel configuration of the $\mathrm{SH}$ and $\mathrm{RH}$, as shown in Figure 4.1, is one of the most efficient configurations that could maintain the main and reheat steam temperatures without spraying to saturation, even for steep load changes. Another key advantage of this configuration is the extra degrees of freedom due to the increased number of attemperator sprays that helps to maximize the efficiency during dynamic optimization while satisfying the operational constraints. Therefore, the drum stress and fatigue damage analysis and optimal load-following are conducted using this configuration.

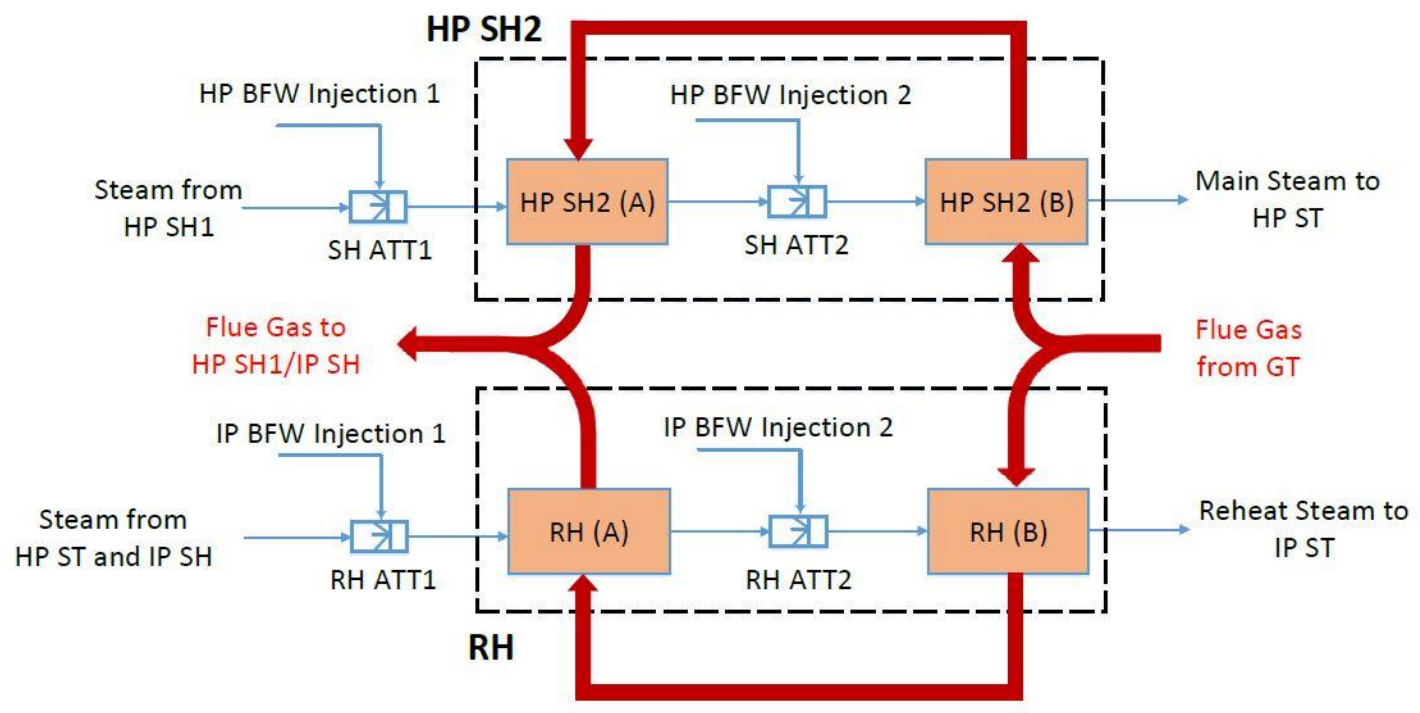

Figure 4. 1. Parallel configuration with two-stage attemperation

Load-following operation of NGCC plants can be done under fixed-pressure mode or slidingpressure mode (Apan-Ortiz et al., 2018). Under the fixed-pressure mode, the drum pressure and therefore the temperature of the saturated steam from the drum remains fairly constant. Under the sliding-pressure operation, the drum pressure slides as the load decreases. Sliding-pressure operation leads to higher efficiency (Apan-Ortiz et al., 2018). However, under sliding-pressure 
operation, the HP drum experiences large variations in steam pressure and temperature affecting the transient response of mechanical and thermal stresses depending on the detailed drum design.

\subsubsection{Drum geometry}

In this study, the drum wall thickness is calculated using EN 12952-3 Standard (2011) given by Equation 4.1:

$$
S_{c}=\frac{d_{c} P_{c}}{\left(2 M A S-P_{c}\right) E}
$$

where $P_{c}$ is internal design pressure, $d_{c}$ is inner diameter of the vessel, $E$ is the joint efficiency, $M A S$ is the maximum allowable stress of material, and $s_{c}$ is the minimum required thickness of the vessel.

Table 4. 1. HP Drum geometry and material

\begin{tabular}{|c|c|c|c|}
\hline & Inner Diameter $(\mathrm{mm})$ & Wall Thickness $(\mathrm{mm})$ & Material \\
\hline HP Drum & 1828.8 & 177.8 & SA 516 Gr.70 \\
\hline Downcomer pipe & 203.2 & 76.2 & SA-105 \\
\hline
\end{tabular}

Table 4.1 lists the drum geometry and material. The drum was fabricated using SA516 Grade 70 carbon steel and the downcomer pipe was made from SA-105 carbon steel (EPRI, 2005 and 2006). It should be noted that the downcomer pipe can have a larger wall thickness near the junction with the drum.

\subsubsection{Temperature transient and thermo-mechanical stress evolution}

As the boiler drum is horizontal and possess cylindrical symmetry, temperature of the drum wall is assumed to vary only in the radial direction. Dynamic model of the drum wall can be written as:

$$
\frac{1}{r} \frac{\partial}{\partial r}\left(r \frac{\partial T}{\partial r}\right)=\frac{1}{\alpha_{w}} \frac{\partial T}{\partial t}
$$

where $\alpha_{w}$ is wall thermal diffusivity, $r$ is drum radius.

Principal stresses on the component wall in a cylindrical coordinate are calculated by considering superposition of both mechanical and thermal stresses.

$$
\begin{gathered}
\sigma_{r}=\sigma_{m, r}+\sigma_{t, r} \\
\sigma_{\theta}=\sigma_{m, \theta}+\sigma_{t, \theta}
\end{gathered}
$$




$$
\sigma_{z}=\sigma_{m, z}+\sigma_{t, z}
$$

where subscripts $r, \theta$ and $z$ denote radial, tangential, and axial directions, respectively. $m$ and $t$ denote mechanical and thermal stresses, respectively. Using classic elasticity theory (Hetnarski et al., 2009), thermo-mechanical principal stresses are calculated for each layer of the wall $r_{i}$.

$$
\begin{gathered}
\sigma_{m, r}\left(r_{i}\right)=\frac{P_{\text {in }} r_{\text {in }}^{2}-P_{\text {out }} r_{\text {out }}^{2}}{r_{\text {out }}^{2}-r_{\text {in }}^{2}}+\left(P_{\text {out }}-P_{\text {in }}\right) \frac{r_{\text {in }}^{2} r_{\text {out }}^{2}}{r_{i}^{2}\left(r_{\text {out }}^{2}-r_{\text {in }}^{2}\right)} \\
\sigma_{m, \theta}\left(r_{i}\right)=\frac{P_{\text {in }} r_{\text {in }}^{2}-P_{\text {out }} r_{\text {out }}^{2}}{r_{\text {out }}^{2} r_{\text {in }}^{2}}-\left(P_{\text {out }}-P_{\text {in }}\right) \frac{r_{i n}^{2} r_{\text {out }}^{2}}{r_{i}^{2}\left(r_{\text {out }}^{2}-r_{\text {in }}^{2}\right)} \\
\sigma_{m, z}\left(r_{i}\right)=\frac{P_{\text {in }} r_{\text {in }}^{2}-P_{\text {out }} r_{\text {out }}^{2}}{r_{\text {out }}^{2} r_{\text {in }}^{2}} \\
\sigma_{t, r}\left(r_{i}\right)=\frac{\alpha_{m} E_{m}}{1-v} \frac{1}{r_{i}^{2}}\left(\frac{r_{i}^{2}-r_{\text {in }}^{2}}{r_{\text {out }}^{2}-r_{\text {in }}^{2}} \int_{r_{\text {in }}}^{r_{\text {out }}} \operatorname{Tr} d r-\int_{r_{\text {in }}}^{r_{i}} \operatorname{Tr} d r\right) \\
\sigma_{t, \theta}\left(r_{i}\right)=\frac{\alpha_{m} E_{m}}{1-v} \frac{1}{r_{i}^{2}}\left(\frac{r_{i}^{2}+r_{i n}^{2}}{r_{\text {out }}^{2}-r_{\text {in }}^{2}} \int_{r_{\text {in }}}^{r_{\text {out }}} \operatorname{Tr} d r+\int_{r_{\text {in }}}^{r_{i}} \operatorname{Tr} d r-\operatorname{Tr}_{i}^{2}\right) \\
\sigma_{t, z}\left(r_{i}\right)=\frac{\alpha_{m} E_{m}}{1-v}\left(\frac{2}{r_{\text {out }}^{2}-r_{\text {in }}^{2}} \int_{r_{\text {in }}}^{r_{\text {out }}} \operatorname{Tr} d r-T\right)
\end{gathered}
$$

In Equations 4.6-4.11, $P$ is pressure; $\alpha_{m}$ is thermal expansion coefficient; $E_{m}$ is Young's modulus, and $v$ is Poisson's ratio. Subscripts 'in' and 'out' indicate inner and outer surfaces, respectively.

\subsubsection{Simplified mechanical stress and thermal stress calculation}

While the models presented in Section 4.2.2 are generic and can be applied to any cylindrical pressure vessels, mechanical and thermal stress models for the boiler drum can be simplified based on their typical operating conditions and boundary conditions.

For the boiler drum, the radial mechanical stress on the drum's inner and outer surfaces is much smaller than tangential and axial mechanical stresses and can be neglected. Both tangential and axial mechanical stresses are tensile. The tangential stress on the inner surface is the largest and roughly twice of the axial stress, which is constant over the thickness. Therefore, only tangential mechanical stress on drum inner surface is considered and calculated using Equation 4.12 as per the standards such as EN 12952-3 (2011) and TRD 301 (2001).

$$
\sigma_{\theta}^{P}=\frac{d_{m} P_{i n}}{2 s}
$$


where $d_{m}$ is mean diameter of shell and $s$ is shell wall thickness.

Because there are no normal thermal expansion constraints on the drum inner and outer surfaces, radial thermal stress is negligible. Tangential and axial stresses over the drum wall thickness are similar in magnitude as well as in direction (compressive or tensile). Inner and outer walls would experience stresses in different directions (compressive or tensile) during the temperature transient. In addition, the inner wall surface experiences the largest thermal stress.

In standards such as EN 12952-3 (2011) and TRD 301 (2001), the tangential thermal stress on wall inner surface is calculated using Equation 4.13:

$$
\sigma_{\theta}^{T}=\frac{\alpha_{m} E_{m}}{1-v} \Delta T
$$

where $\Delta T$ is through-wall temperature difference, which is the difference between integral mean wall temperature $T_{m}$ and inner surface temperature $T_{i n}$. The plant-wide model along including the drum wall energy conservation model shown in Equation 4.2 can be used to calculate $\Delta T$. A simpler approach is used to calculate $\Delta T$ in EN 12952-3 (2011) and TRD 301 (2001) assuming a quasi-steady-state temperature condition.

$$
\Delta T=T_{m}-T_{i n}=\frac{1}{\alpha_{w}} \Phi_{w} s^{2} \frac{\partial T}{\partial t}
$$

where $\frac{\partial T}{\partial t}$ is temperature change rate and $\Phi_{w}$ is shape factor. It can be observed that the temperature difference is proportional to the square of wall thickness and proportional to the temperature change rate.

\subsubsection{Stress concentration due to the component discontinuity}

As we can see in Figure 4.2, the drum is connected to other pipes, e.g. the downcomer and riser tubes. The discontinuity, such as the drum-downcomer junction, causes the stress concentration and can lead to larger stress amplitude during load-following. In general, drum-downcomer junction can be treated as a typical cylindrical shell with a hole. A similar computational approach can be applied to other similar component junctions.

Since the radial stress in the shell is small compared to other principal stresses (Equations 4.64.11), the shell with a hole is approximated as the plate with a hole as shown in Figure 4.2, where Position A is located in the axial direction and Position B is located in the tangential direction. 
This junction is stretched in the perpendicular directions to $\sigma_{1}$, the tangential thermal or mechanical stress of shell, and $\sigma_{2}$, the axial thermal or mechanical stress (Dzierwa and Taler, 2015; Dzierwa, 2016).

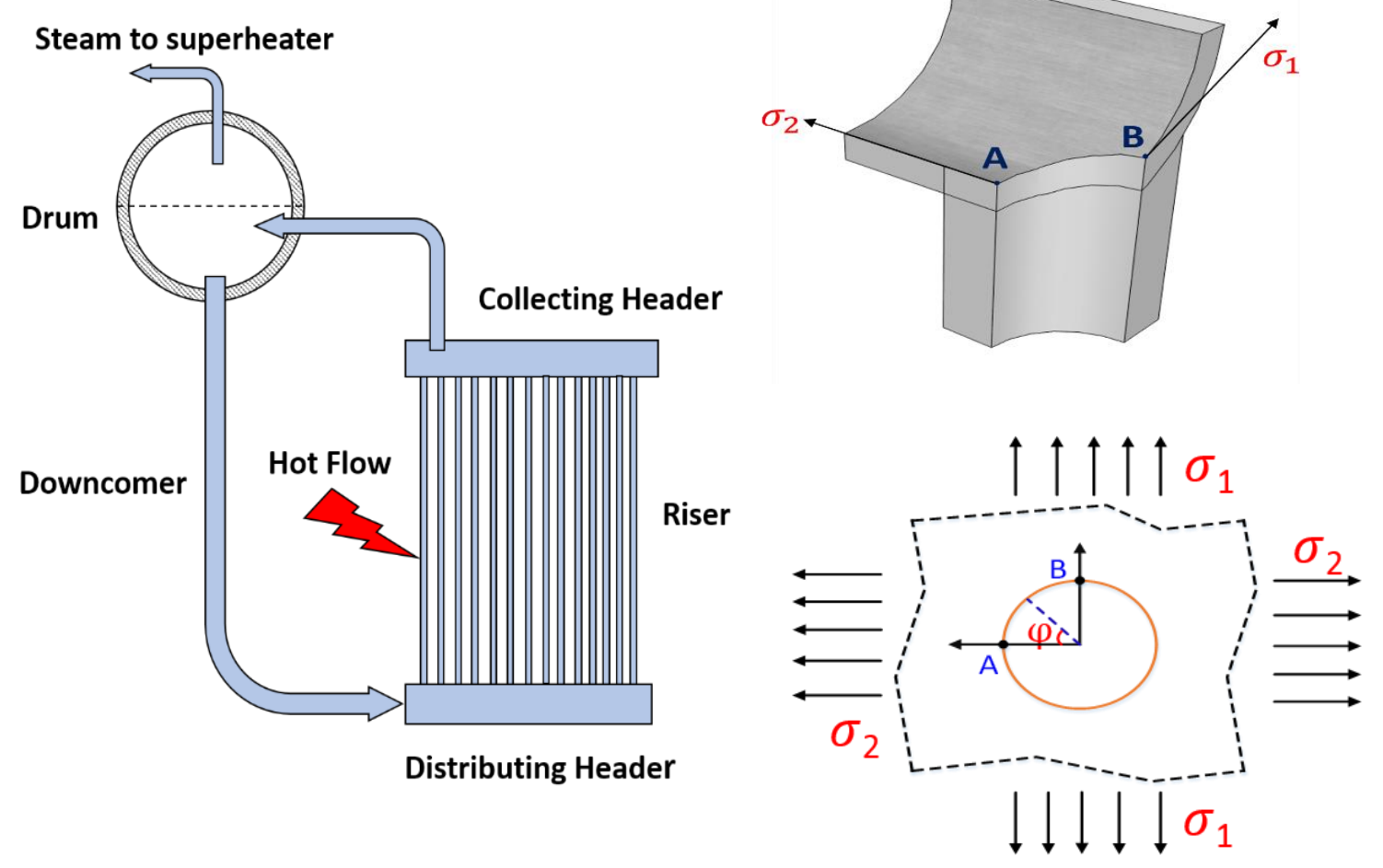

Figure 4. 2. Schematic and approximation of cylindrical shell with a hole

Equations 4.15-4.18 are used to calculate $\lambda$, the theoretical stress concentration factor, which is defined as the corresponding circumferential stress $\sigma_{\varphi}$ divided by the tangential stress $\sigma_{\theta}$. As shown in the system of equations, $\lambda$ depends on the position angle $\varphi$ and the ratio of stress magnitude $\beta$ (Pilkey and Pilkey, 2008).

$$
\begin{gathered}
\sigma_{\varphi}=\left(\sigma_{1}+\sigma_{2}\right)+2\left(\sigma_{1}-\sigma_{2}\right) \cos 2 \varphi \\
\sigma_{2} / \sigma_{1}=\beta \\
\sigma_{\varphi}=\sigma_{1}(1+\beta)+2 \sigma_{1}(1-\beta) \cos 2 \varphi \\
\lambda=\frac{\sigma_{\varphi}}{\sigma_{1}}=(1+\beta)+2(1-\beta) \cos 2 \varphi
\end{gathered}
$$


The circumferential thermo-mechanical stresses around the junction are different depending on the position. The theoretical stress concentration factors at Position A and B are determined as shown in Table 4.2. Since the magnitude of thermal stresses in the axial and tangential directions is almost the same, the ratio of thermal stress magnitude is considered to be 1 while the corresponding stress concentration factor is considered to be 2 around the hole. As the magnitude of mechanical stress in the axial direction is roughly half of that in the tangential direction, consequently, the mechanical stress concentration factor at position B is only $1 / 5$ of the stress concentration factor at position $\mathrm{A}$.

Table 4. 2. Relation of stress concentration factors at different positions

\begin{tabular}{|c|c|c|c|c|c|c|}
\hline & \multicolumn{3}{|c|}{ Thermal stress } & \multicolumn{3}{c|}{ Mechanical stress } \\
\cline { 2 - 7 } & $\beta$ & $\sigma_{\varphi}$ & $\lambda$ & $\beta$ & $\sigma_{\varphi}$ & $\lambda$ \\
\hline Position A $\left(\varphi=0^{\circ}\right)$ & 1 & $2 \sigma_{1}$ & $\mathbf{2}$ & 0.5 & $2.5 \sigma_{1}$ & $\mathbf{2 . 5}$ \\
\hline Position B $\left(\varphi=90^{\circ}\right)$ & 1 & $2 \sigma_{1}$ & $\mathbf{2}$ & 0.5 & $0.5 \sigma_{1}$ & $\mathbf{0 . 5}$ \\
\hline
\end{tabular}

The stress concentration factor is also affected by the shell-branch geometries and welded joint type. The stress concentrations noted above can lead to a larger stress amplitude. For example, TRD 301 (2001) assumes that the thermal stress concentration factor on the edge of a hole is constant and is equal to 2 similar to what has been noted in Table 4.2. EN 12952-3 (2011) has been improved by introducing a variable stress concentration factor $\lambda_{t}$, which depends on the heat transfer coefficient on the drum inner surface and the drum-downcomer geometries. In addition, an empirical correlation is given in EN 12952-3 (2011) for computing the mechanical stress concentration factor $\lambda_{m}$ at shell-branch junction.

$$
\begin{gathered}
\lambda_{t}=\left\{\left[2-\frac{h+2700}{h+1700} z+\frac{h}{h+1700}\left(\exp ^{-7 z}-1\right)\right]^{2}+0.81 z^{2}\right\}^{1 / 2} \\
z=\frac{d_{m b}}{d_{m}} \\
\lambda_{m}=2.2+\exp ^{W} \times £^{Q} \\
\mathrm{~W}=-1.14\left(\frac{s_{b}}{s}\right)^{2}-0.89\left(\frac{s_{b}}{s}\right)+1.43 \\
Q=0.326\left(\frac{s_{b}}{s}\right)^{2}-0.59\left(\frac{s_{b}}{s}\right)+1.08
\end{gathered}
$$




$$
£=\frac{d_{m b}}{d_{m}} \sqrt{\frac{d_{m}}{2 s}}
$$

In Equations 4.19-4.24, $d_{m b}$ is mean diameter of branch, $s_{b}$ is branch wall thickness, and $h$ is heat transfer coefficient.

It should be noted that the empirical correlations suggested in EN 12952-3 is applicable to Position A. Concentration factors for Position B is calculated based on the stress concentration factor for Position A from EN 12952-3 and the relation between Position A and B as shown in Table 2. Overall, the circumferential stress at drum-downcomer junction is calculated using Equation 25.

$$
\sigma_{\varphi, k}=\lambda_{m, k} \frac{d_{m} P_{i n}}{2 s}+\lambda_{t, k} \frac{\alpha_{m} E_{m}}{1-v} \Delta T
$$

where subscript $k$ represents Position A or B.

\subsubsection{Fatigue damage}

Due to the relatively low operating temperature, the creep damage on HP drum is low. However, it can undergo considerable fatigue damage if frequent cycling occurs. The fatigue damage is defined as the actual cycle number of cycles divided by the maximum allowable cycle number as given by Equation 26:

$$
D_{f}=\frac{N}{N_{A}(\Delta \sigma)}
$$

where $N_{A}$ is the maximum allowable cycle number under a certain stress range $\Delta \sigma . N_{A}$ is evaluated according to the fatigue curves of material of construction (i.e. ferritic and austenitic steel for the drum) given in EN 12952-3 (2011).

The Tresca criterion is widely used to determine the equivalent stress amplitude $\Delta \sigma$ for fatigue damage estimation. For a triaxial component, the principal stresses $\sigma_{j}$ and the principal stress differences $\Delta \sigma_{i j}$ are varied with respect to time under the load-following. According to the variations of the principal stress differences, the maximum $\Delta \sigma_{i j, \max }$ and the minimum $\Delta \sigma_{i j, \min }$ during the transient are determined. Then, the equivalent stress range is calculated.

$$
\Delta \sigma=\operatorname{Max}\left(\left|\Delta \sigma_{r \theta, \max }-\Delta \sigma_{r \theta, \min }\right| ;\left|\Delta \sigma_{r z, \max }-\Delta \sigma_{r z, \min }\right| ;\left|\Delta \sigma_{z \theta, \max }-\Delta \sigma_{z \theta, \min }\right|\right)
$$

In Equation 4.27, the term $\Delta \sigma_{i j}$ indicates the difference between $i$ and $j$ principal stresses. 


\subsection{Dynamic optimization}

Dynamic optimization under load-following operations can be useful to maximize the plant efficiency. Due to the lack of access to the plant-specific historical data for operation and maintenance costs of the NGCC plant and lack of sufficient data in the open literature to develop correlation between the plant cycling operation and equipment damage cost, constraints on stress bounds are considered for dynamic optimization. In addition to stress, main steam and reheat steam temperatures should also be bounded within a narrow range. It should also be ensured that the dew points are not reached due to the attemperator sprays. When the desired ramp rate is high, the solution to the above optimization problem can be infeasible without relaxing the ramp rate constraint. In this work, we assume that:

- the plant needs to satisfy the average ramp rate, not the instantaneous ramp rate. This means that if a utility desires to follow, say, a 5\% load change/min ramp rate while decreasing its load from $100 \%$ to $50 \%$, then at any point in time, the ramp rate can be different than $5 \% / \mathrm{min}$, but the plant needs to reach 50\% load exactly in $10 \mathrm{~min}$ if the ramp rate is not relaxed.

- the plant cannot exceed the desired average ramp rate but can relax it if needed to satisfy the constraints.

If the relaxation in the ramp rate is user-specified, then a single-objective dynamic optimization problem as given by Equation 4.28 can be solved. In Equation 4.28, the first constraint denotes the equality and inequality constraints due to the plant-wide model. The second and third constraints are for the main and reheat steam temperatures, respectively. The fourth and fifth constraints are for the temperatures at the inlet of the SH stages and $\mathrm{RH}$ stages, respectively, which must remain above their respective dew points. The sixth constraint satisfies that the HP drum stress, with maximum amplitude $\max _{a m p}\left(\sigma_{H P}\right.$ drum $)$, is constrained within a certain upper/tensile bound and lower/compressive bound. As the drum stresses at different locations in the drum have varied amplitudes under load-following, this constraint considers the maximum stress variation during transients considering all drum locations that are evaluated. The constraint for the average ramp rate is given by the seventh constraint, where $n$ denotes the desired ramp rate. The final constraint satisfies the terminal constraint that the plant load reaches the desired load at the end of the ramp. Obviously, as ramprate is relaxed, the end time for the ramp, $t_{\text {fin }}$, needs to be modified accordingly. 
These optimization studies are done using APD that employs a sequential optimization approach where the process flowsheet is solved by using an embedded DAE solver. This approach makes it difficult to optimize trajectories of a large number of decision variables. Therefore, trajectory of the respective attemperator spray flow controller setpoints is considered as the decision variables in this problem. In addition, trajectory of the ramp rate is also the decision variable. It should be noted that even though real-time ramp rate can be different from the desired ramp rate (e.g. 5\% load change/min) in dynamic optimization, it has the upper and lower bound (e.g. 1\% load change/min to $7.5 \%$ load change/min). The setpoints and control of remaining controlled variables are based on the coordinated control approach as described in Section 2.2.4.

$$
\begin{aligned}
& \max _{u} \frac{\int_{t_{i n i}}^{t_{f i n}} \eta_{t h} d t}{t_{f i n}-t_{i n i}} \\
& \text { s.t. } f(x, y, u) \leq 0 \quad x, y, u \in R^{n} \\
& T_{s p, M S}-\Delta T_{M S} \leq T_{M S} \leq T_{s p, M S}+\Delta T_{M S} \\
& T_{s p, R S}-\Delta T_{R S} \leq T_{R S} \leq T_{s p, R S}+\Delta T_{R S} \\
& T_{S H, i} \geq T_{\text {dew }, S H, i}+\Delta T_{\text {dew }, S H} \\
& T_{R H, i} \geq T_{\text {dew }, R H, i}+\Delta T_{\text {dew }, R H} \\
& \sigma_{\text {lower }} \leq \max _{\text {amp }}\left(\sigma_{\text {HP drum }}\right) \leq \sigma_{\text {upper }} \\
& \frac{n \% \text { load } \text { change } e_{\text {desired }}}{\min }-\Delta \text { ramprate }_{\text {lower }} \leq \text { ramprate }_{\text {ave }} \leq \frac{n \% \text { load }_{\text {change }}}{\text { desired }} \\
& \operatorname{Load}\left(t=t_{\text {fin }}\right)=\operatorname{Load}_{\text {desired }}\left(t=t_{\text {fin }}\right)
\end{aligned}
$$

where $\eta_{t h}$ is the thermal efficiency of power plant, $T$ is the steam temperature and $\Delta T$ is the allowable temperature deviation /difference. $\sigma$ is the drum stress at the junction part, ramprate is the plant load ramp rate under the load-following and $\Delta$ ramprate is the allowable average ramp rate deviation. The subscripts 'sp', 'dew', 'ave' , 'upper' and 'lower' denote setpoint, dew point, average value, upper bound and lower bound, respectively; ' $M S$ ' and ' $R S$ ' represent main steam and reheat steam, respectively; ' $S H$ ' and ' $R H$ ' denote superheater and reheater inlet steams, respectively; $i$ represents $\mathrm{SH} / \mathrm{RH}$ stages.

While the power plant operator may have the option to relax the ramprate in some cases, in many cases it is desired that the deviation of the ramprate from the desired ramprate is minimized. Since the minimum relaxation needed to satisfy the constraints 1-6 would depend on the state of the 
system, desired ramprate, (whether the plant is ramping up or down), the plant design , and the plant control system design, the user-specified relaxation may not be able to satisfy the constraints or can largely exceed the minimum relaxation. At this point, one important question arises: will the relaxation of the ramprate be minimized by the optimizer so that the user can simply provide a larger relaxation for satisfying the equality and inequality constraints? To answer this question, the important distinction between the ramp-up and ramp-down operation needs to be considered with respect to their impact on efficiency. NGCC efficiency monotonically decreases as the load is decreased. Therefore, when the dynamic optimization problem given by Equation 4.28 is solved for ramp-up operation, the deviation of the average ramp rate from the desired ramp rate gets minimized by the optimizer since doing so maximizes the efficiency. Therefore, so long as the user specifies a large relaxation for the ramp rate while ramping up, the constraint boundary for ramp relaxation will not be reached. On the other hand, if the plant load is to be ramped down, then if a larger relaxation than what is needed to satisfy the constraints 1-6 in Equation 4.28, is specified by the user, then the optimizer will relax the ramprate as much as possible (i.e., will reach the maximum relaxation specified by the user) since lowering the ramp rate improves the efficiency. Therefore, for the cases where the user may not be permitted to relax the ramprate beyond the minimal value, the following multi-objective optimization problem can be solved:

$$
\begin{aligned}
& \min _{u} \Delta \text { ramprate }_{\text {lower }} \\
& \max _{u} \frac{\int_{t_{\text {ini }}}^{t_{f i n}} \eta_{t h} d t}{t_{f i n}-t_{\text {ini }}} \\
& \text { s.t. } f(x, y, u) \leq 0 \quad x, y, u \in R^{n} \\
& T_{s p, M S}-\Delta T_{M S} \leq T_{M S} \leq T_{s p, M S}+\Delta T_{M S} \\
& T_{s p, R S}-\Delta T_{R S} \leq T_{R S} \leq T_{s p, R S}+\Delta T_{R S} \\
& T_{S H, i} \geq T_{\text {dew }, S H, i}+\Delta T_{\text {dew }, S H} \\
& T_{R H, i} \geq T_{\text {dew }, R H, i}+\Delta T_{\text {dew }, R H} \\
& \sigma_{\text {lower }} \leq \max _{\text {amp }}\left(\sigma_{\text {HP drum }}\right) \leq \sigma_{\text {upper }} \\
& \frac{n \% \text { load change } e_{\text {desired }}}{\min }-\Delta \text { ramprate }_{\text {lower }} \leq \text { ramprate }_{\text {ave }} \leq \frac{n \% \text { load }_{\text {change }}}{\text { desired }} \\
& \operatorname{Load}\left(t=t_{\text {fin }}\right)=\operatorname{Load}_{\text {desired }}\left(t=t_{\text {fin }}\right)
\end{aligned}
$$


For solving the multi-objective dynamic optimization problem given above, the lexicographic approach is used (Bhattacharyya and Rengaswamy, 2010; Paul et al., 2017; Miettinen, 2002). If there are $n$ optimization objectives, then in the lexicographic approach, the objective functions are arranged in order according to their importance and an $n$-stage optimization problem is solved. In the first stage, the most important objective is optimized while in the second stage the next important objective is optimized subject to the additional constraint introduced by the solution of the first stage optimization problem. This approach continues till the $n^{\text {th }}$ stage optimization problem where additional constraints based on the solution from $n-1$ stages are included. The solution of the lexicographic approach is Pareto-optimal (Miettinen, 2002). The lexicographic approach is very appropriate for the multi-objective optimization problem given above, since the power plant operational objectives are ordered in terms of their importance/priorities during load following. For a load-following power plant responding to the grid demand, following the desired ramprate as closely as possible is often the most important objective. Therefore, minimizing the deviation from the desired ramp rate is the most important objective. Thus, the following twostage optimization problem is proposed:

Stage 1 optimization:

$$
\begin{aligned}
& \min _{u} \Delta \text { ramprate }_{\text {lower }} \\
& \text { s.t. } f(x, y, u) \leq 0 \quad x, y, u \in R^{n} \\
& T_{s p, M S}-\Delta T_{M S} \leq T_{M S} \leq T_{s p, M S}+\Delta T_{M S} \\
& T_{s p, R S}-\Delta T_{R S} \leq T_{R S} \leq T_{s p, R S}+\Delta T_{R S} \\
& T_{S H, i} \geq T_{\text {dew }, S H, i}+\Delta T_{\text {dew }, S H} \\
& T_{R H, i} \geq T_{\text {dew }, R H, i}+\Delta T_{\text {dew }, R H} \\
& \sigma_{\text {lower }} \leq \max _{\text {amp }}\left(\sigma_{\text {HP drum }}\right) \leq \sigma_{\text {upper }} \\
& \frac{n \% \text { load } \text { change } e_{\text {desired }}}{\min }-\Delta \text { ramprate }_{\text {lower }} \leq \text { ramprate }_{\text {ave }} \leq \frac{n \% \text { load }_{\text {change }}}{\text { desired }} \\
& \operatorname{Load}\left(t=t_{\text {fin }}\right)=\operatorname{Load}_{\text {desired }}\left(t=t_{\text {fin }}\right)
\end{aligned}
$$

Stage 2 optimization:

$$
\max _{u} \frac{\int_{t_{i i n}}^{t_{f i n}} \eta_{t h} d t}{t_{f i n}-t_{i n i}}
$$

s.t. $f(x, y, u) \leq 0 \quad x, y, u \in R^{n}$ 


$$
\begin{aligned}
& T_{s p, M S}-\Delta T_{M S} \leq T_{M S} \leq T_{s p, M S}+\Delta T_{M S} \\
& T_{s p, R S}-\Delta T_{R S} \leq T_{R S} \leq T_{s p, R S}+\Delta T_{R S} \\
& T_{S H, i} \geq T_{\text {dew }, S H, i}+\Delta T_{\text {dew }, S H} \\
& T_{R H, i} \geq T_{\text {dew }, R H, i}+\Delta T_{\text {dew }, R H} \\
& \sigma_{\text {lower }} \leq \max _{\text {amp }}\left(\sigma_{\text {HP drum }}\right) \leq \sigma_{\text {upper }} \\
& \frac{n \% \text { load } \text { change } e_{\text {desired }}}{\min }-\Delta \text { ramprate }_{\text {lower }, \min } \leq \text { ramprate }_{\text {ave }} \leq \frac{n \% \text { load }_{\text {change }}}{\text { desired }} \\
& \operatorname{Load}\left(t=t_{\text {fin }}\right)=\operatorname{Load}_{\text {desired }}\left(t=t_{\text {fin }}\right)
\end{aligned}
$$

In Eq. (4.31), $\Delta$ ramprate $_{\text {lower,min }}$ is the optimal objective obtained from the first stage of optimization.

In APD, FEASOPT (a feasible path SQP algorithm) and DMO (Dynamic Multi-Objective solver) optimizers are used. The initial guesses of spray flow rate are from the coordinated control system as discussed in Section 3.3, while the initial value of the ramprate is constant as the desired average ramprate. Therefore, results obtained from the coordinated control system under the linear loadfollowing operation are used as the initial guess for dynamic optimization.

\subsection{Results and discussion}

\subsubsection{HP Drum stress transient under the load-following operation}

These studies are conducted considering that the plant load starts ramping down in the first hour from $100 \%$, reaching $25 \%$ in 15 min (i.e., $5 \%$ load change per min), then stays at $25 \%$ load for 4 hr $45 \mathrm{~min}$, then ramps up to $100 \%$ at a constant ramp rate of 5\% load change per min. The total simulation time is $12 \mathrm{hr}$ to fully capture the HP drum stress transient.

\section{$\underline{\text { Tangential stress on wall inner surface }}$}

Figure 4.3 shows the drum pressure and temperature transients under the load-following scenario, reflecting the sliding pressure operation of the plant. Figure 4.4 shows the transients in the tangential thermo-mechanical stress on the drum inner surface. As expected, the mechanical stress is always in the tensile direction and proportional to the drum internal pressure, thus decreasing as the drum pressure drops and then rising back as the plant ramps up to the full load. Thermal stress shows some interesting behavior. First, as the load decreases, the inner surface temperature becomes lower than the outer surface. During this time, the thermal stress on the inner surface is 
tensile. As the plant load stays at $25 \%$, the temperature difference between the inner and outer surfaces reduces thus the thermal stress decreases and eventually becomes negligible. When the load starts ramping up, the inner temperature becomes larger than the outer surface temperature thus leading to compressive stress. As the plant load becomes steady, the temperature difference between inner and outer surfaces becomes very small leading to negligible thermal stress.

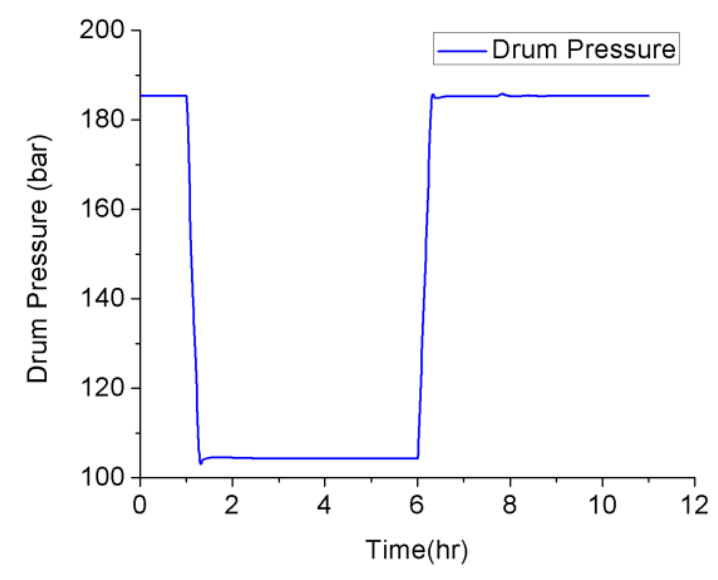

(a)

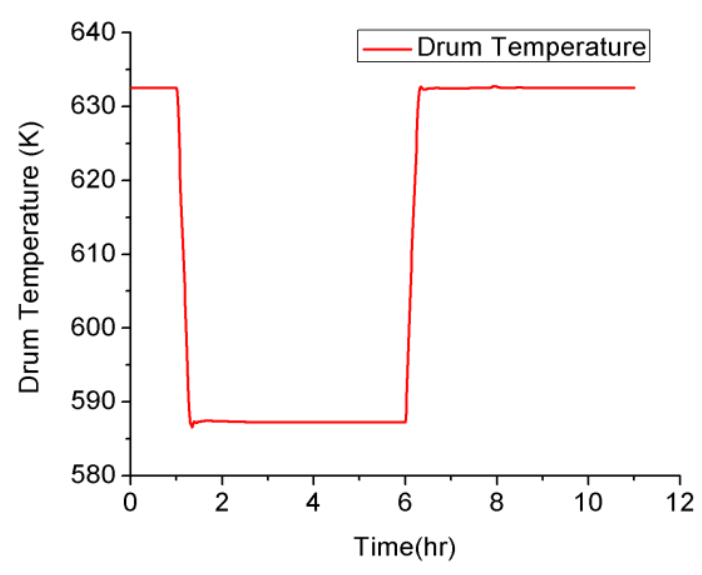

(b)

Figure 4. 3. Drum pressure and temperature transients under load-following operation: (a) pressure (b) temperature

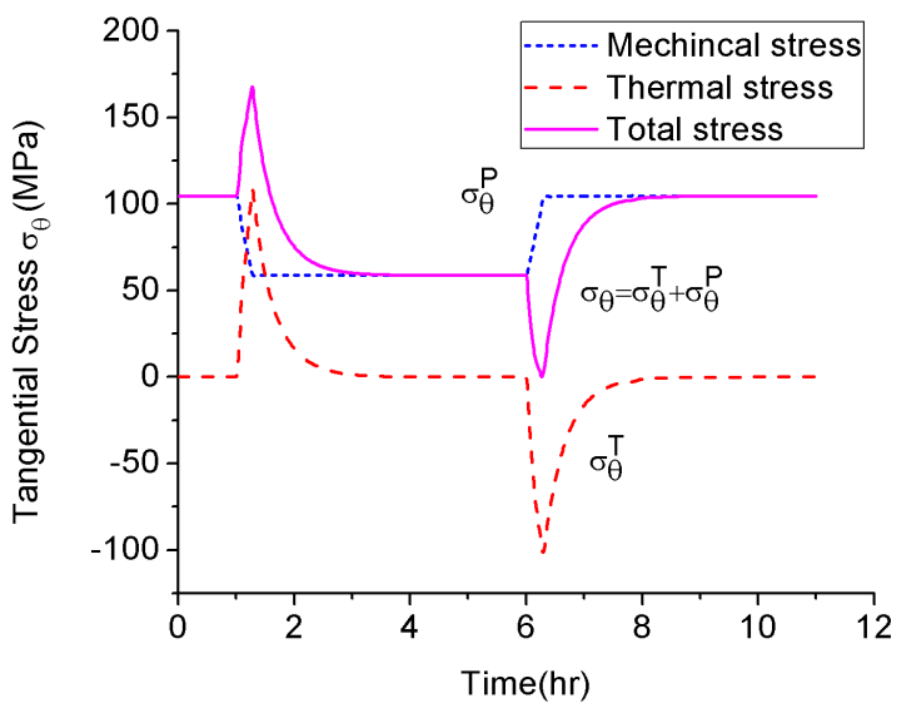

Figure 4. 4. Tangential stress transient on drum inner surface under load-following 
As the drum wall thickness is high, the magnitude of the thermal stress is large. It can be observed that the thermal stress is compensated by the mechanical stress as they are opposite in direction during both ramp-up and -down. As a result, even though the thermal stress is compressive during ramp up operation, the total stress remains slightly tensile due to the increase in the mechanical stress that is tensile.

\section{Circumferential stress at drum/downcomer junction}

Under load-following operations, through-wall temperature difference and corresponding thermal stress increase roughly as the square of wall thickness, as shown in Equation 4.14, and mechanical stress decreases proportionally to the wall thickness as shown in Equation 4.12. As wall thickness keeps increasing, the thermal stress becomes predominant, which leads to an increase in stress amplitude.

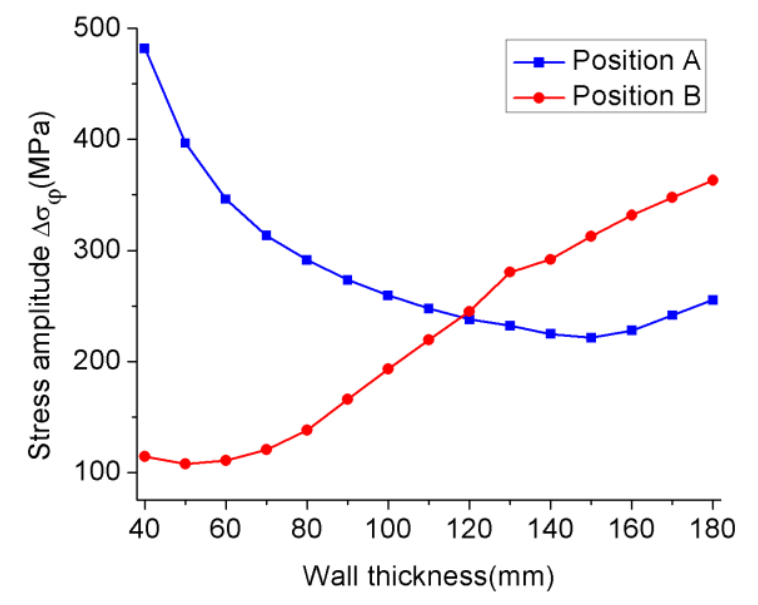

Figure 4. 5. Stress amplitude with respect to the drum wall thickness at Positions A and B

Resulting stress amplitude calculated over the entire ramp down and ramp up operation for different drum wall thickness is shown in Figure 4.5 for Position A and B. As noted before, only Position A is considered in many of the existing codes such as EN 12952-3. However, Figure 4.5 shows that the dominating stress amplitude strongly depends on the drum wall thickness. Figure 4.5 shows that the minimum stress amplitude for Position A occurs at around $150 \mathrm{~mm}$ wall thickness, which is less than the minimum required thickness $\left(s_{c}=169.9 \mathrm{~mm}\right)$ calculated using EN 12952-3 Standard (2011) for the nominal operating conditions and material of construction given in Table 4.1. Considering the drum design thickness of $177.8 \mathrm{~mm}$, given in Table 4.1, Position B 
experiences a larger stress amplitude as shown in Figure 4.5. Therefore, besides Position A, the fatigue damage should also be assessed at Position B.

Table 4.3 shows that compared to Position A, more fatigue damage is accumulated at Position B due to the larger stress amplitude $\Delta \sigma$. In Table 4.3, the allowable number of cycles before a failure is likely to occur is relative to that for Position A, which is shown as unity. It shows that allowable number of cycles for Position B is about 7\% of that for Position A. These results show that Position $\mathrm{B}$ is considerably more vulnerable to failure due to cycling than Position A. Figure 4.6 shows the circumferential stress profile in Positions A and B during the simulated load-following scenario. It shows that Position B can be subjected to compressive stress, for which most materials have lower tolerance (Shankar et al., 2006).

Since Position B is the most stressed part of the drum under the load-following and more vulnerable to failure given the design, the circumferential stress at drum/downcomer junction Position $\mathrm{B} \sigma_{\varphi, B}$ is considered to be the constraint (i.e. $\sigma_{\varphi, B}=\max _{a m p}\left(\sigma_{H P}\right.$ drum $)$ )in the dynamic optimization problem.

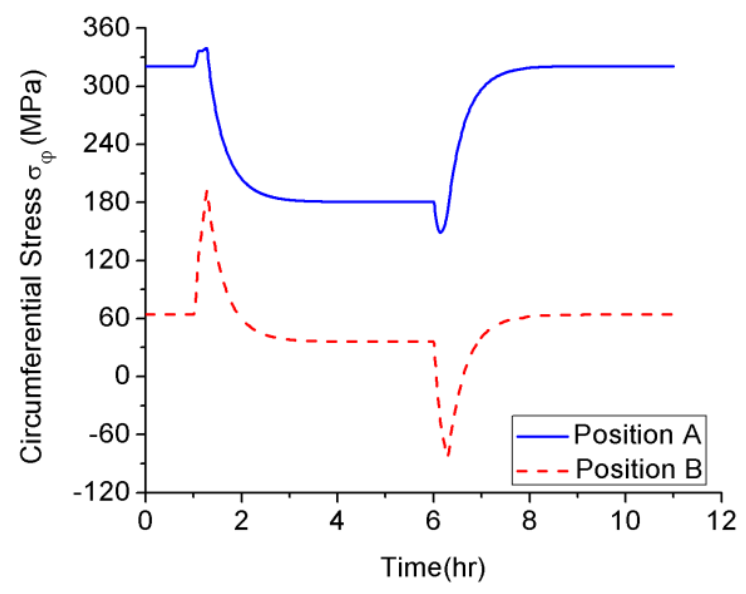

Figure 4. 6. Transients of circumferential stress at drum/downcomer junction Table 4. 3. Fatigue damage estimation at drum/downcomer junction

\begin{tabular}{|c|c|c|c|c|c|}
\hline & \multicolumn{5}{|c|}{ Drum-downcomer junction } \\
\hline & $\lambda_{t}$ & $\lambda_{m}$ & $\Delta \sigma(\mathrm{MPa})$ & $\begin{array}{c}\text { Allowable number } \\
\text { of Cycles } N_{A}\end{array}$ & $\begin{array}{c}\text { Relative Allowable } \\
\text { Number of Cycles }\end{array}$ \\
\hline $\begin{array}{c}\text { Position A } \\
\left(\varphi=0^{\circ}\right)\end{array}$ & 1.44 & 3.07 & 188.3 & $7.5 \times 10^{6}$ & 1 \\
\hline $\begin{array}{c}\text { Position B } \\
\left(\varphi=90^{\circ}\right)\end{array}$ & 1.44 & 0.614 & 267.6 & 525,265 & 0.07 \\
\hline
\end{tabular}




\subsubsection{Dynamic optimization under the load-following operation}

Results from the dynamic optimization are generated by considering a load ramp down from 100\% to $25 \%$ then back to $100 \%$ at a desired average ramprate of $5 \%$ load change per minute, similar to Section 4.4.1. In the typical power plant operation under sliding pressure mode, the steam pressure is changed linearly with respect to load. Thus, if a 5\% load change per minute is desired then that ramprate is imposed for all instants of time until the plant load reaches its new steady state set

point. As a result, the drum pressure changes linearly over the entire load following scenario till it reaches the new steady state value. This typical industrial approach is denoted as 'Linear' in the results presented below. These results will be compared with the results from dynamic optimization studies denoted as 'Optimal'.

\section{Optimal process under a constant ramp rate neglecting stress constraint}

Results in this subsection are generated by neglecting the stress constraint. Since the plant configuration considers a 2-stage attemperation for both $\mathrm{SH}$ and $\mathrm{RH}$, all constraints including the main steam temperature could be satisfied by the conventional 'linear' approach as well, while avoiding spraying to saturation. Since ramprate relaxation is not needed for satisfying the constraints under this scenario, only the single objective optimization problem given by Equation 4.28 is solved without the stress constraint. As the steam temperature can be maintained very close to its setpoint, steam temperature transients are not shown in subsequent results.

It was found that dynamic optimization leads to about $1 \%$ higher thermal efficiency at low load than the linear operation. Also, the least spray at ATT leads to the highest plant efficiency (Wang et al., 2020). Figures 4.7 (a-d) compare the results between the conventional linear approach and dynamic optimization. The dynamic optimization leads to an overall higher thermal efficiency. It is observed that the optimizer reduces the spray at both HP SH2 and RH ATT resulting in a higher steam inlet temperature and a lower driving force for heat exchange in HP SH2 and RH. Consequently, more exhaust heat is recovered in the downstream HP EVA for more HP steam generation leading to higher plant efficiency. It is also observed that the drum steam pressure is higher for the optimal profile at low load as seen in Figure 4.7 (d). 


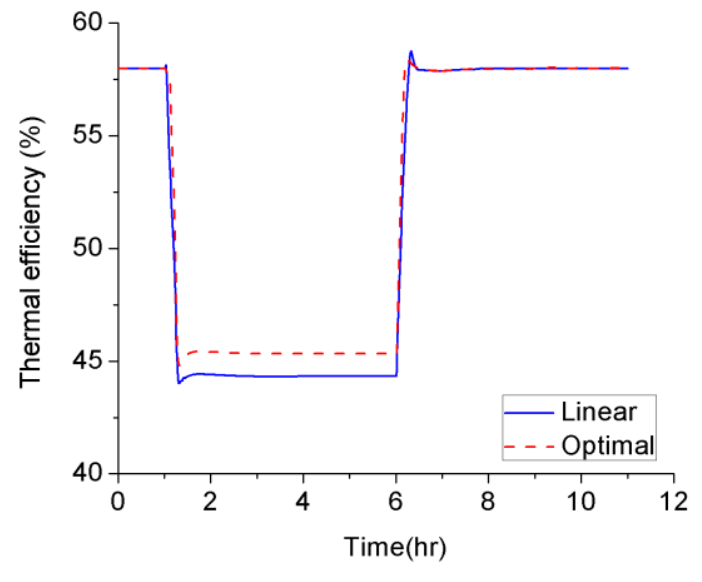

(a)

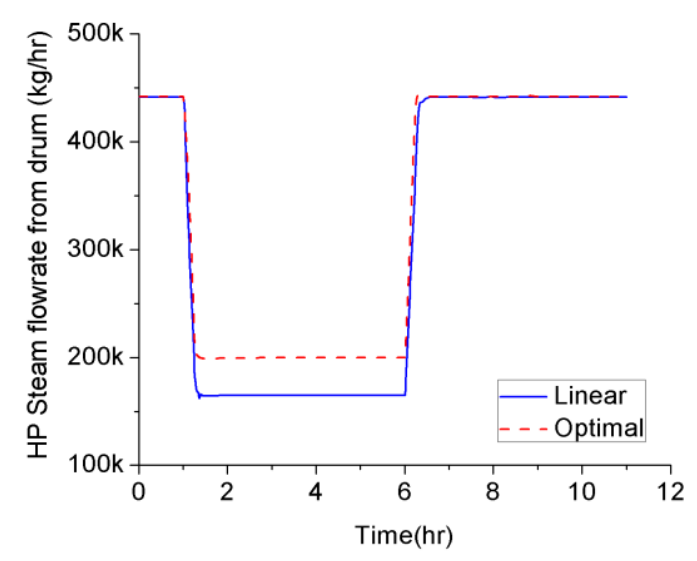

(c)

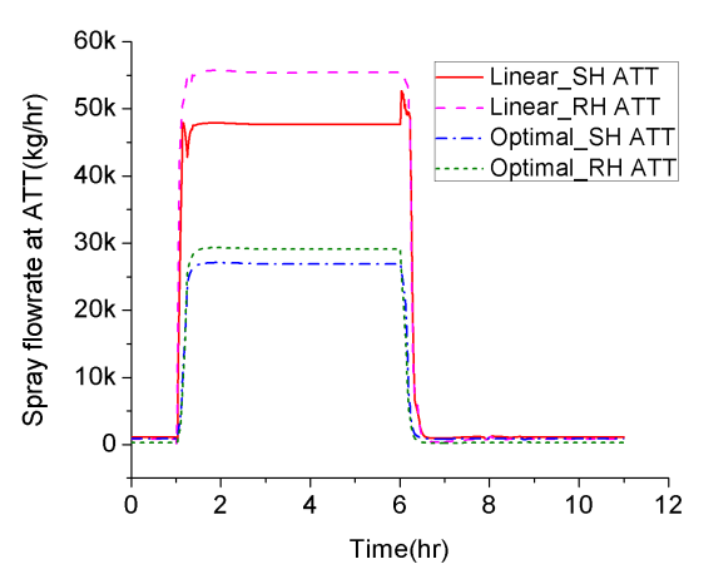

(b)

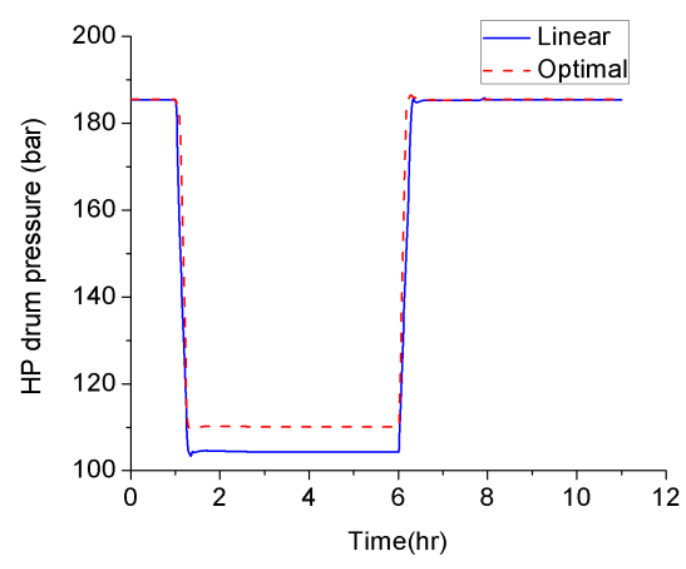

(d)

Figure 4. 7. Comparison between dynamic optimization and coordinated control system: (a) thermal efficiency (b) total spray flow at SH/RH ATT (c) HP steam flow from HP drum (d) HP drum pressure

Figure 4.8(a) shows the profile of tangential mechanical and thermal stresses on the drum inner surface for the linear approach as well as for dynamic optimization. Figure 4.8 (b) shows the stress profile at the drum/downcomer junction at Position B. There are only minor differences in the stress profile between the linear approach and dynamic optimization for all locations evaluated. 


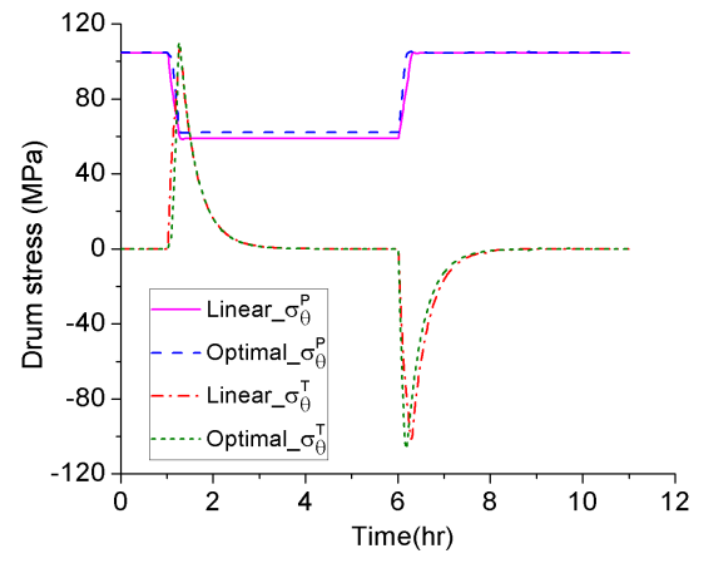

(a)

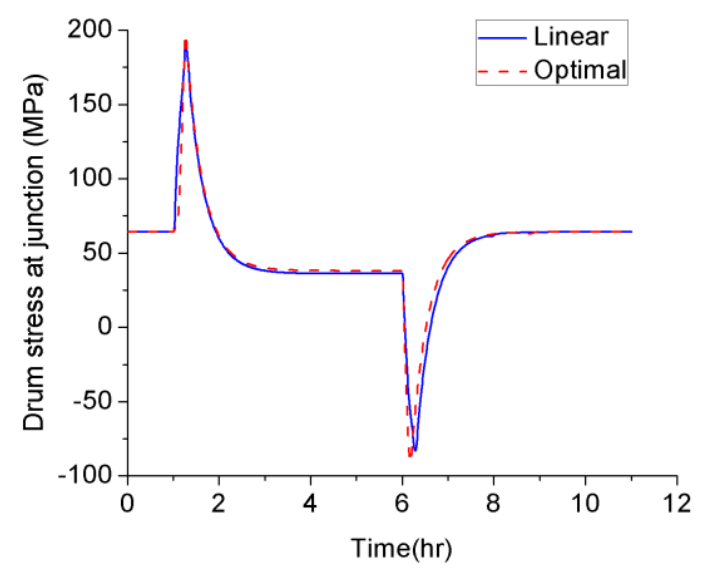

(b)

Figure 4. 8. Comparison of stress transient between dynamic optimization and conventional linear approach: (a) tangential stress at drum inner surface (b) circumferential stress at drum/downcomer junction at Position B

In fact, drum stream pressure difference between linear approach and dynamic optimization results in negligible mechanical stress difference. On the other hand, since thermal stress is proportional to the temperature change rate as shown in Equation 4.14, nonlinear optimal operation with varied real-time ramprate could lead to more flexible steam temperature change and corresponding thermal stress during the transient than the conventional linear operation. More details will be shown in the next subsection.

\section{Optimal process under a constant ramp rate with different stress constraints}

Results in this subsection are generated by considering different stress constraints. These stress constraints not only depend on the specific material of construction, but also on the operational history of a plant as well as the level of conservatism exercised by plant operators. It should be noted that for ramp down studies, only $\sigma_{\text {upper }}$ may be active, if at all, while for ramp up, only $\sigma_{\text {lower }}$ may be active, if at all, depending on the value of the constraint bound. Sensitivities to different upper and lower bounds of stress, i.e. $\sigma_{\text {lower }}$ and $\sigma_{\text {upper }}$ are evaluated. In particular, the following bounds are evaluated, $\sigma_{\text {lower }}=-70,-82,-95 \mathrm{MPa}$ and $\sigma_{\text {upper }}=200,191,175$ $\mathrm{MPa}$. The rationale behind selecting these bounds is given as follows. Out of these bounds, $\sigma_{\text {lower }}=-82 \mathrm{MPa}$ and $\sigma_{\text {upper }}=191 \mathrm{MPa}$ are the same as the values that would be reached by 
following a strictly linear profile for $5 \%$ per min ramp up and ramp down, respectively. The other two bounds are selected such that they are above or below the values reached using the linear profile, but such that the average ramprate is not relaxed compared to the desired ramprate. Since no relaxation of ramprate is required, only single objective optimization problems are solved for the results presented in this section. For ease of analysis, the studies presented here are presented separately for ramp-down and ramp-up operations.

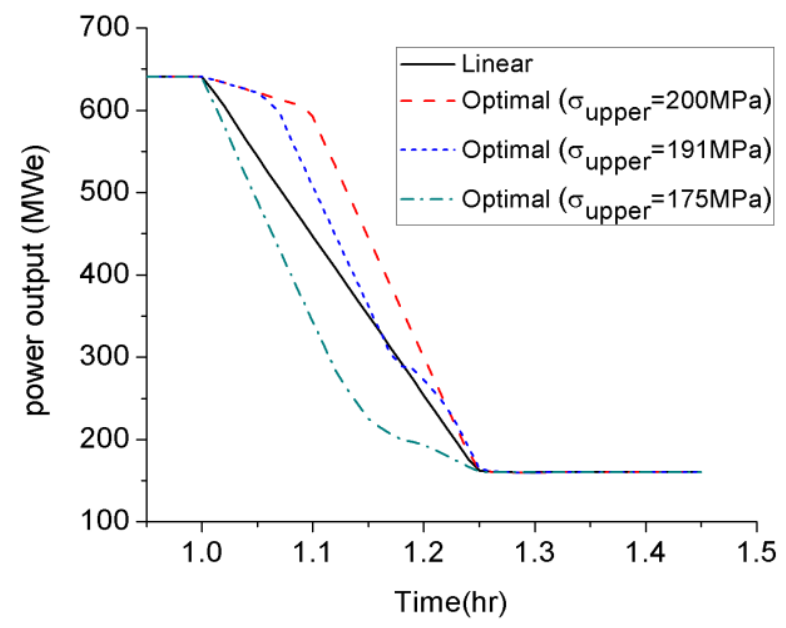

(a)

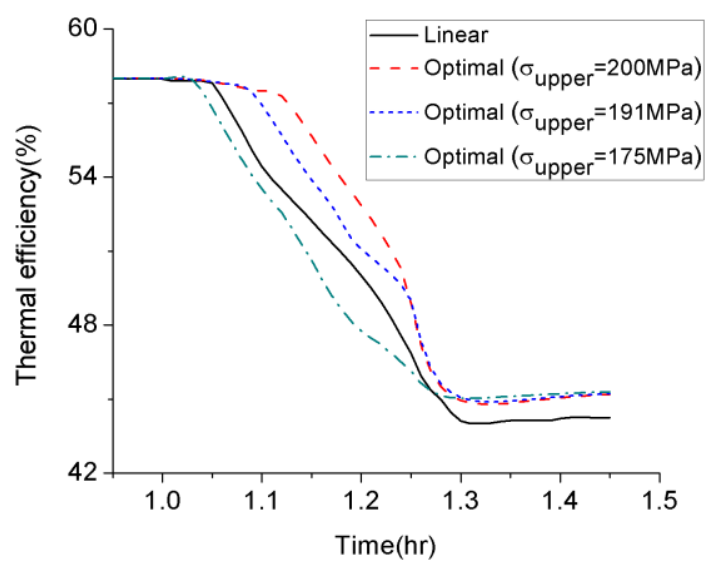

(b)

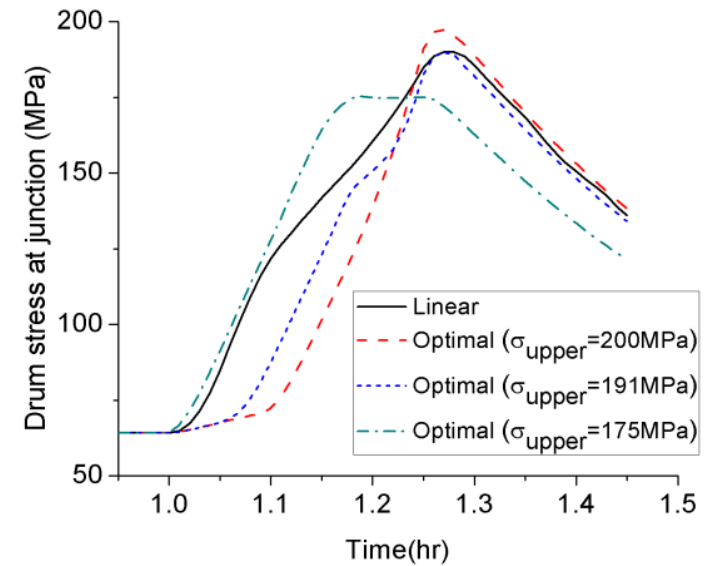

(c)

Figure 4. 9. Comparison of linear and optimal profiles under different stress constraints for 5\% average ramp down in load per min: (a) power output (b) thermal efficiency (c) HP drum stress at drum/downcomer junction at Position B 
Figures 4.9(a), (b), (c) compare power, thermal efficiency and drum stress at the junction (the maximum stress), respectively, for the linear profile vs. the optimal profile for $5 \%$ average ramp down. As shown in Table 4.4, dynamic optimization leads to about $1 \%$ higher efficiency than the linear profile, even if the upper bound for stress is set at the same value as the linear profile. It is observed that the optimal ramp rate is considerably slower early in the beginning of ramp down compared to the linear profile, thus taking advantage of the higher thermal efficiency at higher loads. It then follows a steeper profile than the linear rate. Subsequently, the optimal ramprate becomes much lower than the linear profile to avoid the maximum stress bound and finally increases again to satisfy the average ramp constraint. When the stress upper bound is set at 200 $\mathrm{MPa}$, the optimal ramp rate is even slower in the beginning than when the stress limit is $191 \mathrm{MPa}$, since a faster ramprate could be followed for rest of the profile without exceeding the stress limit. In this case, the dynamic optimization leads to about $1.4 \%$ higher thermal efficiency than the linear profile. When the stress constraint is lower than the linear profile (i.e., at $175 \mathrm{MPa}$ ), the ramp rate at the beginning is higher than the linear profile, but as the system approaches the stress limit, the ramprate decreases but can still achieve the desired average ramprate. As shown in Table 4.4, the time average thermal efficiency for this case is $0.3 \%$ lower than the linear profile.

Table 4. 4. Plant average efficiency under different ramp-down processes with the fixed average ramp rate

\begin{tabular}{|c|c|c|c|c|}
\hline & Linear & \multicolumn{3}{|c|}{ Optimal } \\
\hline Stress upper bound (MPa) & 191 & 200 & 191 & 175 \\
\hline Time average thermal efficiency (\%) & 50.3 & 51.7 & 51.3 & 50.0 \\
\hline
\end{tabular}

Table 4. 5. Plant average efficiency under different ramp-up processes with the fixed average ramp rate

\begin{tabular}{|c|c|c|c|c|}
\hline & Linear & \multicolumn{3}{|c|}{ Optimal } \\
\hline Stress lower bound (MPa) & -82 & -95 & -82 & -70 \\
\hline Time average thermal efficiency (\%) & 53.5 & 54.6 & 54.5 & 54.3 \\
\hline
\end{tabular}

Figures 4.10 (a), (b), (c) compare power, thermal efficiency and drum stress at the junction (point of maximum stress), respectively, for the linear profile vs. the optimal profile for 5\% average ramp-up in load per min. Table 4.5 shows that the dynamic optimization leads to about $1 \%$ higher efficiency than the linear profile even though the lower bound of stress is set at the same value as 
the linear profile. Opposed to the ramp-down process, the ramp up profile is steeper early in the process since higher efficiency is obtained at higher load. To avoid reaching the stress constraint, the ramprate becomes slower at a later time. The higher the value of the stress lower bound, the earlier the ramprate starts becoming slower, as expected. As a result, as the value of the stress constraint becomes higher, the improvement in efficiency with respect to the linear profile becomes smaller as shown in Table 4.5. For all the stress bounds considered in this study, efficiency obtained through dynamic optimization is superior to the linear profile.

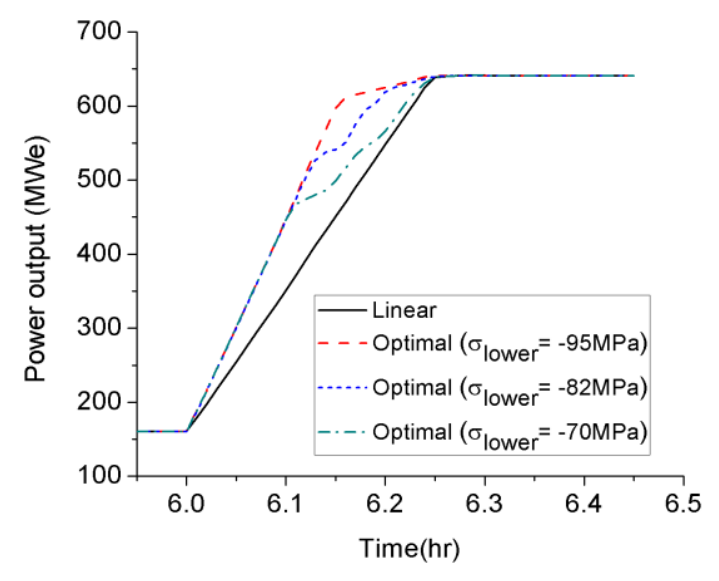

(a)

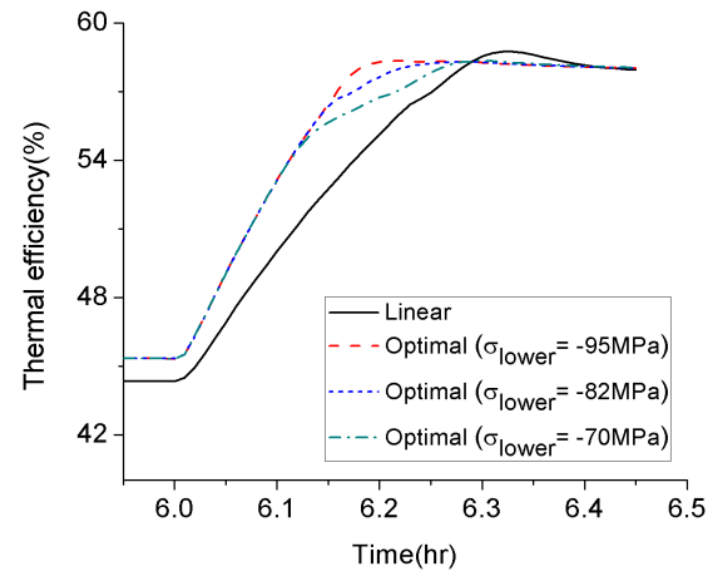

(b)

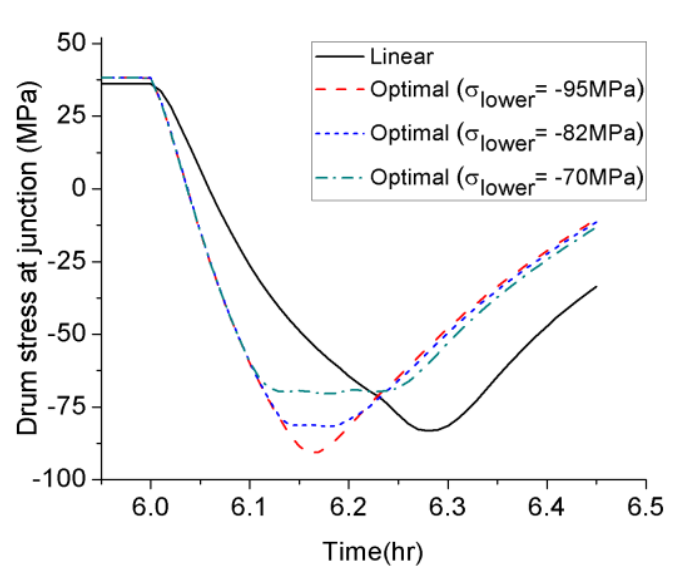

(c)

Figure 4. 10. Comparison of linear and optimal profiles under different stress constraints for $5 \%$ average ramp up in load per min (a) Power output (b) Thermal efficiency (c) HP drum stress at drum/downcomer junction at Position B 


\section{Optimal process under varied ramp rate with average ramprate relaxation}

For the studies presented in this section, upper and lower bounds on drum stress are tightened compared to the earlier section, thus relaxation of average ramp rate becomes necessary. Therefore, the multi-objective optimization problem given by Equations 4.30 and 4.31 is solved. Results in this section are those obtained at the end of second stage optimization given by Equation 4.31 .

As noted earlier, while ramping up the load, a user can provide a large enough relaxation in the ramprate and solve a single objective optimization problem since the optimizer will automatically minimize the ramprate relaxation since doing so improves the efficiency. Thus, the multi-objective problem is of importance mainly for ramping down the load.

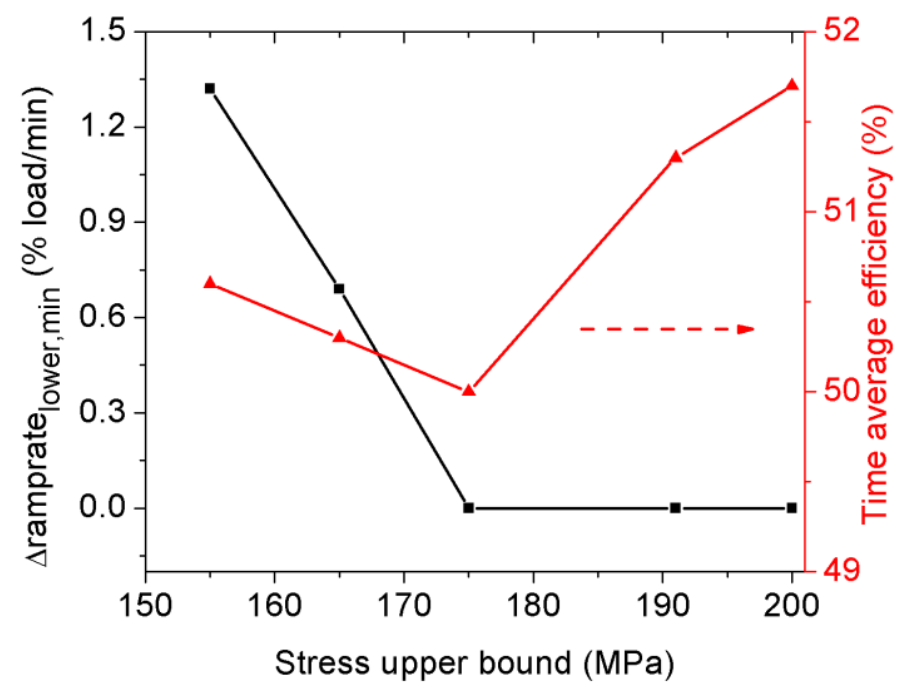

Figure 4. 11. Effect of the stress upper bound on the minimum ramprate relaxation and time average thermal efficiency for a desired rate of $5 \%$ rampdown per minute

Figure 4.11 shows the minimum relaxation in rate for rampdown as the stress upper bound is changed. It shows that when the upper bound of stress is higher than $175 \mathrm{MPa}$, ramparate does not need to be relaxed, which was also captured in the studies presented in the earlier section. As the upper bound on stress is decreased further, the minimum ramprate relaxation required for satisfying the stress constraints keeps increasing. When the stress upper bound is above $175 \mathrm{MPa}$, time average thermal efficiency keeps decreasing as the stress upper bound is reduced as shown in earlier section. However, as the ramprate relaxation keeps increasing, the efficiency goes up again 
as the average ramprate becomes lower. Corresponding profiles presented in Figure 4.12 make these trends clear.

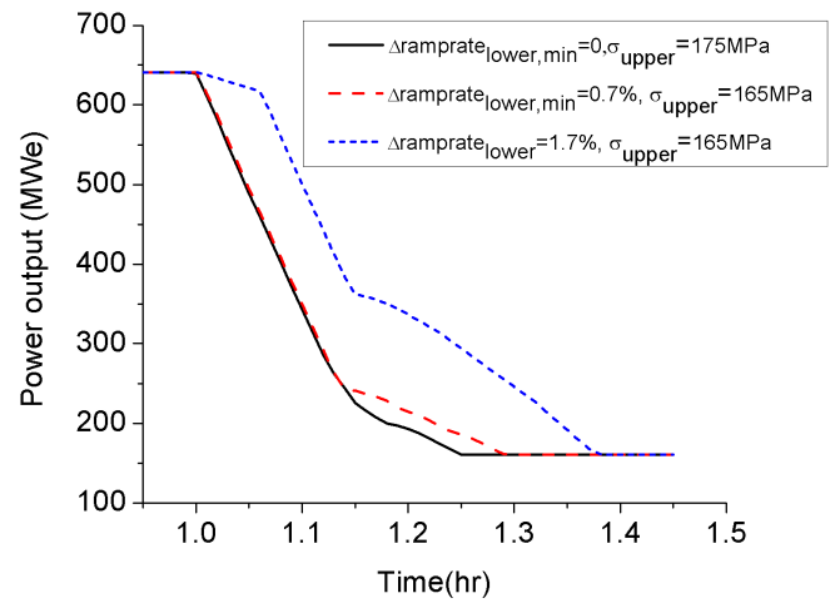

(a)

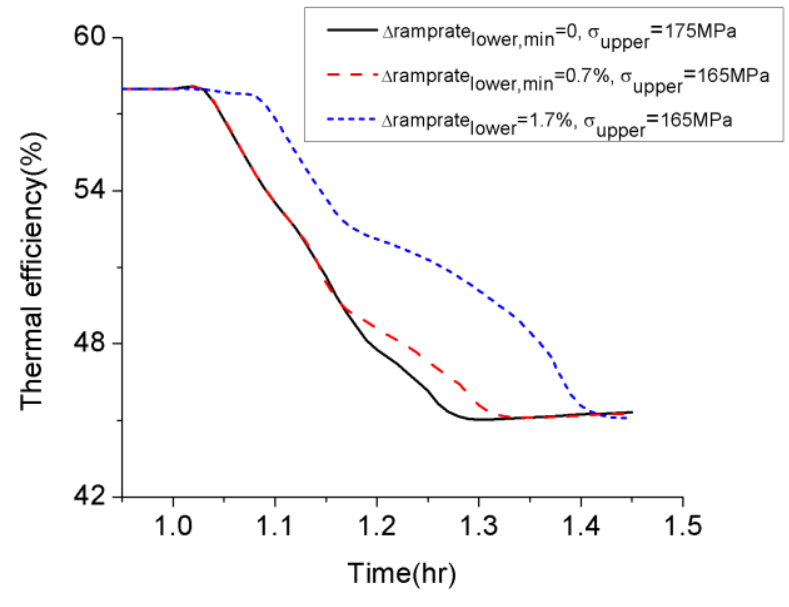

(b)

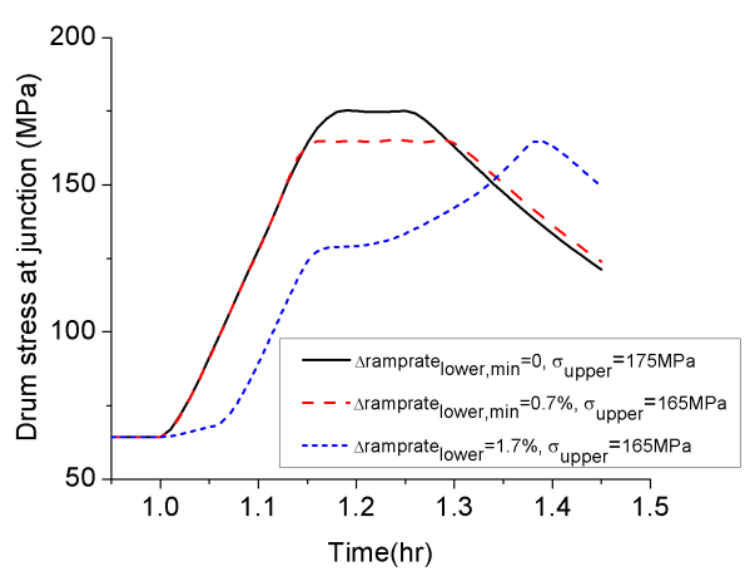

(c)

Figure 4. 12. Comparison of different ramp-down processes with the fixed/relaxed average ramp rate: (a) power output (b) thermal efficiency (c) HP drum stress at drum/downcomer junction at Position B

Figures 4.12(a), (b), (c) compare power output, thermal efficiency and HP drum stress at the junction of the drum and downcomer for various ramprate relaxations when the desired rate is $5 \%$ average ramp down in load per min. For reference, it also includes the case when the stress upper bound is $175 \mathrm{MPa}$, where no relaxation is needed. When the stress upper limit is reduced to 165 
$\mathrm{MPa}$, the multi-objective optimization leads to a minimum relaxation of $0.7 \%$ average ramprate, i.e., about $4.3 \%$ time average ramprate. Corresponding results when the ramprate relaxation is $1.7 \%$, i.e., the average ramprate of $3.3 \%$, are also shown. As expected, as ramprate relaxation increases, it leads to an increase in the efficiency. Table 4.6 shows that compared to the case when there was no relaxation in ramprate (i.e. the upper limit of stress constraint was $175 \mathrm{MPa}$ ), the time average-thermal efficiency improves by $0.3 \%$ and $2.5 \%$ when the ramprate relaxation is at its minimum and at $1.7 \%$ for the stress constraint of $165 \mathrm{MPa}$. The reason for the increase in thermal efficiency becomes clear by analyzing Figure 4.12(a) that shows that the duration of the initial slower ramprate keeps increasing as the ramprate is relaxed more, thus leading to a higher efficiency as shown in Figure 4.12(b).

Table 4. 6. Plant average efficiency under different ramp-down processes with the fixed/relaxed average ramp rate

\begin{tabular}{|c|c|c|c|}
\hline$\Delta$ ramprate $_{\text {lower }}(\%$ load change/min $)$ & 0 (mininum) & 0.7 (mininum) & 1.7 \\
\hline Stress constraint $(\mathrm{MPa})$ & 175 & 165 & 165 \\
\hline Time Average Thermal eff $(\%)$ & 50.0 & 50.3 & 52.5 \\
\hline
\end{tabular}

Figure 4.13 shows the time average thermal efficiency as the ramprate is relaxed more than the minimum when the stress upper bound is $165 \mathrm{MPa}$. As expected, a considerably higher time average efficiency can be obtained by relaxing the ramprate. The study shows that depending on the operational flexibility on ramprate relaxation, time-average efficiency for the rampdown operation can be improved.

Figure 4.14 shows the minimum relaxation in the rampup rate required as the stress lower bound is changed when the desired time average rampup rate is $5 \%$ per minute. As presented in the previous section, ramprate does not need to be relaxed when the lower bound of stress is below $70 \mathrm{MPa}$. As the lower bound on stress is increased above $-70 \mathrm{MPa}$, the minimum relaxation in the ramprate required for satisfying the stress constraints keeps increasing. As shown in an earlier section, with the increase in the lower bound on stress, the time average thermal efficiency keeps dropping since a slower ramprate is required towards the end of the ramp to avoid violating the stress constraint. This trend continues with further tightening of the stress constraint leading to a steeper fall in the efficiency. 


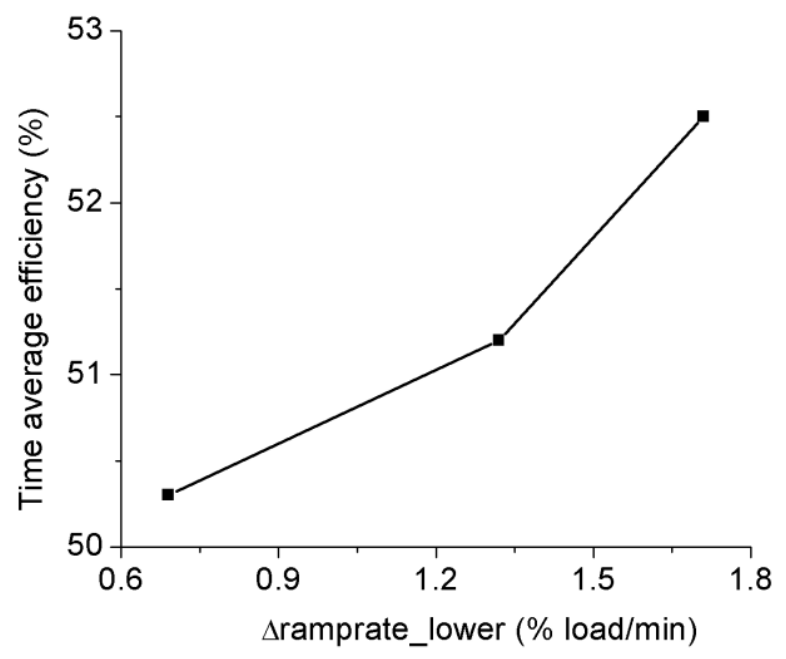

Figure 4. 13. Effect of ramprate relaxation on time average efficiency for ramp down when stress upper bound of $165 \mathrm{MPa}$ and desired ramprate is 5\% load change per min

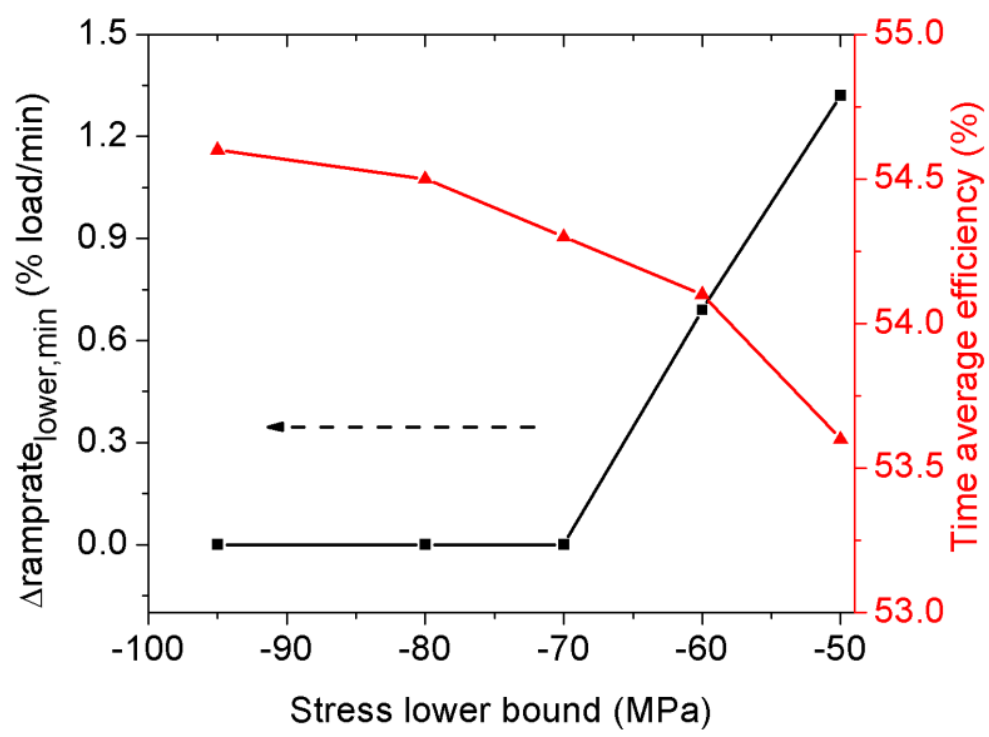

Figure 4. 14. Effect of the stress lower bound on the minimum ramprate relaxation and time average thermal efficiency for a desired rate of $5 \%$ rampup per minute

Figures 4.15 (a), (b), (c) compare power output, thermal efficiency and HP drum stress at the drum/downcomer junction for two values of stress lower bound, $-70 \mathrm{MPa}$, when no relaxation is needed, and $-60 \mathrm{MPa}$, when the minimum relaxation is about $0.7 \%$. It is observed that at the beginning of rampup, the rate of increase is similar for both cases while the slope becomes less 
steep when the stress lower bound is $-60 \mathrm{MPa}$ leading to a loss in efficiency of $0.3 \%$ compared to the case with lower bound of $-70 \mathrm{MPa}$. As noted earlier, for ramp up, even though the ramprate is relaxed further and a single objective optimization problem is solved, the results do not change from that obtained when relaxation is the minimum since the minimum ramparte relaxation leads to the maximum efficiency while ramping up.

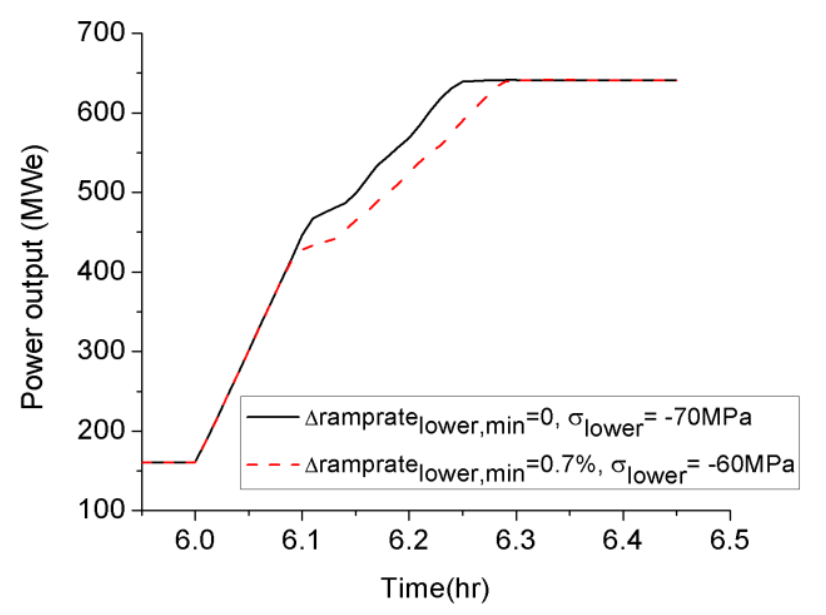

(a)

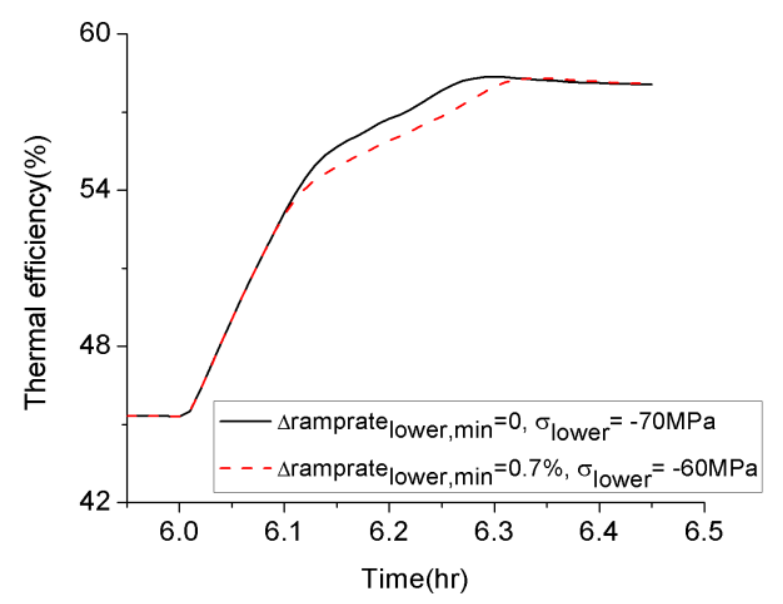

(b)

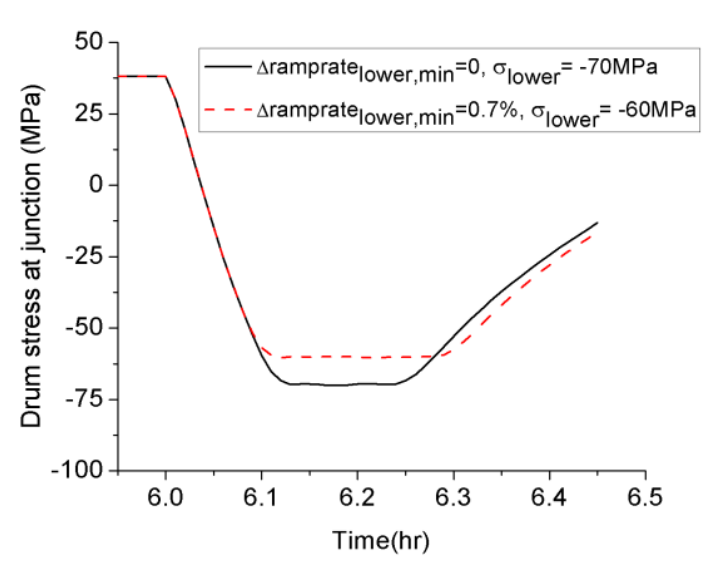

(c)

Figure 4. 15. Comparison of different ramp-up processes with the fixed/relaxed average ramp rate: (a) power output (b) plant thermal efficiency (c) HP drum stress at drum/downcomer junction at Position B 


\section{Optimal process analysis}

Under the load-following condition, spray flow rate at HP SH2/RH ATT can be optimized to not only maintain the main and reheat steam temperature within the saturation constraint but also achieve a higher efficiency than the case using traditional coordinated control system. However, the effect of attemperator spray flowrate on the HP drum pressure variation and stress transient is limited.

Using a nonlinear load-following profile, rather than the conventional linear profile, provides the additional flexibility to not only satisfy the drum stress constraint but also obtain a higher plant efficiency. A higher ramp rate is conducive for the ramp-up process, while a lower ramp rate is beneficial for the ramp-down process because of the increase in the efficiency at higher plant load and efficiency.

The tightened stress constraint requires a lower average ramp rate to prevent the stress violation. For the ramp down process, the multi-objective optimization can help to obtain the minimum deviation from the desired average ramp rate while maximizing the efficiency. When the average ramp rate can be further relaxed, the trade-off between load-following deviation and transient efficiency loss is nonlinear. for the ramp up process, the single-objective optimization is sufficient to maximize the efficiency since minimal deviation from the desired ramprate is automatically achieved.

\subsection{Conclusion}

The HP drum fatigue damage is estimated by considering the through-wall temperature transients and thermo-mechanical stress evolutions in the HP drum. Multiple locations at the drumdowncomer junction are monitored and the most stressed part is identified as the constraint in the dynamic optimization of the load-following operation.

It was observed that the maximum circumferential stress amplitude occurs at the edge of the drum/downcomer junction. The spray flow rate at HP SH2/RH ATT can be optimized to not only satisfy the saturation constraint of the main and reheat steam temperature but also to achieve a higher efficiency than the traditional coordinated control system.

Several sensitivity studies were conducted by ramping down the load from $100 \%$ to $25 \%$ then back to $100 \%$ at a desired average ramprate of $5 \%$ load change per minute. When the stress constraint 
is not considered, dynamic optimization lead to about $1.4 \%$ and $1.1 \%$ improvements in time average efficiency for ramp-down and ramp-up respectively compared to the conventional linear profile. Sensitivities to a number of upper and lower bounds on stress constraints were evaluated where ramprate relaxation was not required for satisfying stress constraints. While ramping down, dynamic optimization lead to about a $1 \%$ improvement in time average thermal efficiency compared to the linear profile even if the stress upper bound was set at the same value as the linear profile. When the stress upper bound was changed from $200 \mathrm{MPa}$ to $175 \mathrm{MPa}$, optimal time average thermal efficiency dropped by about $1.7 \%$ during ramping down. While ramping up, optimization also lead to about a $1 \%$ improvement in time average thermal efficiency compared to that using the linear profile, even though the lower bound of stress is same to that reached by the linear profile. When the stress upper bound was changed from -95 MPa to -70 MPa, optimal time average thermal efficiency dropped by about $0.3 \%$ during ramping up. Sensitivity studies were also conducted by tightening stress constraints further when the multi-objective optimization problem was solved while ramping down to minimize relaxation in the stress constraint while maximizing efficiency. It was observed that relaxing the ramprate more than the minimum lead to an increase in the time average efficiency. While ramping up, it was observed that as the lower bound on stress is increased beyond a threshold, the minimum relaxation in the ramprate kept increasing and the time average thermal efficiency kept dropping. Compared to the case when the stress lower bound was -70 MPa, where no relaxation was needed, the time average efficiency was $0.3 \%$ lower for the case when the stress lower bound was $-60 \mathrm{MPa}$, where the minimum ramprate relaxation was about $0.7 \%$.

The study shows that the industry standard linear profile can not only lead to lower efficiency but can violate the stress constraints depending on the desired ramprate as well as upper and lower bounds on the constraints. The multi-objective dynamic optimization approach can play a critical role for load trajectory optimization not only for maximizing efficiency during load-following but also for avoiding violation of stress constraints at critical locations and for avoiding spraying to saturation. The study also shows that there is strong tradeoff between the relaxation in ramprate and the time- average thermal efficiency. 


\section{Chapter 5. Optimal load-following of NGCC plant with stress monitoring of both HP drum and superheater/reheater}

\subsection{Literature review}

Besides the thick-walled HP drum, superheater (SH) and reheater $(\mathrm{RH})$ are also the vulnerable components in NGCC plant under the load-following. Both SH and RH sections are particularly susceptible to overheating during part load operation (Modliński et al., 2019; Jackson et al., 2019). The creep rupture failure of $\mathrm{SH} / \mathrm{RH}$ tubes caused by overheating is a major cause of forced outages of power plants (Viswanathan et al., 2014). This would be expected by looking at the creep rupture data shown in Appendix B for a typical material of construction for SH/RH tubes (Bendick et al., 2010). As the temperature keep increasing, the expected rupture time can reduce considerably even at a lower stress magnitude. In order to avoid overheating and resulting creep rupture in the $\mathrm{SH} / \mathrm{RH}$, it is crucial to maintain the final main/reheat steam temperature during load-following.

The cracking of SH headers at ligament locations (header-tube junctions) caused by severe temperature fluctuation and thermal transient is another important issue for fossil power plants. Brevus et al. (2014) evaluated the probability of fracture for the superheater collector by considering the shape factor and fatigue crack depth on the inner surface. The stress calculation of SH header with tube holes is required for the development of fatigue crack model. One way is using a stress transfer function (Chen et al., 1993; Rosario et al., 1995). It can convert measured temperatures, pressures and flowrates into stresses without a thermo-mechanical stress model. Another approach is through development of detailed finite element method (FEM) model of thermo-mechanical stress distribution in the SH header with tube holes (Mukhopadhyay et al., 2001; Kwon et al., 2006; Yasniy et al., 2016 and 2017). The first approach is unit dependent and large amount of operating data are required to determine the transfer function parameters. The FEM models show the high accuracy in stress analysis, but they are computationally expensive and intractable for the dynamic optimization of the plant operation. Therefore, the similar stress calculation approach for drum-downcomer junction shown in Chapter 4 would be used for SH/RH header-tube junction.

In the literature, ligament cracking in superheater headers is either associated with thermal transients that occur during startup/ shutdown (Rosario et al., 1995) or under the fluctuations at steady state operation (Kwon et al., 2006; Yasniy et al., 2016 and 2017). Few works in the literature 
on the effect of load-following operation on the SH section. Madejski and Taler (2013) conducted a thermo-mechanical stress analysis of the superheater tubes under transient operation. It was observed that a large amount of spray in the attemperator can lead to high stress variation in superheater section due to fast steam cooling. Therefore, the impact of steam attemperation under the fast load-following on the SH/RH fatigue cracking should be further investigated.

In this chapter, $\mathrm{SH} / \mathrm{RH}$ transient performances under the load-following operation are evaluated. Multiple location in SH/RH sections are monitored and the most stressed location is identified. Dynamic optimization of the load-following operation under plant-wide equipment stress constraints, including drum and SH/RH stress constraints, is formulated. Transient responses of the optimal load-following processes under different stress constraints are investigated and compared with the conventional linear operation using coordinated control system (CCS).

\section{2. $\quad \mathrm{SH} / \mathrm{RH}$ geometry and stress monitoring location}

\subsubsection{SH/RH geometry}

Table 1 lists the SH/RH geometry and material. Grade 91 steel (SA-213 T-91) is widely used for the high temperature components of boiler, such as HP SH and IP RH (Bendick et al., 2010). The SH/RH wall thickness is also determined using EN 12952-3 Standard (2011) with consideration of internal pressure, equipment geometry as well as material properties. Due to the higher operating pressure, HP SH section has a larger wall thickness, which leads to higher thermal stress.

Table 5. 1. HP SH/IP RH geometry and material

\begin{tabular}{|c|c|c|c|}
\hline & Outer Diameter(mm) & Wall Thickness $(\mathrm{mm})$ & Material \\
\hline HP SH Tube A/B & 38 & $\mathbf{5 . 0 8}$ & SA-213 T-91 \\
\hline HP SH Header A/B & 216 & $\mathbf{4 4 . 4 5}$ & SA-335 P-91 \\
\hline IP RH Tube A/B & 51 & 3.05 & SA-213 T-91 \\
\hline IP RH Header A/B & 324 & 21.44 & SA-335 P-91 \\
\hline
\end{tabular}

\subsubsection{SH/RH junction stress monitoring under the load-following operation}

Due to the stress concentration caused by component discontinuity, SH/RH header-tube junctions experience much higher stress variation than $\mathrm{SH} / \mathrm{RH}$ tubes under the load-following operation. Two specific locations on the edge of header-tube joint are considered. As shown in Figure 5.1, 
Position A is located in the axial direction of header and Position B is located in the tangential direction. The details about the header-tube junction stress calculation have been discussed in previous Section 4.2.3

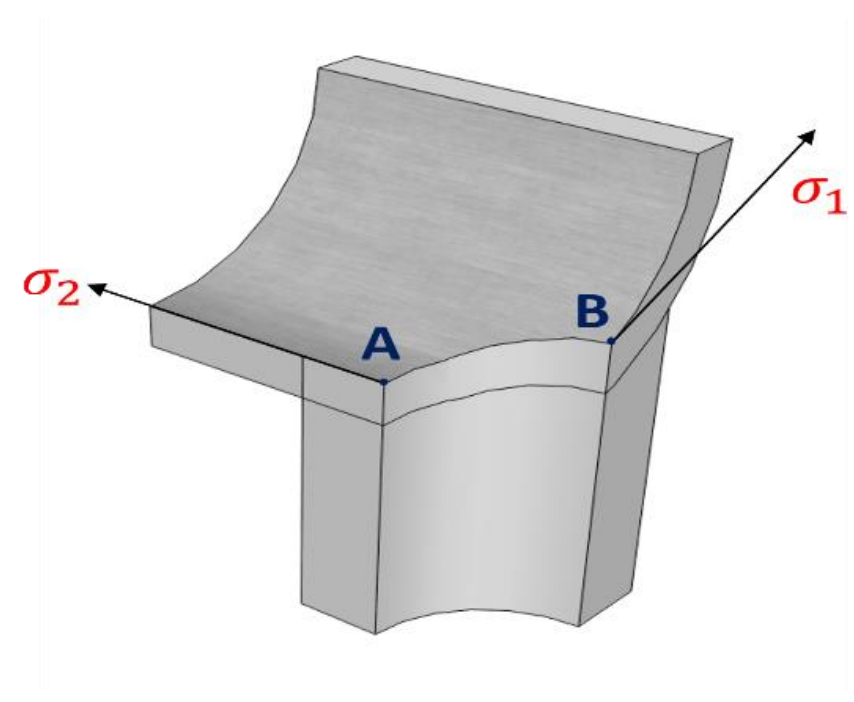

Figure 5. 1 Schematic of SH/RH header-tube junction

Also, NGCC plant with two-stage attemperation and parallel configuration of the $\mathrm{SH}$ and $\mathrm{RH}$ is adopted for load-following operation and $\mathrm{SH} / \mathrm{RH}$ stress analysis. As shown in Figure 5.2, the transient response of SH/RH header-tube junction at eight locations of HRSG are monitored for the equipment health analysis.

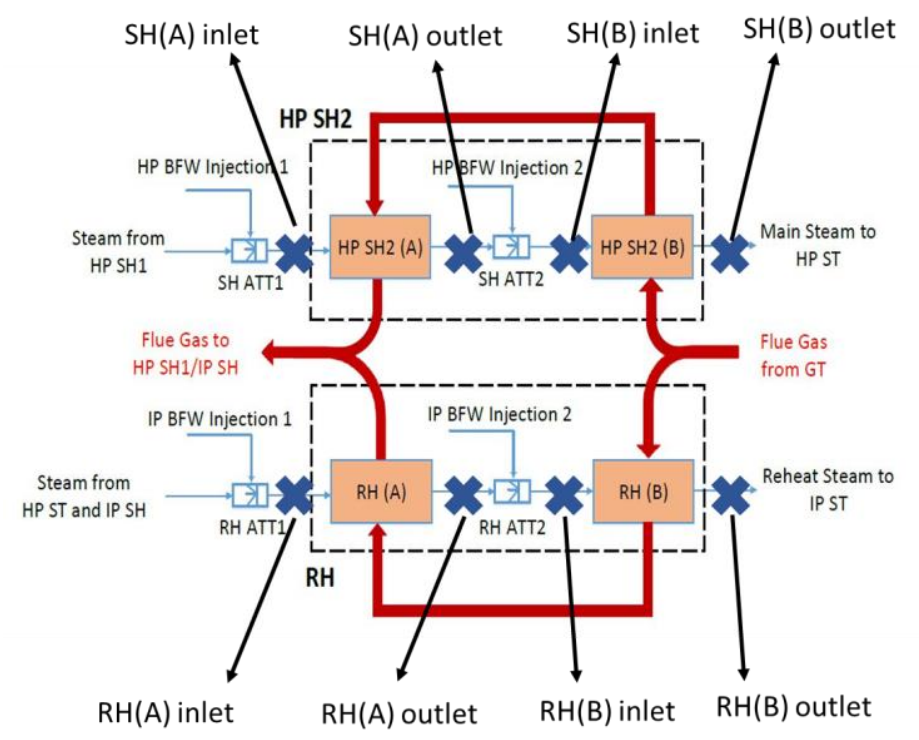

Figure 5. 2. Different locations for SH/RH head-tube junction stress monitoring 
Similar to Chapter 4, following load following operation is simulated for the results presented below. The plant load starts ramping down at $1 \mathrm{st} \mathrm{hr}$ from $100 \%$ to $25 \%$ at $5 \%$ load change per min, stays at $25 \%$ load for $4 \mathrm{hr} 45 \mathrm{~min}$, then ramps up to $100 \%$ at a constant ramp rate of $5 \%$ load change per min. The total simulation time is $12 \mathrm{hr}$. The ramp operation mimics a situation where the fossil-fired power load is brought to the minimum load when solar energy becomes available and then rises back up again as the solar energy becomes unavailable. Obviously, how long the plant stays at the lowest load will depend on a specific region and a particular day, but the transients of interest mainly takes place during ramp up and down as shown in the following study.

The typical linear operation using industrial coordinate control system (CCS) is denoted as 'Linear' in the results presented below. The results from the dynamic optimization is denoted as 'Optimal'. In the 'Linear' operation, the ramprate is constant, (i.e. linear) and due to the sliding pressure operation of the plant, the pressure decreases with the decrease in the load or vice versa during the increase in load.

\subsection{Dynamic optimization}

Since the SH/RH header-tube junction stress at different locations are monitored under the loadfollowing, all the locations with large stress amplitude leading to fatigue damage can be identified. Then stress constraints of $\mathrm{SH}$ and $\mathrm{RH}$ at one or more vulnerable locations are added into the dynamic optimization formulation shown in Chapter 4 to generate a new dynamic optimization problem with plant-wide equipment stress constraints.

In Equation 5.1, the objective and most of constraints are the same with those in Equation 4.28. Seventh and eighth constraints denote the $\mathrm{SH}$ and $\mathrm{RH}$ header-tube junction stresses.

$$
\begin{gathered}
\max _{u} \frac{\int_{t_{\text {ini }}}^{t_{f i n}} \eta_{t h} d t}{t_{f i n}-t_{\text {ini }}} \\
\text { s.t. } f(x, y, u) \leq 0 \quad x, y, u \in R^{n} \\
T_{s p, M S}-\Delta T_{M S} \leq T_{M S} \leq T_{s p, M S}+\Delta T_{M S} \\
T_{s p, R S}-\Delta T_{R S} \leq T_{R S} \leq T_{s p, R S}+\Delta T_{R S} \\
T_{S H, i} \geq T_{d e w, S H, i}+\Delta T_{d e w, S H} \\
T_{R H, i} \geq T_{d e w, R H, i}+\Delta T_{d e w, R H} \\
\sigma_{\text {drum,lower }} \leq \max _{\text {amp }}\left(\sigma_{H P} \text { drum }\right) \leq \sigma_{\text {drum,upper }}
\end{gathered}
$$




$$
\begin{aligned}
& \sigma_{S H, l o w e r} \leq \max _{a m p}\left(\sigma_{S H}\right) \leq \sigma_{S H, u p p e r} \\
& \sigma_{R H, l o w e r} \leq \max _{a m p}\left(\sigma_{R H}\right) \leq \sigma_{R H, \text { upper }} \\
& \frac{n \% \text { load } \text { change }_{\text {desired }}}{\min }-\Delta \text { ramprate }_{\text {lower }} \leq \text { ramprate }_{\text {ave }} \leq \frac{n \% \text { load }_{\text {change }} \text { desired }}{\min } \\
& \operatorname{Load}\left(t=t_{\text {fin }}\right)=\operatorname{Load}_{\text {desired }}\left(t=t_{\text {fin }}\right)
\end{aligned}
$$

where $\sigma$ is the stress at the junction part, ' $S H$ ' and ' $R H$ ' denote superheater and reheater section, respectively.

Similar to Chapter 4, a multi-objective optimization is also formulated by appending SH and RH header-tube junction stresses to the Lexicographic optimization approach for cases when the ramp rate needs to be relaxed.

Stage 1 optimization:

$$
\begin{aligned}
& \min _{u} \Delta \text { ramprate }_{\text {lower }} \\
& \text { s.t. } f(x, y, u) \leq 0 \quad x, y, u \in R^{n} \\
& T_{s p, M S}-\Delta T_{M S} \leq T_{M S} \leq T_{s p, M S}+\Delta T_{M S} \\
& T_{s p, R S}-\Delta T_{R S} \leq T_{R S} \leq T_{s p, R S}+\Delta T_{R S} \\
& T_{S H, i} \geq T_{\text {dew }, S H, i}+\Delta T_{\text {dew }, S H} \\
& T_{R H, i} \geq T_{\text {dew }, R H, i}+\Delta T_{\text {dew }, R H} \\
& \sigma_{\text {drum,lower }} \leq \max _{a m p}\left(\sigma_{H P \text { drum }}\right) \leq \sigma_{\text {drum,upper }} \\
& \sigma_{S H, \text { lower }} \leq \max _{a m p}\left(\sigma_{S H}\right) \leq \sigma_{S H, \text { upper }} \\
& \sigma_{R H, \text { lower }} \leq \max _{a m p}\left(\sigma_{R H}\right) \leq \sigma_{R H, \text { upper }} \\
& \frac{n \% \text { load } \text { change }_{\text {desired }}}{\min }-\Delta \text { ramprate }_{\text {lower }} \leq \text { ramprate }_{\text {ave }} \leq \frac{n \% \text { load }_{\text {change }}}{\text { desired }} \\
& \operatorname{Load}\left(t=t_{\text {fin }}\right)=\operatorname{Load}_{\text {desired }}\left(t=t_{\text {fin }}\right)
\end{aligned}
$$

Stage 2 optimization:

$$
\max _{u} \frac{\int_{t_{i i n}}^{t_{f i n}} \eta_{t h} d t}{t_{f i n}-t_{i n i}}
$$

s.t. $f(x, y, u) \leq 0 \quad x, y, u \in R^{n}$

$$
\begin{gathered}
T_{s p, M S}-\Delta T_{M S} \leq T_{M S} \leq T_{s p, M S}+\Delta T_{M S} \\
T_{s p, R S}-\Delta T_{R S} \leq T_{R S} \leq T_{s p, R S}+\Delta T_{R S}
\end{gathered}
$$




$$
\begin{gathered}
T_{S H, i} \geq T_{\text {dew }, S H, i}+\Delta T_{\text {dew }, S H} \\
T_{R H, i} \geq T_{\text {dew }, R H, i}+\Delta T_{\text {dew }, R H} \\
\sigma_{\text {drum,lower }} \leq \max _{\text {amp }}\left(\sigma_{H P \text { drum }}\right) \leq \sigma_{\text {drum }, \text { upper }} \\
\sigma_{S H, \text { lower }} \leq \max _{\text {amp }}\left(\sigma_{S H}\right) \leq \sigma_{S H, \text { upper }} \\
\sigma_{R H, \text { lower }} \leq \max _{\text {amp }}\left(\sigma_{R H}\right) \leq \sigma_{R H, \text { upper }} \\
\frac{n \% \text { load change } \text { desired }_{\text {min }}-\Delta \text { ramprate } \text { lower }, \text { min }_{\text {min }} \leq \text { ramprate }_{\text {ave }} \leq \frac{n \% \text { load change }}{\text { desired }}}{\text { min }} \\
\text { Load }\left(t=t_{\text {fin }}\right)=\operatorname{Load}_{\text {desired }}\left(t=t_{\text {fin }}\right)
\end{gathered}
$$

\subsection{Results and discussion}

\subsubsection{Optimal process under a constant average ramp rate neglecting stress constraint}

In this section, the results of $\mathrm{SH} / \mathrm{RH}$ from the dynamic optimization are generated by neglecting all stress constraints. For the conventional linear load-following approach, the constraints including the $\mathrm{SH} / \mathrm{RH}$ steam temperature while avoiding spraying to saturation could be satisfied as well. We found that dynamic optimization leads to a higher thermal efficiency than the linear operation mainly due to less total spray at attemperator (ATT). Here, only stress amplitudes of $\mathrm{SH} / \mathrm{RH}$ header-tube junctions are summarized in Table 5.2.

Table 5.2 shows that due to the large wall thickness and thermal stress, $\mathrm{SH}$ sections generally experience larger stress amplitude than RH sections. Specifically, since large amount of spray is used at ATT located at the inlet of SH, the header-tube junctions at $\mathrm{SH}$ inlets are the most stressed components. On the other hand, since the final steam temperature are well maintained, the SH(B) outlet experiences the small stress amplitude, which is mainly subjected to mechanical stress. Unlike the drum, both Positions A and B at header-tube junction can be vulnerable one depending on whether the thermal stress is intensified or compensated by mechanical stress.

Figure 5.3(a) shows that the profile of $\mathrm{SH}(\mathrm{A})$ inlet steam temperature under dynamic optimization is considerably different compared to the linear operation. In fact, the $\mathrm{SH}(\mathrm{A})$ inlet steam temperature rises slightly under dynamic optimization instead of decreasing as observed in the linear operation. As a result, the SH(A) inlet experiences smaller stress amplitude for dynamic optimization as shown in Figure 5.3 (c) and (d). Figure 5.3(b) compares the steam pressure profile 
between the linear and optimal load-following. It is observed that during low load, the steam pressure is slightly higher under dynamic optimization.

Table 5. 2. Stress at SH/RH header-tube junction under load-following

\begin{tabular}{|c|c|c|c|c|}
\hline & \multicolumn{2}{|c|}{$\begin{array}{c}\text { Linear operation } \\
\text { using CCS }\end{array}$} & \multicolumn{2}{c|}{$\begin{array}{c}\text { Dynamic optimization } \\
\text { without stress constraint }\end{array}$} \\
\hline & $\begin{array}{c}\text { max }\left(\sigma_{a m p}\right) \\
(\mathrm{MPa})\end{array}$ & Most stressed part & $\begin{array}{c}\max \left(\sigma_{a m p}\right) \\
(\mathrm{MPa})\end{array}$ & Most stressed part \\
\hline RH(A) inlet & 108 & Position B & 53 & Position A \\
\hline RH(A) outlet & 64 & Position A & 68 & Position A \\
\hline RH(B) inlet & 189 & Position B & 223 & Position B \\
\hline RH(B) outlet & 36 & Position A & 30 & Position A \\
\hline SH(A) inlet & $\mathbf{3 6 9}$ & Position B & 221 & Position A \\
\hline SH(A) outlet & 174 & Position A & 211 & Position B \\
\hline SH(B) inlet & $\mathbf{5 5 1}$ & Position B & $\mathbf{5 9 5}$ & Position B \\
\hline SH(B) outlet & 52 & Position A & 46 & Position A \\
\hline
\end{tabular}

It should be noted that $\mathrm{SH}(\mathrm{A})$ inlet steam temperature shows an initial overshoot under dynamic optimization as the load is ramped up as shown in Figure 5.3(a). The main reason for this is due to the considerably faster dynamics of GT compared to the steam cycle. As the load is ramped up, the temperature of flue gas going through final $\mathrm{SH}(\mathrm{B})$ rises fast compared to the slow rise in the steam flowrate due to the large thermal holdup of the tubes and other solids. It should be noted that even though the steam temperature at the inlet of $\mathrm{SH}(\mathrm{A})$ rises, it still remains lower than the limiting temperature of $850 \mathrm{~K}$ for the corresponding materials of construction (MOC).

Figure 5.4 (a) and (b) show that there is slightly lesser change in the steam temperature and pressure at $\mathrm{SH}(\mathrm{B})$ inlet due to dynamic optimization. Figure 3(c) and (d) show that the there is only a minor difference in the stress profile between the linear approach and dynamic optimization for all locations evaluated.

Table 5.3 shows the maximum and minimum stress as well as stress amplitude under linear operation and dynamic optimization both at $\mathrm{SH}(\mathrm{A})$ and $\mathrm{SH}(\mathrm{B})$ inlet for position $\mathrm{A}$ and $\mathrm{B}$ at the header/tube junction. It shows that while the header-tube junctions at the inlet of $\mathrm{SH}(\mathrm{A})$ experiences lower stress under dynamic optimization, header-tube junctions at $\mathrm{SH}(\mathrm{B})$ inlet experiences higher stress. It can be noted that for the study presented in this section no constraint with respect to stress is considered in the dynamic optimization. 


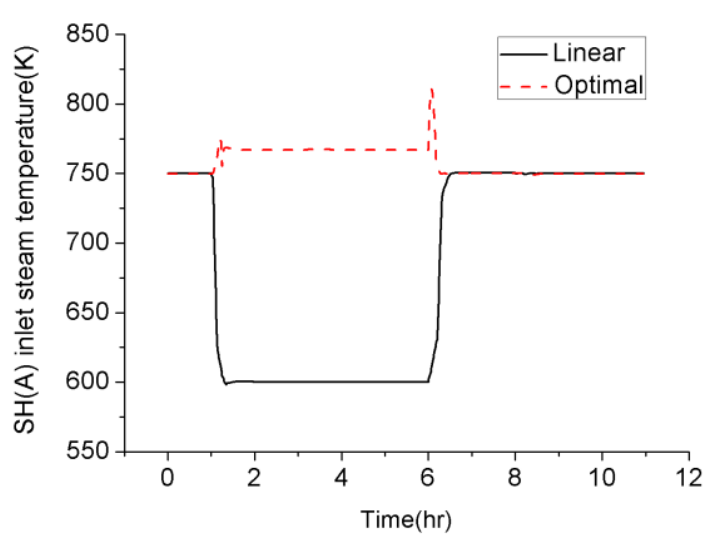

(b)

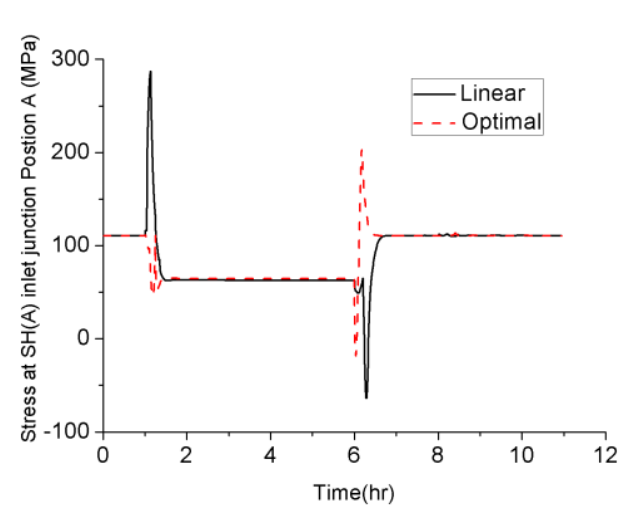

(c)

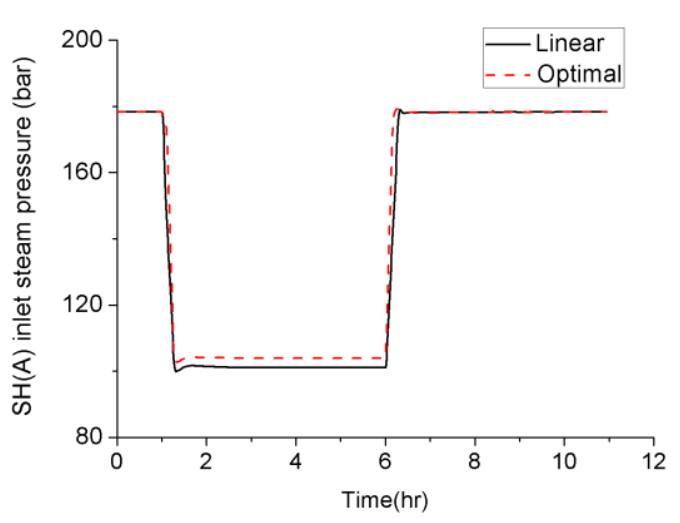

(b)

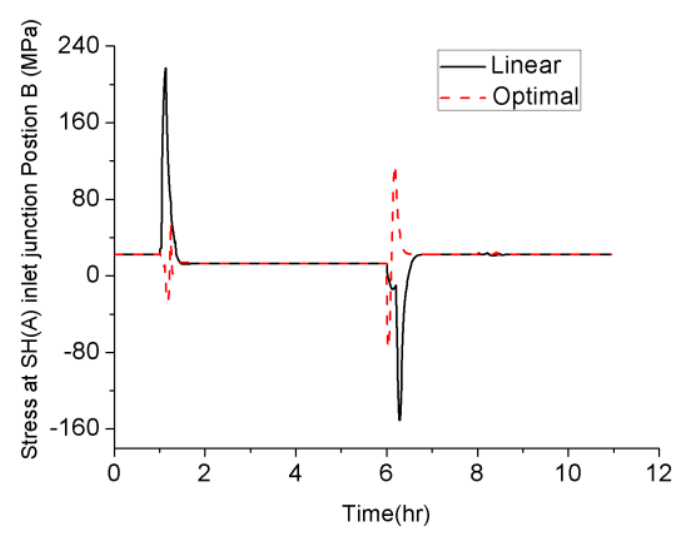

(d)

Figure 5. 3. SH(A) inlet performance under the load-following (a) steam temperature (b) steam pressure (c) stress at Position A of junction(d) stress at Position B of junction

Table 5. 3. Maximum and minimum Stress and stress amplitude at SH inlet headertube junction under load-following

\begin{tabular}{|c|c|c|c|c|c|}
\hline & & \multicolumn{2}{|c|}{$\begin{array}{c}\text { Linear operation } \\
\text { using CCS }\end{array}$} & \multicolumn{2}{c|}{$\begin{array}{c}\text { Dynamic optimization } \\
\text { without stress constraint }\end{array}$} \\
\hline & $\sigma(\mathrm{MPa})$ & Position A & Position B & Position A & Position B \\
\hline \multirow{3}{*}{ SH (A) inlet } & $\sigma_{\max }$ & 287 & 217 & 203 & 115 \\
\cline { 2 - 6 } & $\sigma_{\min }$ & -64 & -151 & -18 & -75 \\
\cline { 2 - 6 } & $\sigma_{a \operatorname{mp}}$ & 351 & $\mathbf{3 6 9}$ & $\mathbf{2 2 1}$ & 190 \\
\hline \multirow{3}{*}{ SH (B) inlet } & $\sigma_{\max }$ & 380 & 327 & 386 & 333 \\
\cline { 2 - 6 } & $\sigma_{\min }$ & -162 & -223 & -197 & -262 \\
\cline { 2 - 6 } & $\sigma_{\text {amp }}$ & 542 & $\mathbf{5 5 1}$ & 583 & $\mathbf{5 9 5}$ \\
\hline
\end{tabular}




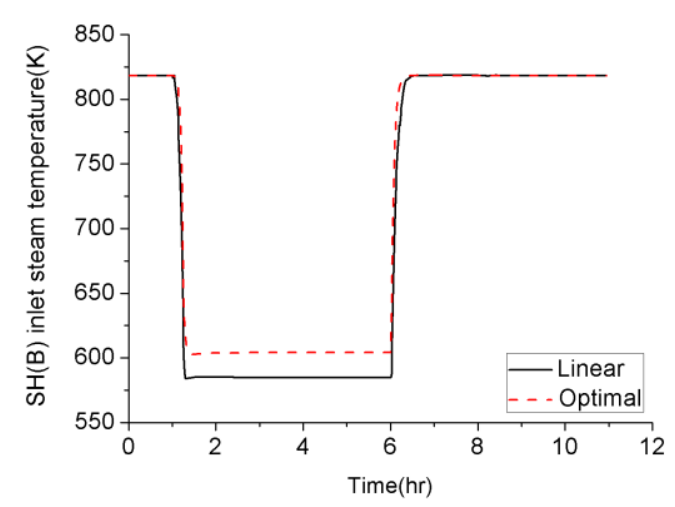

(a)

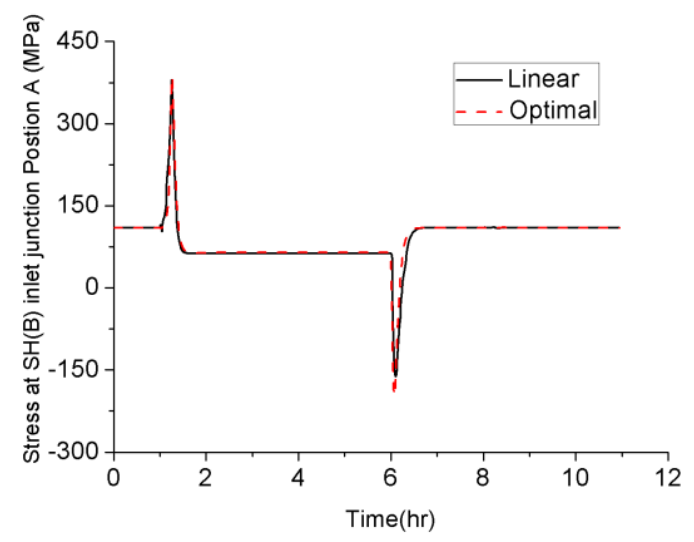

(c)

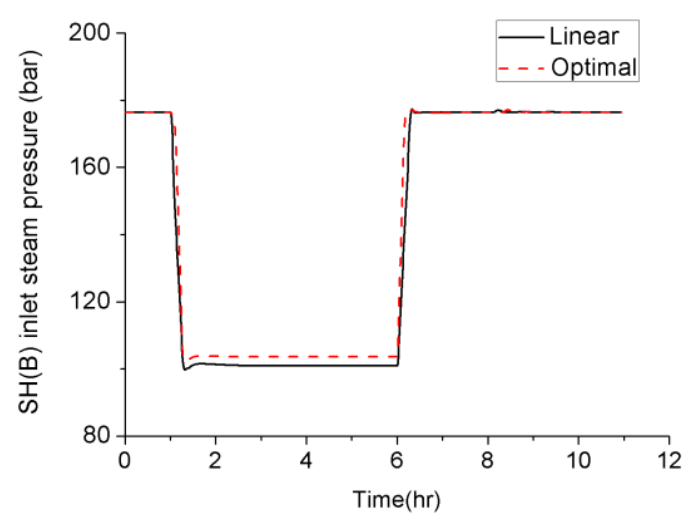

(b)

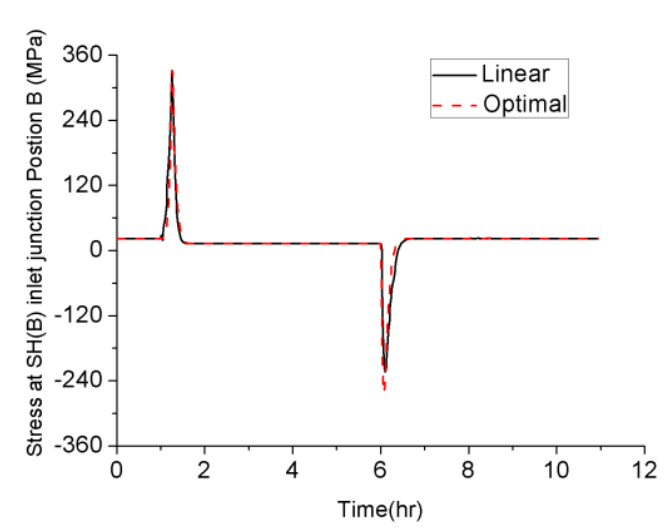

(d)

Figure 5. 4. SH(B) inlet performance under the load-following (a) steam temperature (b) steam pressure (c) stress at Position A of junction(d) stress at Position B of junction

\subsubsection{Optimal process when the drum stresses are limiting}

The results presented in this subsection correspond to the cases when the drum stress is limiting, i.e. those presented in Section 4.4.2. As presented earlier, as the stress upper and lower limits are tightened, relaxing the ramp rate becomes necessary for satisfying the stress constraints. The most stressed SH part at the SH(B) inlet junction Position B is evaluated. Therefore, results are presented only for that location.

\section{Optimal ramp-down process with different stress constraints}


Figure 5.5 (a), (b) and (c) show the linear and optimal profiles of plant power, $\mathrm{SH}(\mathrm{B})$ inlet steam temperature and stress at junction Position B, respectively, under ramp down operation. For the linear profile, the maximum drum stress reached is $191 \mathrm{MPa}$, while for dynamic optimization, following drum stress limits are considered: 200, 191, 175, and $165 \mathrm{MPa}$. It can be noted that when the drum stress limit is set to $165 \mathrm{MPa}$, ramp rate relaxation becomes necessary. It can be observed that there is considerable difference in the steam temperature profiles and stress profiles at $\mathrm{SH}(\mathrm{B})$ inlet between the linear and optimal profiles and among the optimal profiles depending on the drum stress limit.

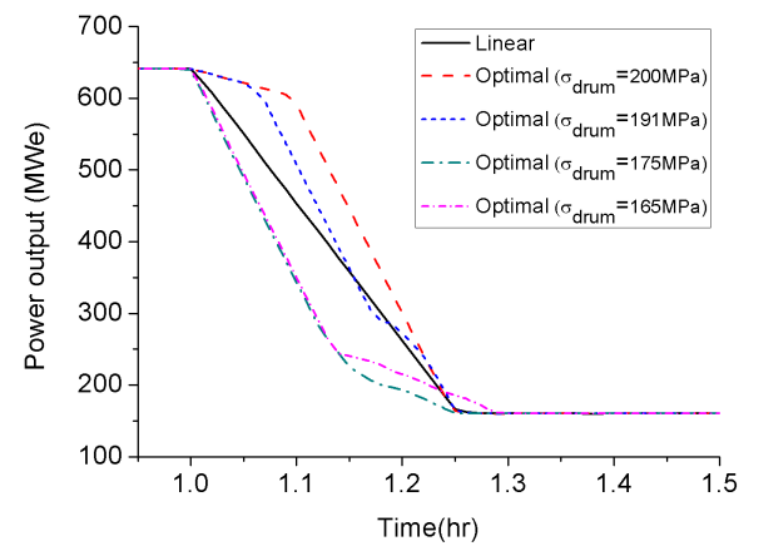

(a)

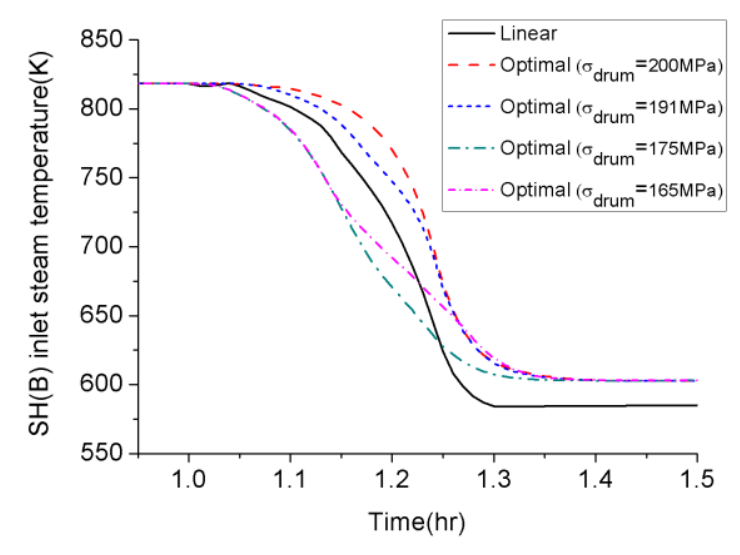

(b)

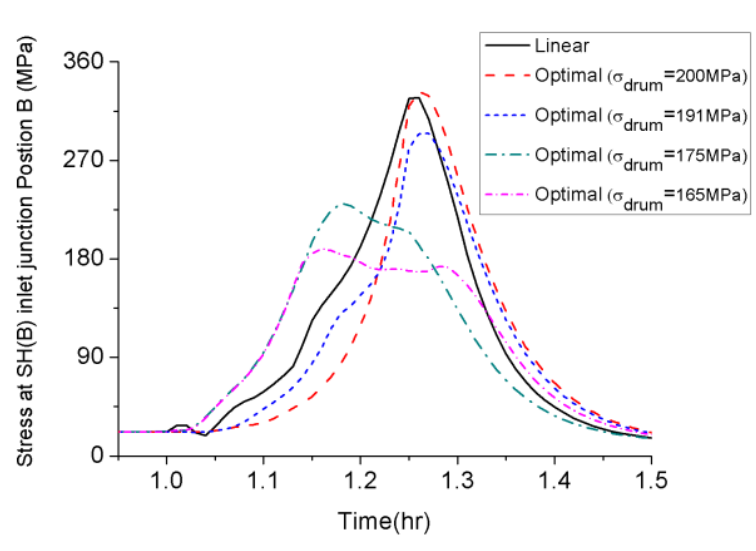

(c)

Figure 5. 5. Linear and optimal profiles under different drum stress constraints for $\mathbf{5 \%}$ average ramp down in load per min: (a) power output, (b) $\mathrm{SH}(\mathrm{B})$ inlet steam temperature, (c) stress at SH(B) inlet junction Position B 
Figure 5.5(c) shows that the linear operation leads to the similar stress magnitude at $\mathrm{SH}(\mathrm{B})$ inlet junction as the optimal case with maximum drum stress upper bound. When the drum stress upper bound keeps decreasing, the maximum stress at $\mathrm{SH}(\mathrm{B})$ inlet junction decreases. In fact, the stress evolution depends on the load transition. Figure 5.5 (a) and (b) indicate that no matter the average ramprate is fixed or relaxed, when the real-time ramp rate is higher, the steam temperature transient is more aggressive. Correspondingly, the stress at the junction rises more quickly since the larger thermal stress is induced by the larger temperature gradient.

Table 5.4 lists the maximum stress magnitude at $\mathrm{SH}(\mathrm{B})$ inlet junction under the different drum stress upper bounds. It can be observed in Table 5.4 and Figure 5.5(c) that as the maximum drum stress is lowered, it also leads to lower maximum stress at the $\mathrm{SH}(\mathrm{B})$ inlet junction. It can be noted that depending on the upper stress bound of $\mathrm{SH}(\mathrm{B})$ inlet junction, it can be the limiting stress during load-following operation. This aspect is evaluated in the following sections.

Table 5. 4. SH inlet header-tube junction stress under different ramp-down processes

\begin{tabular}{|c|c|c|c|c|c|}
\hline & Linear & \multicolumn{4}{|c|}{ Optimal } \\
\hline Drum stress upper bound (MPa) & 191 & 200 & 191 & 175 & 165 \\
\hline Maximum stress at SH(B) inlet junction $(\mathrm{MPa})$ & 327 & 333 & 295 & 231 & 189 \\
\hline
\end{tabular}

\section{Optimal ramp-up process with different stress constraints}

Figures 5.6 (a), (b) and (c) show the linear and optimal profiles of plant power, SH(B) inlet steam temperature and stress at junction Position B, respectively, under ramp up operation. It can be observed that while there are considerable differences in the $\mathrm{SH}(\mathrm{B})$ inlet temperature between the linear and optimal profiles, there is not much differences in the $\mathrm{SH}(\mathrm{B})$ inlet temperature profiles under dynamic optimization for all drum stress bounds that are evaluated. As a result, there is not much difference in the stress profiles under dynamic optimization as seen in Figure 5.6(c). However, it is interesting to note that the dynamic optimization when the drum stress is limiting, it also led to a much lower value of stress compared to the linear operation.

Table 5.5 lists the minimum stress (i.e. maximum magnitude of compressive stress) at SH(B) inlet junction under linear operation and under different drum stress lower bounds. As the stress is compressive, the high magnitude is not acceptable. Therefore, it is important to consider the SH(B) inlet junction stress constraint for optimizing the ramp-up operation. 


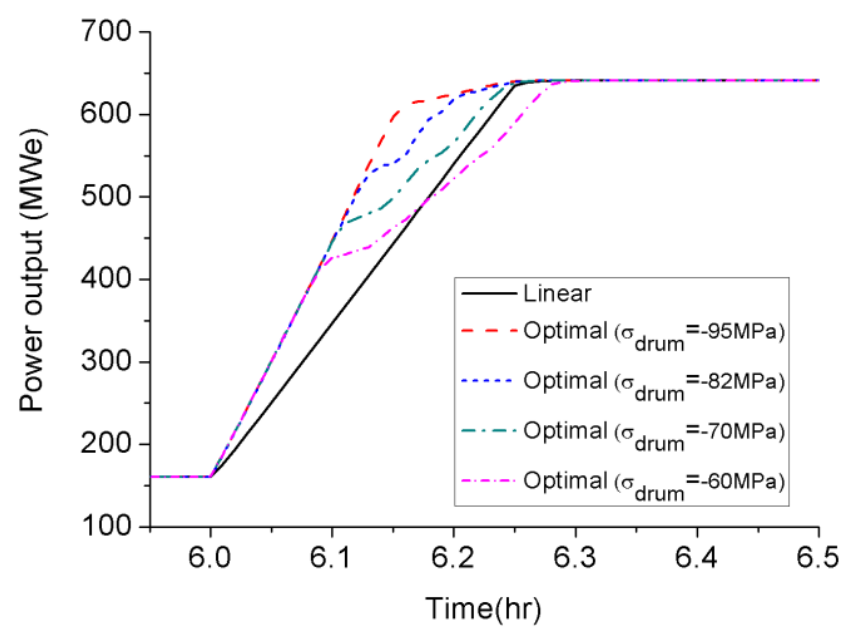

(a)

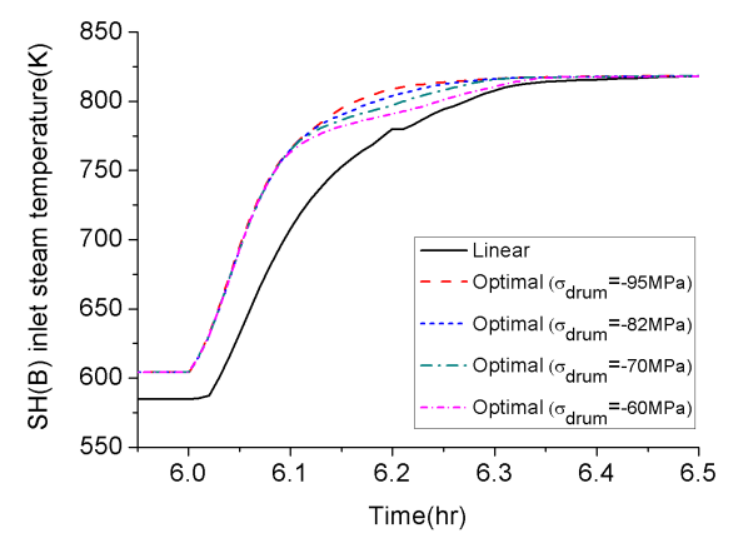

(b)

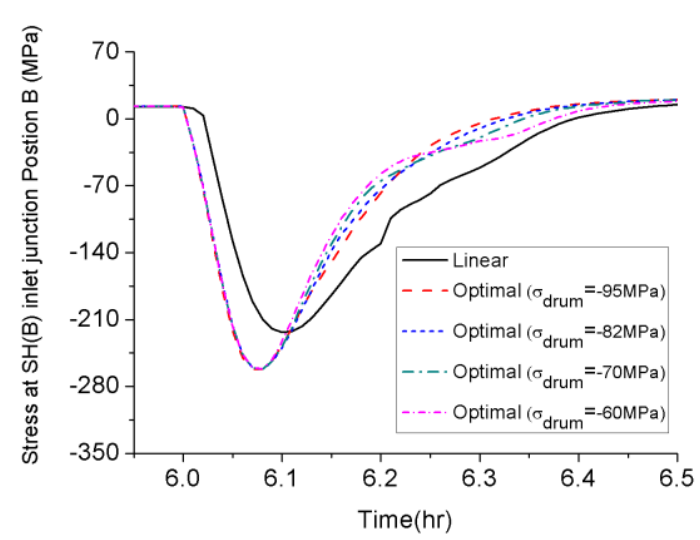

(c)

Figure 5. 6. Comparison of linear and optimal profiles under different drum stress constraints for $5 \%$ average ramp up in load per min: (a) power output, (b) $\mathrm{SH}(\mathrm{B})$ inlet steam temperature, (c) stress at SH(B) inlet junction Position B

Table 5. 5. SH inlet header-tube junction stress under different ramp-up processes

\begin{tabular}{|c|c|c|c|c|c|}
\hline & Linear & \multicolumn{4}{|c|}{ Optimal } \\
\hline Drum stress lower bound (MPa) & -82 & -95 & -82 & -70 & -60 \\
\hline Minimum stress at SH(B) inlet junction (MPa) & -223 & -262 & -262 & -262 & -262 \\
\hline
\end{tabular}




\subsubsection{Optimal operation when the SH stresses are limiting}

The optimal results presented in this section are for the cases when SH stresses are limiting including those when the ramp relaxation may or may not be necessary. It should be noted that when SH constraints are satisfied, RH constraints are also satisfied due to a lesser thermal stress in RH. The linear operation is included for comparison.

\section{Optimal ramp-down process with different stress constraints}

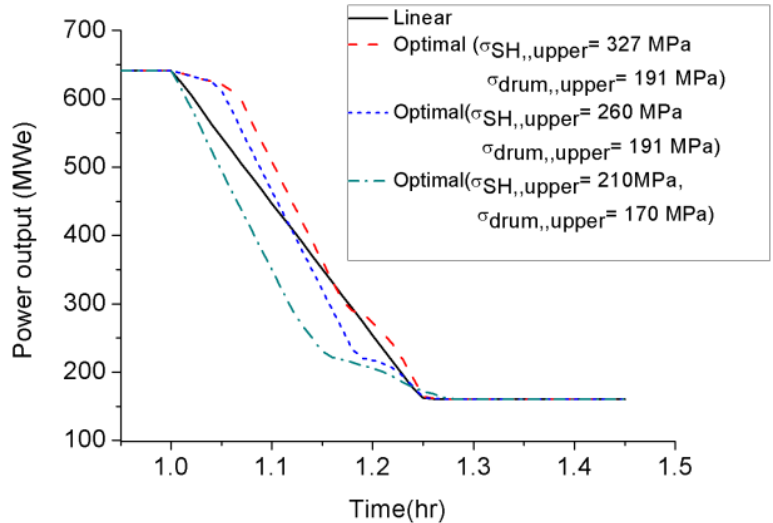

(a)

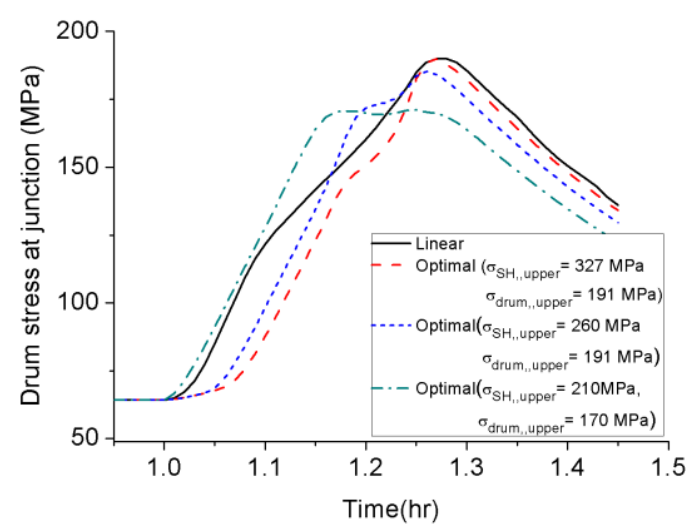

(c)

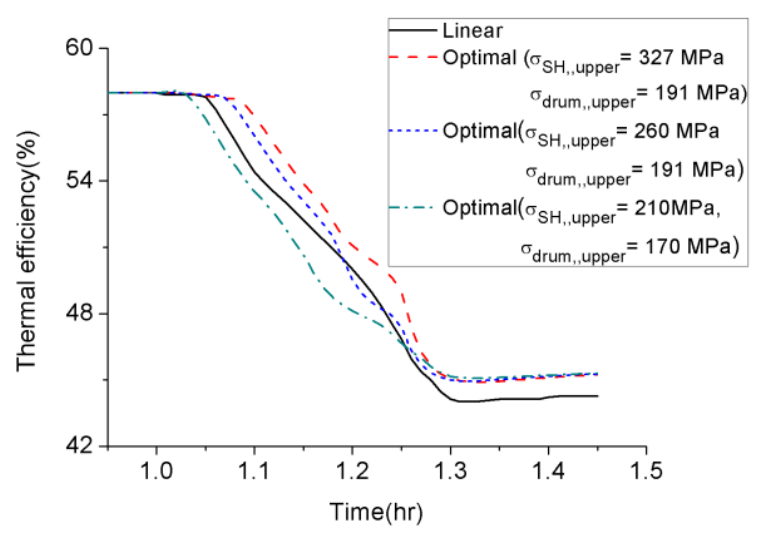

(b)

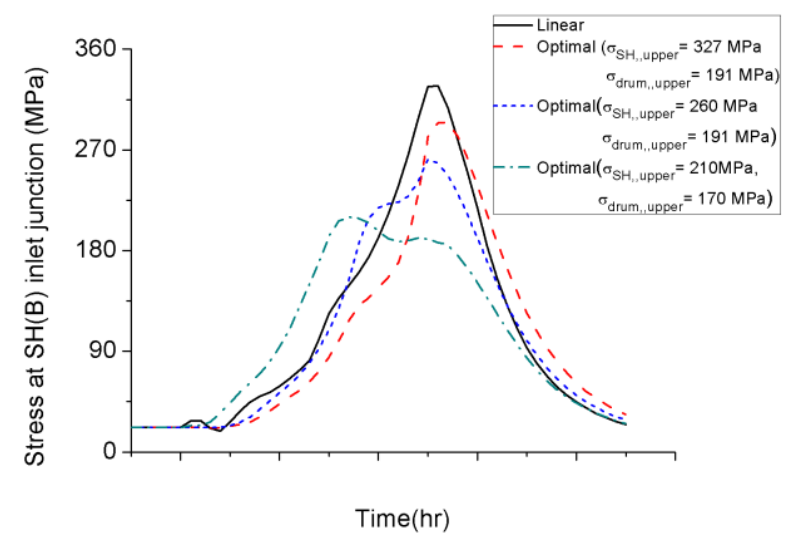

(d)

Figure 5. 7. Linear and optimal profiles under different equipment stress constraints for ramp-down process: (a) power output (b) thermal efficiency (c) stress at HP drum junction Position B (d) stress at SH(B) inlet junction Position B 
Three different optimal cases are simulated here for ramp-down process. In Case 1, the drum and SH stress upper bounds are set to $191 \mathrm{MPa}$ and $327 \mathrm{MPa}$, respectively. The stress bounds are set at the same value as the maximum stress under the linear operation. This case is included here only for comparison of the results. In Case 2, the drum and SH stress upper bounds are set to $191 \mathrm{MPa}$ and $260 \mathrm{MPa}$, respectively. In Case 3, the drum and SH stress upper bounds are set to $170 \mathrm{MPa}$ and $210 \mathrm{MPa}$, respectively. It should be noted that $\mathrm{SH}$ is made from the alloy steel T/P 91 with higher tensile and yield strength than carbon steel SA516 Grade 70 used for drum (Bendick et al., 2010; EPRI, 2005 and 2006). Therefore, stress bounds are higher for the SH materials.

Figure 5.7 (a), (b), (c) and (d) show the linear and optimal profiles of plant power, plant thermal efficiency, stress at drum junction and stress at SH(B) inlet junction, respectively, under ramp down operation for all three cases. Figure 5.7 (a) and (b) show considerable difference in the loadfollowing profiles and thermal efficiency depending on the equipment stress limit. As the drum/SH stress is lowered, it leads to lower thermal efficiency.

Table 5. 6. Comparison of linear and optimal ramp-down profiles under different equipment stress constraints

\begin{tabular}{|c|c|c|c|c|}
\hline & Linear & \multicolumn{3}{|c|}{ Optimal } \\
\hline $\begin{array}{c}\text { Stress upper bound at drum } \\
\text { junction }(\mathrm{MPa})\end{array}$ & $\mathrm{Na}$ & 191 & 191 & 170 \\
\hline $\begin{array}{c}\text { Stress upper bound at } S H(B) \\
\text { inlet junction }(\mathrm{MPa})\end{array}$ & $\mathrm{Na}$ & 327 & 260 & 210 \\
\hline $\begin{array}{l}\text { Time average thermal } \\
\text { efficiency }(\%)\end{array}$ & 50.3 & 51.3 & 50.9 & 50.1 \\
\hline $\begin{array}{l}\text { Maximum stress at drum } \\
\text { junction }(\mathrm{MPa})\end{array}$ & 191 & $\begin{array}{c}191 \\
\text { (active) }\end{array}$ & 186 & $\begin{array}{c}170 \\
\text { (active) }\end{array}$ \\
\hline $\begin{array}{c}\text { Maximum stress at } \mathrm{SH}(\mathrm{B}) \text { inlet } \\
\text { junction }(\mathrm{MPa})\end{array}$ & 327 & 295 & $\begin{array}{c}260 \\
\text { (active) }\end{array}$ & $\begin{array}{c}210 \\
\text { (active) }\end{array}$ \\
\hline $\begin{array}{c}\Delta \text { ramprate } \text { lower } \\
(\% \text { load change/min })\end{array}$ & 0 & 0 & 0 & 0.5 \\
\hline
\end{tabular}

Table 5.6 lists the thermal efficiency and maximum equipment stress magnitude as well as average ramprate relaxation under the different equipment stress upper bound constraints.

For the linear profile, the maximum drum stress is $191 \mathrm{MPa}$ and maximum SH stress is $327 \mathrm{MPa}$. In Case 1 , the drum stress is still limiting and dynamic optimization leads to about $1 \%$ higher efficiency than the linear profile. In Case 2, the SH stress becomes active constraint and leads to a 
lower thermal efficiency than the optimal profile obtained in Case 1, but it is still higher than the linear operation by $0.6 \%$. In Case 3, both drum stress and SH stress become limiting. The thermal efficiency is lower than the linear operation by $0.2 \%$ due to the lower stress upper bound. For this case, even though the ramp rate is high at the beginning of ramp down, the ramprate becomes considerably small towards the end leading to an overall ramprate relaxation of about $0.5 \%$ for satisfying the stress constraints.

\section{Optimal ramp-up process with different stress constraints}

Similar to the ramp-down process, three different optimal cases are simulated here for the rampup. In Case 1, the drum and SH stress lower bounds are set to -82 MPa and -262 MPa, respectively. This case is included here only for comparison as the result under the limiting drum stress. In Case 2, the drum and SH stress lower bounds are set to -82 MPa and -223 MPa, respectively. The stress bounds are set at the same value as the minimum stress under the linear operation. In Case 3, the drum and SH stress lower bounds are set to -82 $\mathrm{MPa}$ and -150 MPa, respectively. Also, stress bounds are lower for the SH materials due to the higher alloy steel strength (Bendick et al., 2010; EPRI, 2005 and 2006).

Figure 5.8 (a), (b), (c) and (d) show the linear and optimal profiles of plant power, plant thermal efficiency, stress at drum junction and stress at $\mathrm{SH}(\mathrm{B})$ inlet junction, respectively, under ramp-up operation for all three cases. Even though the minimum drum stresses (i.e. maximum magnitude of compressive stress) are same for linear and optimal process shown in Figure 5.8 (c), the loadfollowing profiles and corresponding thermal efficiency shown in Figure 5.8 (a) and (b) are varied depending on the different SH stress lower bounds shown in Figure 5.8 (d). As the SH stress lower bound increases, it leads to lower thermal efficiency.

Table 5.7 lists the thermal efficiency and minimum equipment stress as well as average ramprate relaxation under the different equipment stress lower bound constraints.

For the linear profile, the minimum drum stress is $-82 \mathrm{MPa}$ and minimum SH stress is $-223 \mathrm{MPa}$. In Case 1, the drum stress is still limiting and dynamic optimization leads to about $1.3 \%$ higher efficiency than the linear profile. However, the minimum SH stress reaches -262 MPa and it is lower than the linear operation. In Case 2, the SH lower bound of -223 MPa is same as linear operation. Both drum and SH stress constraint are active constraints and lead to a lower thermal 
efficiency than the optimal profile obtained in Case 1, but it's still higher than the linear operation by $0.8 \%$. In Case 3 , both drum stress and SH stress are limiting constraints. Since the SH lower bound increases to $-150 \mathrm{MPa}$, a lower ramprate is required in the early stage of ramp-up process leading to an overall ramprate relaxation of about $0.7 \%$ for satisfying the stress constraints. Also, the thermal efficiency is even lower than the linear operation by $0.1 \%$.

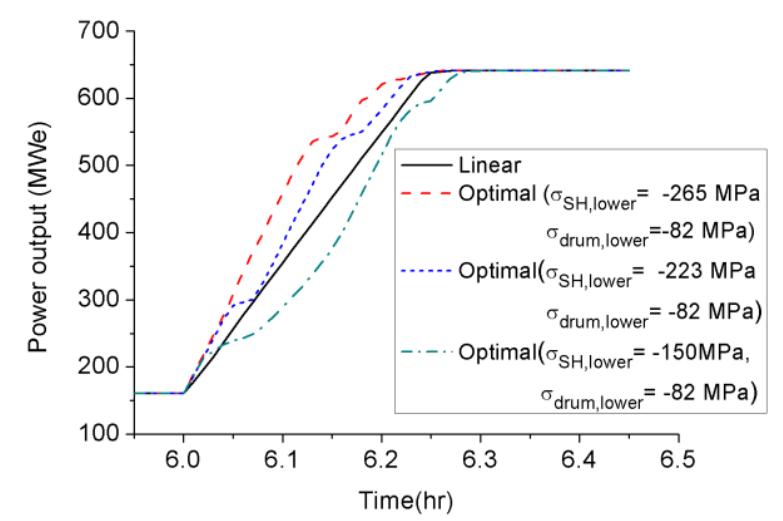

(a)

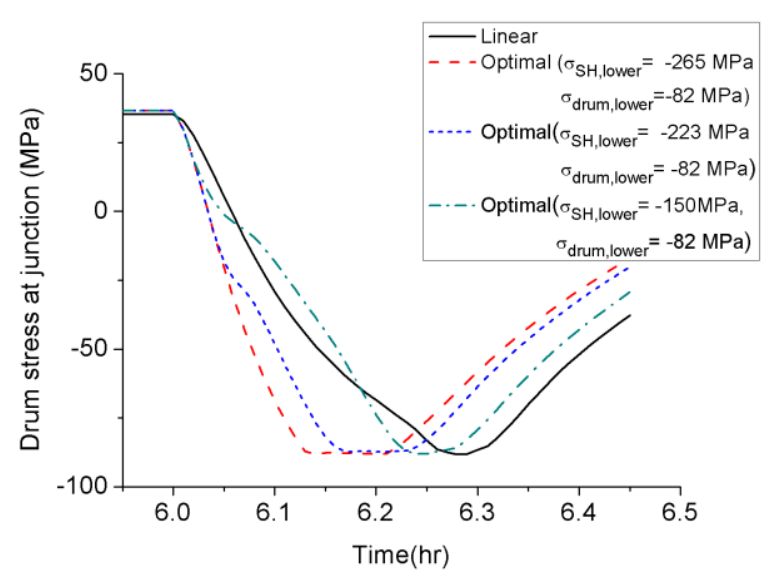

(c)

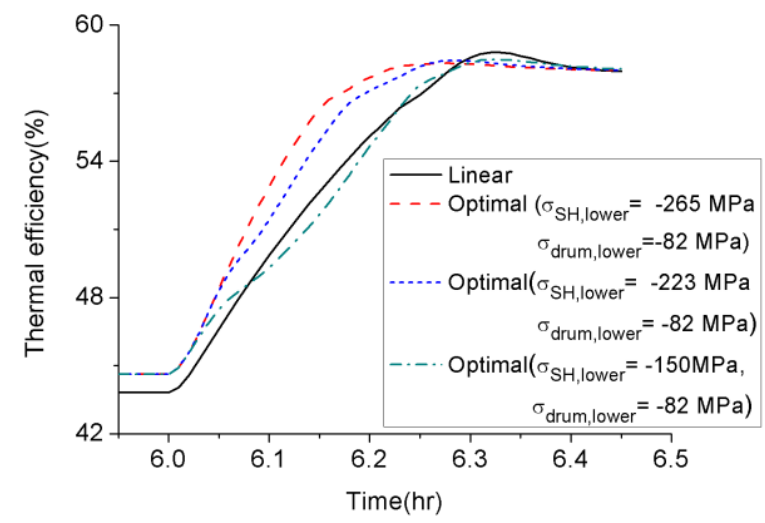

(b)

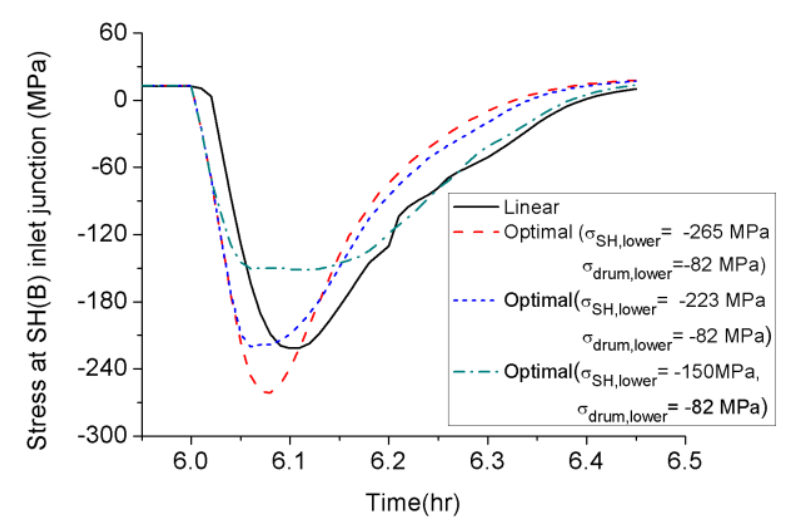

(d)

Figure 5. 8. Linear and optimal profiles under different equipment stress constraints for ramp-up process: (a) power output (b) thermal efficiency (c) stress at HP drum junction Position B (d) stress at SH(B) inlet junction Position B 
Table 5. 7. Comparison of linear and optimal ramp-up profiles under different equipment stress constraints

\begin{tabular}{|c|c|c|c|c|}
\hline & Linear & \multicolumn{3}{|c|}{ Optimal } \\
\hline $\begin{array}{c}\text { Stress lower bound at drum } \\
\text { junction }(\mathrm{MPa})\end{array}$ & $\mathrm{Na}$ & -82 & -82 & -82 \\
\hline $\begin{array}{c}\text { Stress lower bound at } S H \quad(B) \\
\text { inlet junction }(M P a)\end{array}$ & $\mathrm{Na}$ & -265 & -223 & -150 \\
\hline $\begin{array}{c}\text { Time average thermal } \\
\text { efficiency }(\%)\end{array}$ & 53.2 & 54.5 & 54 & 53.1 \\
\hline $\begin{array}{l}\text { Minimum stress at drum } \\
\text { junction }(\mathrm{MPa})\end{array}$ & -82 & $\begin{array}{c}-82 \\
\text { (active) }\end{array}$ & $\begin{array}{c}-82 \\
\text { (active) }\end{array}$ & $\begin{array}{c}-82 \\
\text { (active) }\end{array}$ \\
\hline $\begin{array}{c}\text { Minimum stress at } \mathrm{SH}(\mathrm{B}) \text { inlet } \\
\text { junction }(\mathrm{MPa})\end{array}$ & -223 & -262 & $\begin{array}{c}-223 \\
\text { (active) }\end{array}$ & $\begin{array}{c}-150 \\
\text { (active) }\end{array}$ \\
\hline $\begin{array}{c}\Delta \text { rampratelower } \\
(\% \text { load change } / \mathrm{min})\end{array}$ & 0 & 0 & 0 & 0.7 \\
\hline
\end{tabular}

\subsection{Conclusion}

In order to avoid overheating and resulting creep rupture in the $\mathrm{SH} / \mathrm{RH}$, it is crucial to maintain the final main/reheat steam temperature under the load-following operation. Since a large amount of boiler feed water spray is required in the attemperator, located at the inlet of $\mathrm{SH} / \mathrm{RH}$, during the transient, the fast steam cooling leads to the large stress amplitude at the SH/RH inlet header-tube junction. Due to the higher operation pressure, SH has a larger wall thickness and higher thermal stress. In other words, SH stress rather than RH stress would be the limiting constraint in dynamic optimization.

Depending on the stress constraints in the drum and $\mathrm{SH}$, the limiting constraint can change. It was observed that when SH stress constraint was not considered or the SH stress bound was large, the stress constraints are limiting and the obtained optimal trajectories correspond to the cases in Chapter 4. Then the resulting stress magnitude in the SH section can be high and may not be acceptable. When the drum stress upper limits for ramp-down are lowered, it leads to lower stress in the SH section as well. For ramp-up process, the different drum stress lower limits lead to the same minimum SH stress. The magnitude of SH compressive stress is high so that it is important to consider the SH stress constraint for optimizing the ramp-up operation.

For ramp-down process, three sensitivity studies with different SH stress constraints were conducted, and the drum constraint is set at the same/lower value as the linear profile. In Case 1, 
SH stress and drum stress constraint are set at the values of 327MPa and 191MPa, respectively, which are the same as the linear operation. It was observed that drum stress is limiting constraint and dynamic optimization leads to about $1 \%$ higher efficiency than the linear profile. In Case 2, the drum stress constraint is same as Case 1 and SH stress upper bound decreases to $260 \mathrm{MPa}$. Then, SH stress becomes the active constraint and leads to a lower thermal efficiency than the optimal profile obtained in Case 1, but it is still higher than the linear operation by $0.6 \%$. In Case 3 , drum stress and SH stress decrease to 170MPa and 210MPa, respectively. Both stresses are the limiting constraints. The thermal efficiency is even lower than the linear operation by $0.2 \%$ and an overall ramprate relaxation of about $0.5 \%$ is required for satisfying the stress constraints.

Similarly, three sensitivity studies with different SH stress lower bounds were conducted for rampup process, and the drum lower bound is set at the same value of $-82 \mathrm{MPa}$ as the linear profile. In Case 1, SH stress constraint is set at the values of $-265 \mathrm{MPa}$ and drum stress is limiting. Dynamic optimization leads to about 1.3\% higher efficiency than the linear profile. In Case 2, the SH lower bound is set at the same value of -223 MPa as linear operation. Both drum and SH stress constraint are limiting and thermal efficiency is lower than that in Case 1, but it's still higher than the linear operation by $0.8 \%$. In Case 3, SH lower bound increase to - $150 \mathrm{MPa}$ and both drum stress and $\mathrm{SH}$ stress are limiting constraints. The thermal efficiency is lower than the linear operation by $0.1 \%$ and an overall ramprate relaxation of about $0.7 \%$ is required for satisfying the stress constraints. 


\section{Chapter 6. Reduced order model development}

\subsection{Literature Review}

Due to the computational tractability and accuracy, reduced order models (ROMs) of the dynamic high-fidelity plant models can be used for optimization/scheduling/control of the power plant with/without $\mathrm{CO}_{2}$ capture. Zhang et al. $(2016,2018)$ developed different ROMs for linear or nonlinear model predictive control (MPC) of an MEA-based $\mathrm{CO}_{2}$ capture process. A transfer function model of dynamic process was considered in the linear MPC and a nonlinear, additive, autoregressive model with exogenous (NAARX) was used in the nonlinear MPC. He and Lima (2019) extended the MPC application to the coal-fired power plant with carbon capture and compared different MPC strategies, i.e. dynamic matrix control (DMC)- based linear MPC, and two nonlinear MPCs (NLMPC).

There are few other literatures on reduced order dynamic modeling of power plants. Rua et al. (2020) developed the local model network (LMN) of linear ARX models for an NGCC plant. A model predictive control approach was proposed to conduct the NGCC plant load-following of step change without exceeding the maximum stress limit of the drum. A LMN (also known as bank of linear models) has been proposed by Johansen and Foss (1993), and Prasad et al. (1998). It includes several local linear models for different operating regimes and their interpolation according to the operating conditions. Then, a Gaussian validity function is associated to each local ARX model and all the predicted responses are combined into the final output.

The reduced order dynamic model of the NGCC plant with the equipment health analysis, i.e. stress constraints, is required in the dynamic optimal dispatch of energy systems by our project partner (Kim et al., 2020). In this work, the linear reduced order state-space model is first generated in Aspen Plus Dynamic (APD). Since the model may not accurately capture the transients in through-wall temperature profile thus can lead to inaccuracies in the evaluation of thermal stress, the simple input-output transfer function model is also developed to provide the thermal stress transient under the load-following. This hybrid linear reduced order model is computationally tractable for being used in the optimal scheduling.

\subsection{Linear reduced-order state-space model}

The nonlinear NGCC plant model in APD can be linearized at the different operating conditions by using a featured built-in tool called control design interface (CDI) to generate a large-scale full- 
order linear state space model. Then it may be desired to reduce the order of this model further for computational tractability. Two widely used methods for order reduction of very large-scale linear dynamic systems are the balanced truncation method and the Hankel norm approximation method. Both methods are based on Hankel singular value (HSV) decomposition. (Glover, 1984; Wang and Safonovet, 1990; Antoulas, 1999; Antoulas and Sorensen, 2001; Willcox and Peraire, 2002). Both methods guarantee two of the most important ROM properties: (i) preserving stability of the original system and (ii) satisfying the global error bound (Paul et al. 2016). In this study, the balanced truncation method is used for reducing the order of the linear full-state model generated using APD.

\subsubsection{Linear SIMO state-space model}

The nonlinear model of NGCC plant in APD is linearized at different load conditions (e.g. full load, $80 \%$ load, and $60 \%$ load) to generate the linear SIMO state-space models using the Control Design Interface (CDI) tool.

In the state-space model, input or decision variable is:

1. Natural gas flowrate $(\mathrm{kg} / \mathrm{hr})$

The outputs are:

1. Total power output (MWe)

2. Gas turbine power output (MWe)

3. Main steam temperature $\left({ }^{\circ} \mathrm{C}\right)$

4. Reheat steam temperature $\left({ }^{\circ} \mathrm{C}\right)$

Since 582 state variables are included in the large-scale state-space model, the ROM is required for reducing computational cost.

\subsubsection{Reduced-order model}

Balanced truncation method is used to eliminate the weakly coupled states and generate the ROM on the basis of Hankel singular value (HSV) decomposition. Figure 6.1 shows that only 35 state variables are sufficient for the ROM with the HSV tolerance set at $10^{-5}$. 


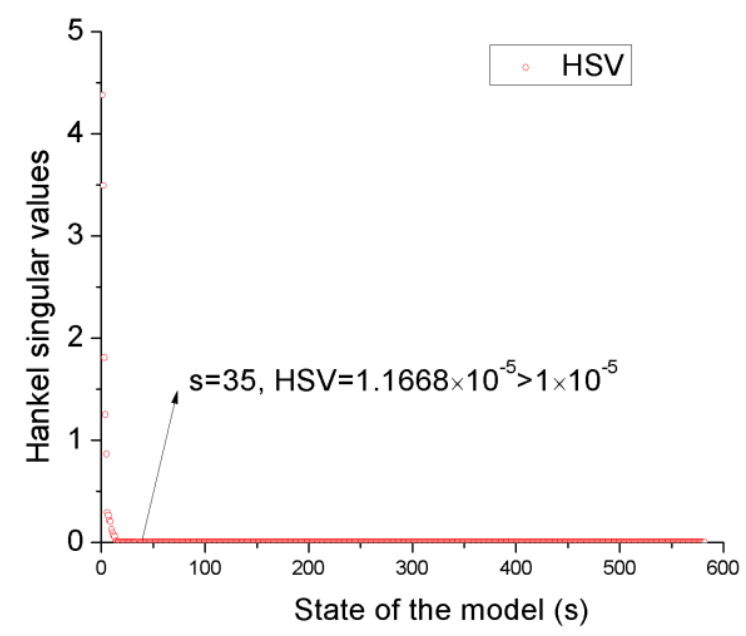

Figure 6. 1. Hankel singular values of the state-space model under full load condition

For evaluating the accuracy of ROM, the natural gas flowrate is varied between the full load to 0.4 load as shown in Figure 6.2.

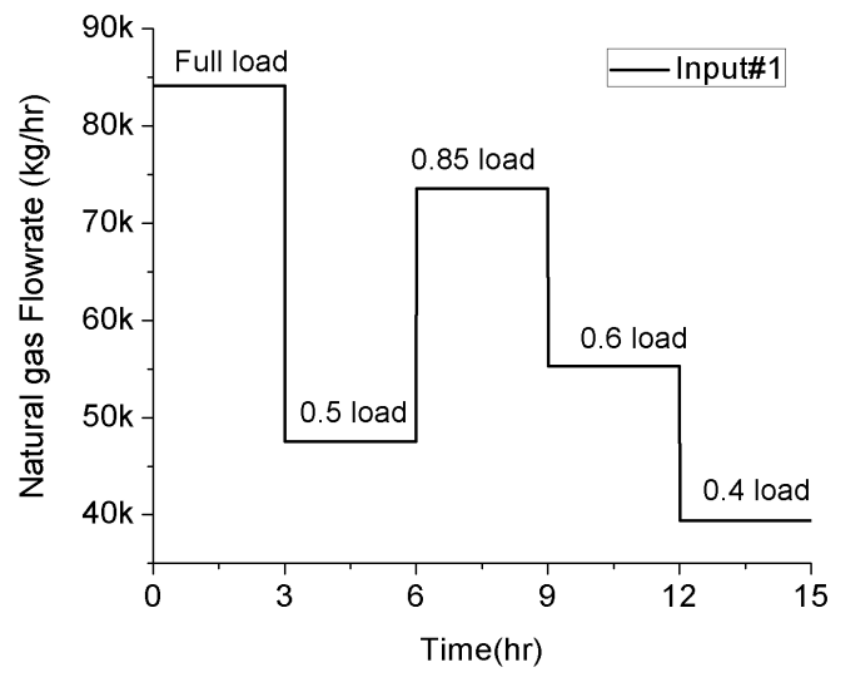

Figure 6. 2. Input variation for the ROM validation

Here, the output responses to the input variation are compared among the nonlinear plant in APD, the full-ordered state space model (FOM), and the ROM.

The FOM and ROM shown in Figure 6.3 are generated at full load condition. Results from the ROM not only compares well with the FOM but also with the high-fidelity nonlinear model in 
APD. Since FOM and ROM are linearized at full load, the discrepancy at low load condition is larger. However, all these discrepancies are less than $10 \%$.

On the other hand, the computation times of different models are varied. The load-following simulation in APD takes 12 min 8s, while it only takes 0.572s using FOM and 0.263s using ROM.

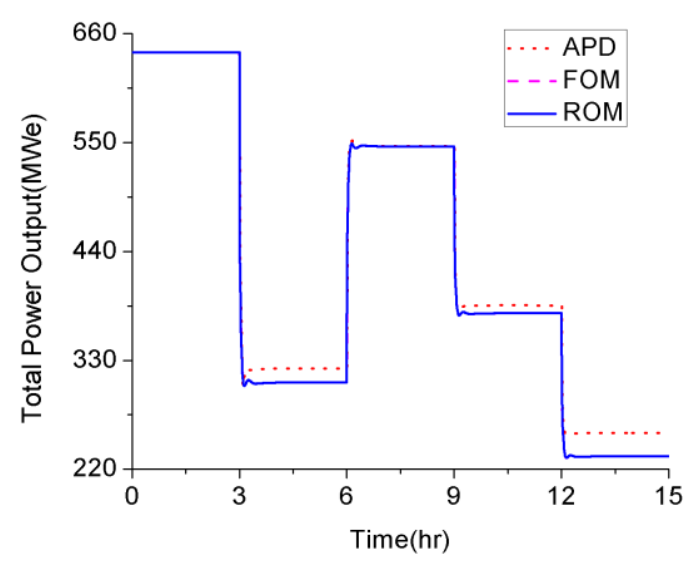

(a)

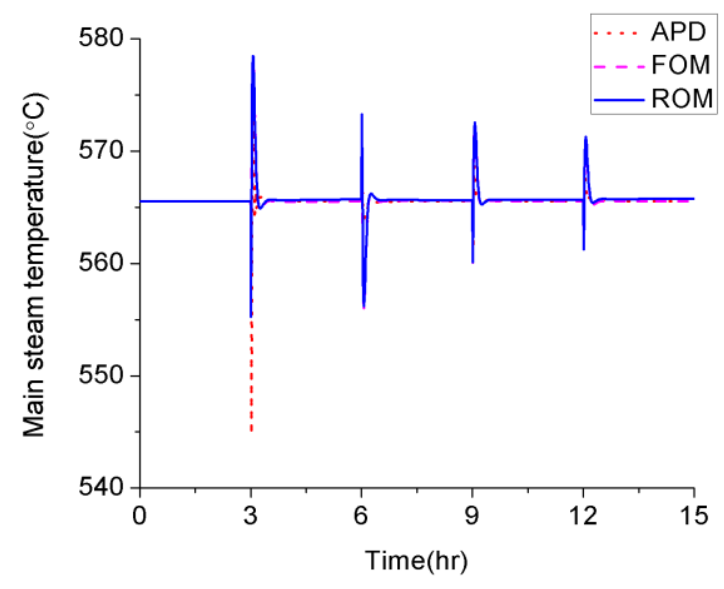

(c)

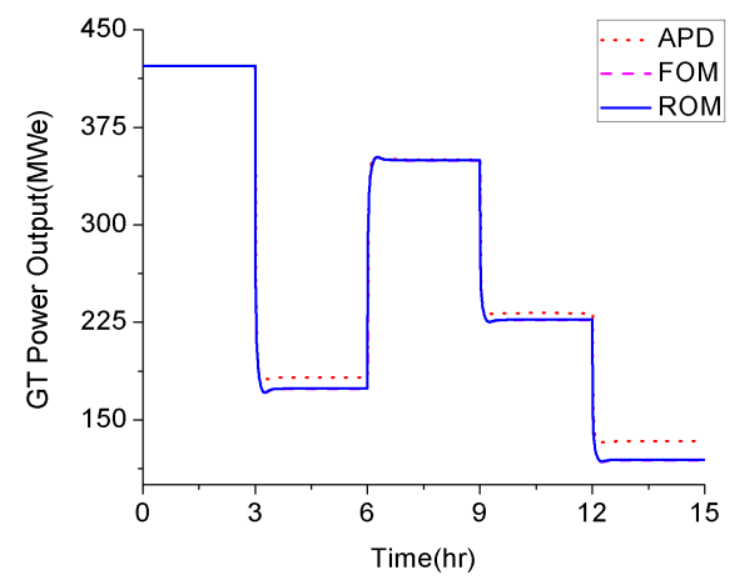

(b)

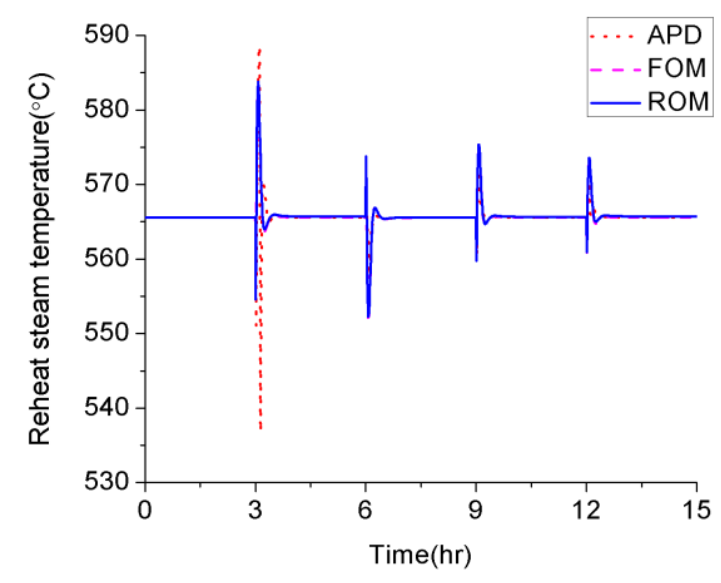

(d)

Figure 6. 3. Output responses to the input variations for linear model generated at full load condition (a) total power output (b) GT power output (c) main steam temperature (d) reheat steam temperature 
Similarly, the ROMs can be generated at different loads (0.8load and 0.6load) and compared with the high-fidelity nonlinear model. The orders of these ROMs are both 35 . Also, good agreement between nonlinear model and ROMs can be seen in Figure 6.4.

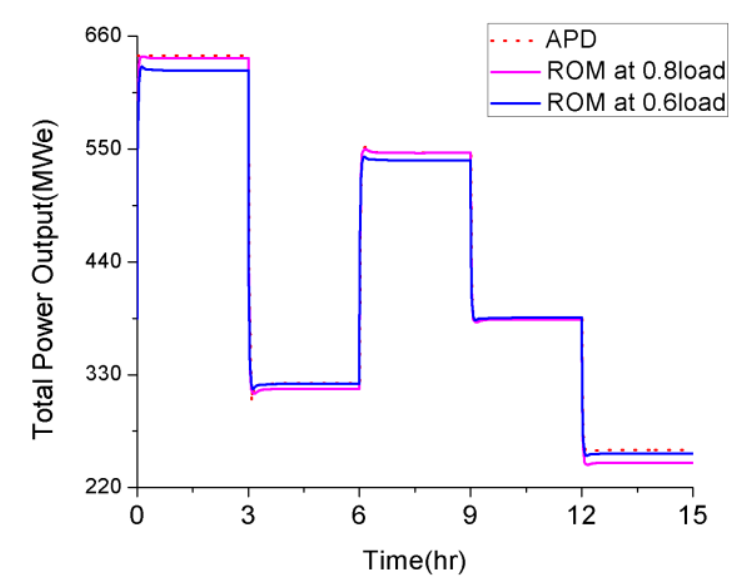

(a)

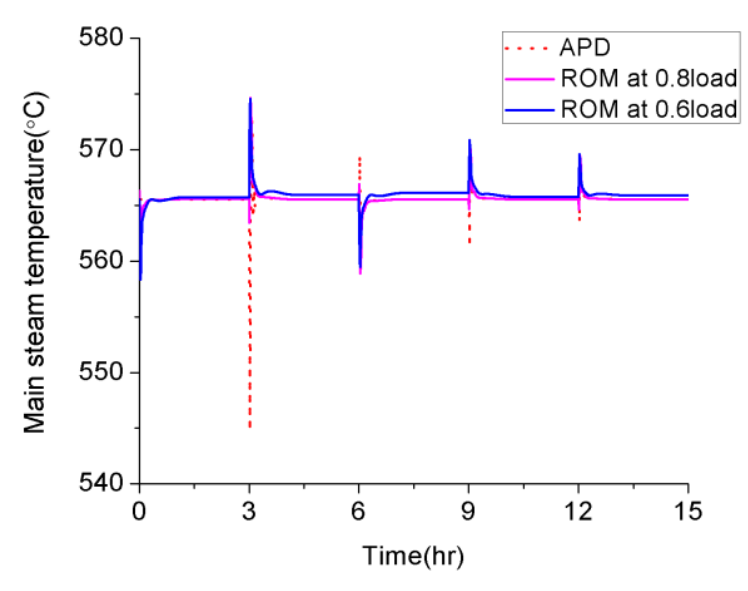

(c)

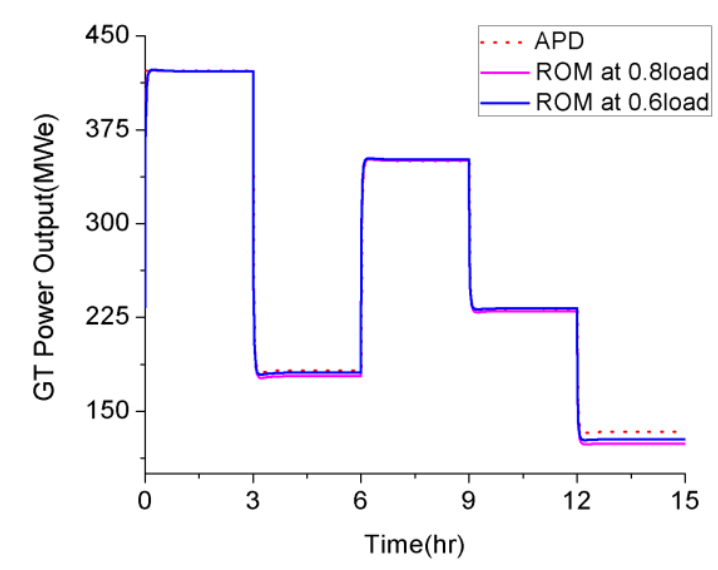

(b)

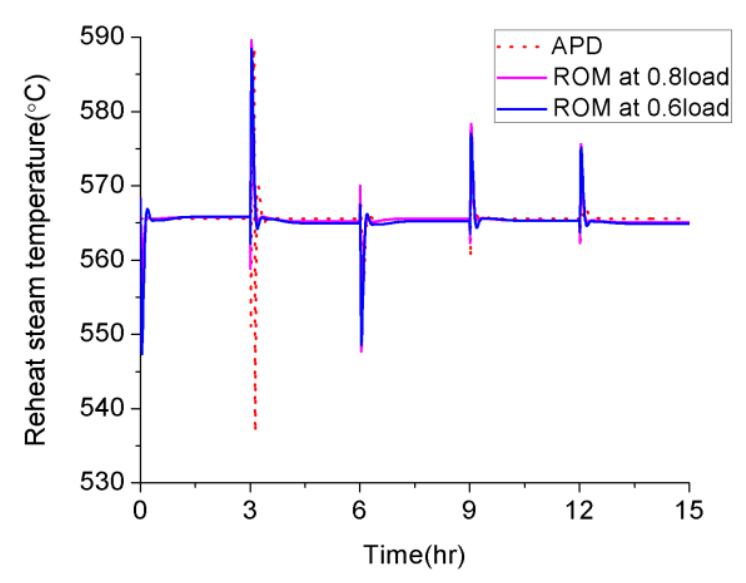

(d)

Figure 6. 4. Output responses to the input variations for linear model generated at 0.8load and 0.6load (a) total power output (b) GT power output (d) main steam temperature (e) reheat steam temperature 


\subsection{Linear transfer function model}

Since the thermal stress is proportional to the first-order temperature derivative as shown in Equation 4.14, the highly nonlinear transient is presented under the load-following. A transfer function model of dynamic process is identified for computing thermal stress.

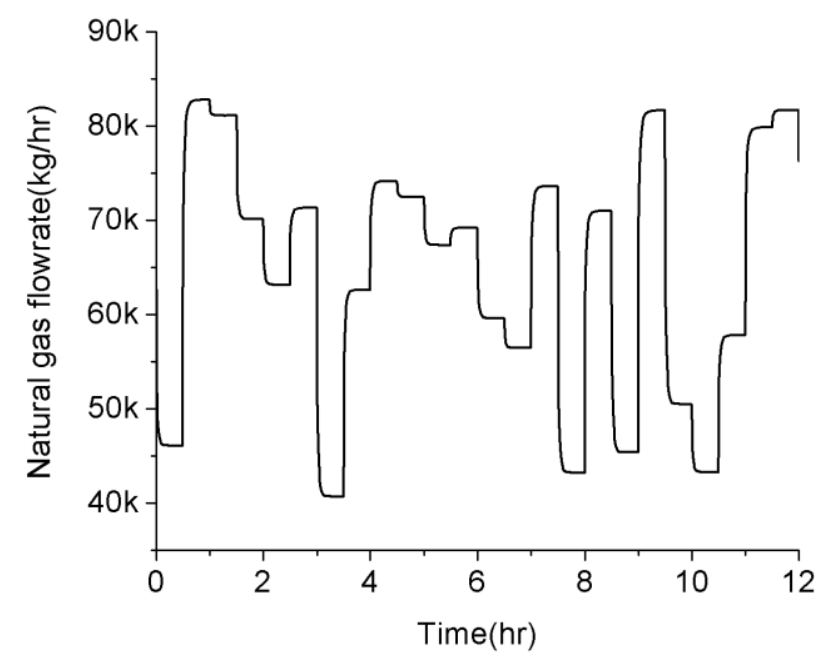

Figure 6. 5. Random signals of input for system identification

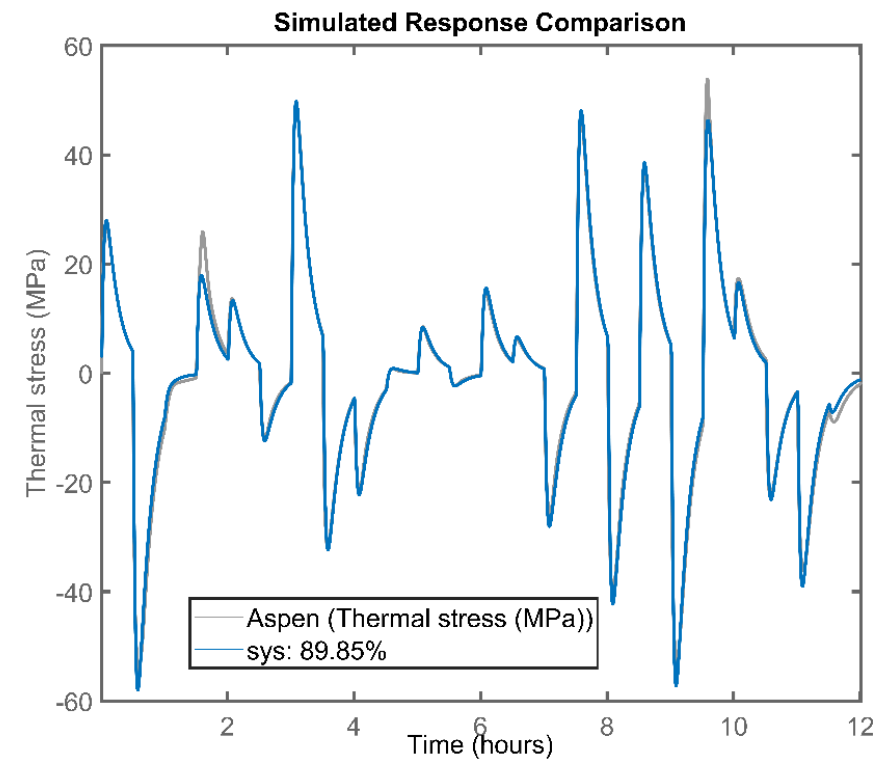

Figure 6. 6. Comparison between model in Aspen Plus Dynamics and identified process model 
Pseudorandom binary sequence (PRBS) signals of input are used for obtaining the output performance for system identification. The signal amplitude generated by the PRBS Signal Generator is set to be variable (random value between 0 and 1, instead of either 0 or 1 ) at each step to ensure the convergence of Aspen Plus Dynamics model over the tested sequence. The random input signals used for natural gas flow rate are shown in Figure 6.5.

The tangential thermal stress on drum inner surface is identified using the transfer function estimation in MATLAB. The obtained transfer function can also be converted to a discrete statespace form. Figure 6.6 shows comparisons between the output of the dynamic simulation and the identified model.

\subsection{Conclusion}

The reduced order state-space models linearized at different load conditions (full load, 0.8 load and 0.6 load) show a good prediction in power output and steam temperature. The input-output transfer function model can provide the thermal stress transient under the load-following. The hybrid linear ROM with highly computational efficiency is a good representation of the nonlinear plant model with equipment damage estimation. 


\section{Chapter 7. Final Remarks}

In this work, a plant-wide dynamic model of the NGCC plant has been developed with detailed equipment level sub-models to capture the plant load-following behavior. Five novel configurations have been proposed for controlling the main steam and reheat steam temperatures while avoiding 'spraying to saturation' during fast load-following by considering different final high-pressure superheater (HP SH2)/ reheater ( $\mathrm{RH})$ arrangements (in series or in parallel) and attemperation strategies (single-stage, two-stage, and damper-assisted attemperation). Loadfollowing operation has been studied under two operational strategies- the industry-standard coordinated control strategy and dynamic optimization. Also, the fatigue/creep damage has been estimated by developing a damage model that can compute through-wall temperature transients and thermo-mechanical stress evolutions in the critical components (i.e. HP drum, superheater and reheater). Multiple locations at the component junctions have been monitored and the most stressed part has been identified as the constraint in the dynamic optimization of the load-following operation. In addition, the reduced order dynamic model of NGCC plant including equipment stress transient has been generated for dynamic optimal scheduling of multiple energy systems.

The main components of the NGCC plant are the GT, HRSG, and ST. Under the load-following, the 1-stage attemperation configuration leads to saturation and cannot maintain the steam temperature irrespective of whether $\mathrm{HP} \mathrm{SH} 2$ and $\mathrm{RH}$ are arranged in series or in parallel. However, the configurations with 2-stage attemperation can maintain the main/reheat steam temperature at its set point without leading to saturation. The spray flow rate at HP SH2/RH ATT can be optimized to not only satisfy the saturation constraint of the main and reheat steam temperature but also to achieve a higher efficiency than the traditional coordinated control system.

The HP drum fatigue damage has been estimated and the maximum circumferential stress amplitude occurs at the edge of the drum/downcomer junction. It was observed that the industry standard linear profile can not only result in lower efficiency but can violate the drum stress constraints depending on the desired ramprate and upper and lower bounds on the constraints. The multi-objective dynamic optimization approach can play a critical role for load trajectory optimization not only for maximizing efficiency during load following but also for avoiding violation of drum stress constraints and for avoiding spraying to saturation. There is a strong tradeoff between the relaxation in ramprate and the time- average thermal efficiency. 
In order to avoid overheating and resulting creep rupture in the $\mathrm{SH} / \mathrm{RH}$, it is crucial to maintain the final main/reheat steam temperature under the load-following. Since a large amount of boiler feed water is sprayed in the attemperator during the transient, the fast steam cooling leads to the large stress amplitude at the $\mathrm{SH}(\mathrm{B})$ inlet header-tube junction. The dynamic optimization of the load-following with SH stress and drum stress constraints are formulated. It was observed that the limiting constraint can change depending on the stress constraints in the drum and SH. Also, the different load trajectories and thermal efficiency performances are obtained. The proper equipment stress constraint should be based on the specific material of construction, the operational history of a plant as well as the level of conservatism exercised by plant operators.

The high-fidelity dynamic models include multiple time scales and multiple spatial scales, it can be computationally intractable to use the detailed models for optimization/scheduling/control. A hybrid reduced order dynamic models have been developed for the NGCC system including the equipment stress estimation so that they can be computationally tractable for being used in dynamic optimization while providing desired accuracy. 


\section{Chapter 8. Future Work}

In this research, mainly creep and fatigue damages are considered. However, the actual power plant can face many other damaging mechanisms, that often act synergistically to cause accelerated failure of boiler components. The feed water chemistry leads to various types of corrosion on the inner surface of the superheater and reheater. In addition, thick oxide scale can form at the tube interiors, that not only causes accelerated failure due to inferior rupture properties and dissimilarity with the tube MOC, but also due to rise in the local tube temperature because of poor thermal properties of the oxide scales. Sulfidic corrosion on the outer surface of the tubes resulting from the sulfur -bearing compounds in the flue gas of coal-fired boilers can lead to reduction in the tube wall thickness. A more comprehensive damage model considering the effect of external and internal corrosion and deposit and consideration of the combined effects of all mechanisms along with creep and fatigue will be highly desired.

Material properties of importance for damage models have uncertainties. Uncertainties in Young's modulus and thermal properties would affect the equipment stress and temperature distribution and transients. Uncertainties in the creep rupture data would affect the creep damage assessment as shown in Appendix B. Therefore, quantifying uncertainties in prediction of failure as a result of material uncertainties will be also desired.

Supplemental firing or duct firing in NGCC plants enables the plant to produce more steam when it is desired to produce more power than the typical base-loaded operation. Supplemental firing can significantly elevate the local temperature near superheater/reheater and can be very damaging to their health. When a duct burner is installed, usually some special alloys are used especially in

first few rows following the duct burner. Investigation of the impact of supplemental firing on plant transient response, equipment health, and consideration of the amount of supplemental firing as a degree of freedom in dynamic optimization will be very valuable.

$\mathrm{CO}_{2}$ capture from pulverized coal power plants is widely investigated, while there are few studies on $\mathrm{CO}_{2}$ capture from NGCC plants. When the capture plant is integrated with an NGCC plant and the host plant undergoes rapid load following, then the transients in the capture plant are affected not only by the transients in the flue gas flow and composition, but also the change in the extraction pressure of the steam from the ST that is sent to the reboiler thus affecting the capture system performance significantly. On the other hand, the capture system affects the performance of the 
NGCC plant due to the transients of steam consumption in the reboiler and transients of other parasitic loads in the capture plant. Therefore, the impact of load-following on the performance of the capture system and synergistic interaction of the capture and NGCC plant should be studied. We have developed a steady-state rate-based model for $\mathrm{CO}_{2}$ capture using MDEA/PZ solvent. The NGCC plant integrated with $\mathrm{CO}_{2}$ capture process was investigated in the steady state condition. Based on the steady-state model, the dynamic equilibrium model of $\mathrm{CO}_{2}$ capture using Murphreeefficiency approach can be developed. Furthermore, the synergy of $\mathrm{CO}_{2}$ capture with NGCC plant can be investigated.

In term of reduced order model, a local model network (LMN) of linear state-space models can be developed. When additional local linear models for different operating loads can be identified and included in the LMN especially for capturing the stress transient more accurately. Also, nonlinear reduced order models can be developed and used in the advanced nonlinear model predictive control and optimal nonlinear scheduling problem. 


\section{Appendix A: The thermo-hydraulic model of HRSG}

\section{A.1. \&-NTU method}

The effectiveness $\varepsilon$ is the ratio of the actual heat transfer rate for a heat exchanger to the maximum possible heat transfer rate. When the heat exchanger includes $n$ tube passes, $\varepsilon$ is calculated as follows:

$$
\varepsilon=\frac{\left[\left(1-\varepsilon_{\mathrm{i}} \mathrm{C}_{\mathrm{r}}\right) /\left(1-\varepsilon_{\mathrm{i}}\right)\right]^{\mathrm{n}}-1}{\left[\left(1-\varepsilon_{\mathrm{i}} \mathrm{C}_{\mathrm{r}}\right) /\left(1-\varepsilon_{\mathrm{i}}\right)\right]^{\mathrm{n}}-\mathrm{C}_{\mathrm{r}}}
$$

where $C_{r}$ is the ratio between the flow heat capacity rate $C_{\min }$ and $C_{\max }$.

The Number of Transfer Units $(N T U)$ and Effectiveness $\varepsilon$ relation is calculated considering a single pass crossflow with the gas flow mixed and the water/steam flow unmixed (Bergman et al., 2011).

$$
N T U_{i}=-\ln \left[1+\frac{1}{C_{r}} \ln \left(1-\varepsilon_{i} \mathrm{C}_{r}\right)\right]
$$

The total surface area $A_{\text {tot }}$ of the heat exchanger is calculated as:

$$
A_{\text {tot }}=\frac{n \cdot N T U_{i} \cdot C_{\min }}{U}
$$

where $U$ is the overall heat transfer coefficient.

\section{A.2. Heat transfer coefficients}

The heat transfer for gas flow across the staggered tube banks in Equation 2.6 includes an arrangement factor $F_{a}$ (Khan et al., 2006):

$$
F_{a}=1+0.1 a+0.34 / b
$$

where $a$ and $b$ represent longitudinal tube pitch and transverse tube pitch.

The liquid phase heat transfer in Equation 2.7 includes the friction factor $f$ for smooth tubes (Gnielinski, 1976):

$$
f=[0.7904 \ln (R e)-1.64]^{-2}
$$

The heat transfer under boiling condition in Equation 9 includes boiling coefficient, liquid-phase coefficient and the corresponding correlation factors (Collier and Thome, 2006). The normalized nucleate pool boiling coefficient $h_{N c B, o}$ is $25580 \mathrm{~W} / \mathrm{m}^{2} \mathrm{~K}$. The liquid-phase forced convection 
coefficient $h_{F O}$ is calculated using Gnelinski correlation as shown in Equation 2.7. The factors are calculated as:

$$
\begin{gathered}
F_{N C B}=0.72 F_{P F}(\varnothing / 150000)^{n f}(d / 0.01)^{-0.4}(R p / 1)^{0.133} \\
F_{P F}=2.816 P_{-} r^{0.45}+\left(3.4+\frac{1.7}{1-P_{-} r^{7}}\right) P_{-} r^{3.7} \\
n f=0.8-0.1 \exp \left(1.75 P_{-} r\right) \\
P_{r}=\frac{P}{P_{C R I T}} \\
F_{F B}=\left[(1-x)^{1.5}+1.9 x^{0.6}\left(\rho_{f} / \rho_{g}\right)^{0.35}\right]^{1.1}
\end{gathered}
$$

where $F_{N c B}$ is a nucleate boiling correlation factor, including the effects of pressure $P_{-} r$, heat flux $\emptyset$, tube diameter $d$, surface roughness $R p ; F_{F B}$ is two-phase multiplier, depending on the vapor fraction $x$ and the density ratio between liquid phase $\rho_{f}$ and gas phase $\rho_{g}$.

$\eta_{0}$ is the efficiency of a finned surface used to calculate the overall heat transfer coefficient $U$ in Equation 2.10.

$$
\eta_{0}=1-\frac{A_{f}}{A_{t o t}}\left(1-\eta_{f}\right)
$$

where $A_{f}$ is the fin surface area, $\eta_{f}$ is the efficiency of the single fin related with the fin height $L$, fin thickness $t$, thermal conductivity of fin $k$ and gas side heat transfer coefficient $h_{g}$ (Bergman et al., 2011).

$$
\begin{gathered}
\eta_{f}=\frac{\tanh (m L)}{m L} \\
m=\sqrt{\frac{2 h_{g}}{k t}}
\end{gathered}
$$




\section{Appendix B: Creep rupture assessment}

\section{B.1 Creep damage model}

Creep is due to the prolonged exposure to high stress and temperature operation conditions. The creep damage is defined as operating duration divided by the expected rupture time.

$$
D_{C}=\frac{t_{o}}{t_{r}(\sigma, T)}
$$

where $t_{r}(\sigma, T)$ is the time to rupture failure at the stress $\sigma$ and temperature $T$. The rupture time $t_{r}$ is estimated using the creep curves under different temperature conditions.

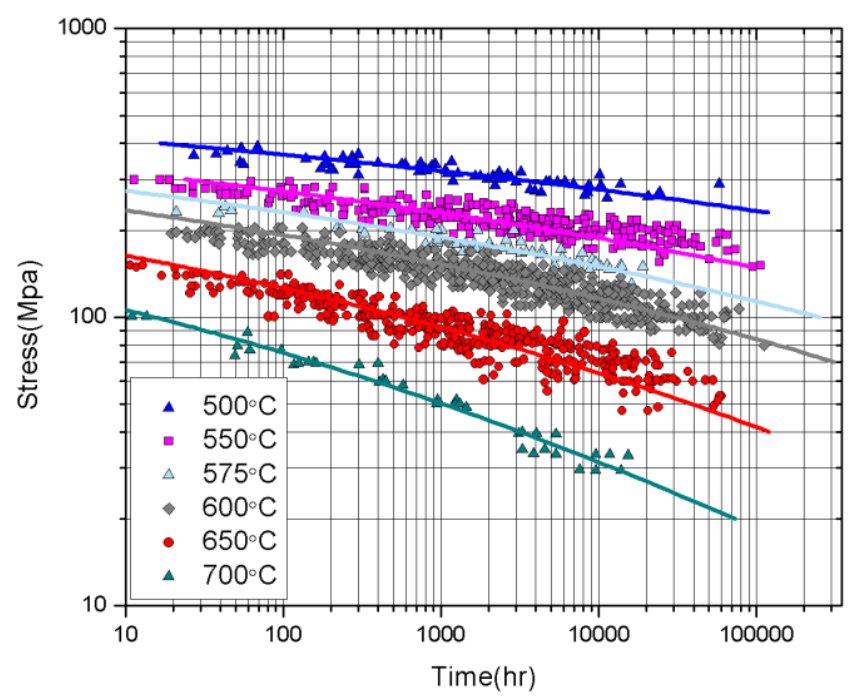

Figure B. 1. Creep-rupture database of Grade 91 steel

Creep curves of SH/RH material (i.e. T/P 91 steel) as shown in Figure B.1 can be found in the literature (Bendick et al., 2010). It was observed that the steepness of creep curves increases as the operating temperature rises. Under the certain stress magnitude, when temperature keeps increasing, the expected rupture time can reduce considerably.

\section{B.2. Creep rupture assessment using minimum commitment (MC) equation}

Since creep rupture test is conducted using uniaxial tensile specimens, the Von Mises equivalent stress $\sigma$ is considered when the creep curves are used to estimate the rupture time.

$$
\sigma=\left[\sigma_{r}^{2}+\sigma_{\theta}^{2}+\sigma_{z}^{2}-\left(\sigma_{r} \sigma_{\theta}+\sigma_{r} \sigma_{z}+\sigma_{z} \sigma_{\theta}\right)\right]^{1 / 2}
$$


A total of 1238 creep data are obtained from the work of Bendick et al. (2010) as shown in Figure B.1. The testing temperature varies from $500{ }^{\circ} \mathrm{C}$ up to $700{ }^{\circ} \mathrm{C}$, and most of the data are concentrated around $550^{\circ} \mathrm{C}, 600^{\circ} \mathrm{C}$ and $650^{\circ} \mathrm{C}$.

The Minimum Commitment (MC) equation is used to assess the database.

$$
\log t_{r}=a_{0}+a_{1} \log \sigma+a_{2} \sigma+a_{3} \sigma^{2}+a_{4} T+\frac{a_{5}}{T}
$$

where $t r$ is the predicted time $(\mathrm{hr}), \sigma$ is the stress $(\mathrm{MPa}), T$ is the temperature $(\mathrm{K})$ and $a$ is the coefficient. The coefficients determined by MC equation are listed in Table B.1.

Table B. 1. Coefficients of MC equation for Grade91

\begin{tabular}{cccccc}
\hline$a_{0}$ & $a_{1}$ & $a_{2}$ & $a_{3}$ & $a_{4}$ & $a_{5}$ \\
\hline-6.55 & -3.53 & -0.015 & $-4.98 \times 10^{-06}$ & -0.0068 & 22283.77 \\
\hline
\end{tabular}

The scatters of material creep rupture data lead to the uncertainties in creep rupture assessment. Figure B. 2 shows the fitted isothermal curves and 95\% confidence intervals. Confidence intervals for the MC coefficients are calculated and listed in Table B.2.

Table B. 2. 95\% confidence intervals for coefficients of MC equation

\begin{tabular}{ccc}
\hline Coefficient & Baseline value & Confidence interval \\
\hline$a_{0}$ & -6.55 & {$[-7.74,-5.36]$} \\
\hline$a_{1}$ & -3.53 & {$[-4.08,-2.99]$} \\
\hline$a_{2}$ & -0.015 & {$[-0.018,-0.011]$} \\
\hline$a_{3}$ & $-4.98 \times 10^{-6}$ & {$\left[-1.07 \times 10^{-5}, 7.13 \times 10^{-7}\right]$} \\
\hline$a_{4}$ & -0.0068 & {$[-0.0077,-0.0059]$} \\
\hline$a_{5}$ & 22283.77 & {$[22283.76,22283.77]$} \\
\hline
\end{tabular}



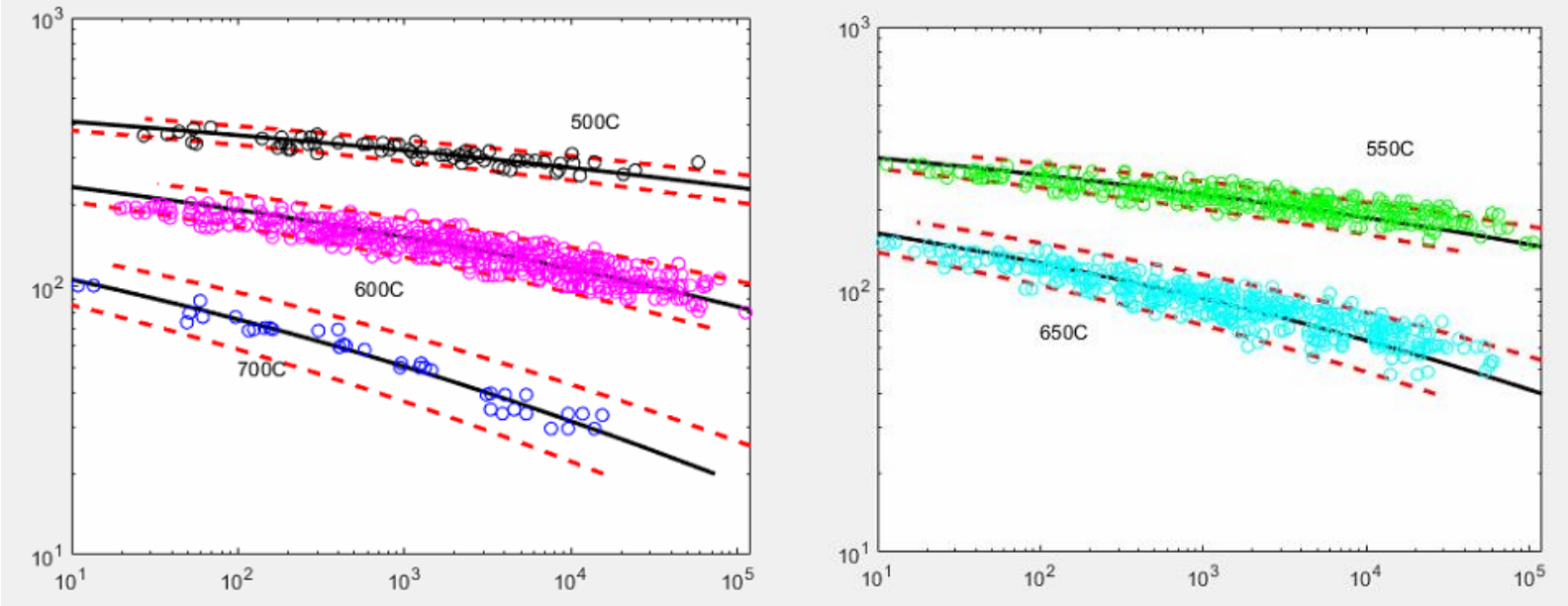

Figure B. 2. Different isothermal curves and 95\% confidence bounds for creep-rupture database 


\section{Appendix C: Publications and Presentations}

\section{Publications}

1. Wang, Y., Bhattacharyya, D., Turton, R (2021). Optimal Load-following Operation of NGCC Power Plants with Stress Monitoring of the HP drum and Superheater header. In Preparation.

2. Wang, Y., Bhattacharyya, D., Turton, R. (2021). Optimal Load-following of Natural Gas Combined Cycle (NGCC) Power Plants with Stress Monitoring of the Thick-walled Boiler Drum. Applied Energy, Submitted.

3. Wang, Y., Bhattacharyya, D., Turton, R. (2020). Evaluation of Novel Configurations of Natural Gas Combined Cycle (NGCC) Power Plants for Load-Following Operation using Dynamic Modeling and Optimization. Energy \& Fuel, 34(1), 1053-1070.

4. Wang, Y., Bhattacharyya, D., Turton, R. (2019). Dynamic Modeling and Control of a Natural Gas Combined Cycle Power Plant for Load-Following Operation. In Computer Aided Chemical Engineering, 47, 101-106. Elsevier, 2019.

5. Kim, R., Wang, Y., Vudata, S. P., Bhattacharyya, D., Lima, F. V., \& Turton, R. (2020). Dynamic Optimal Dispatch of Energy Systems with Intermittent Renewables and Damage Model. Mathematics, 8(6), 868.

6. He, X., Wang, Y., Bhattacharyya, D., Lima, F. V., Turton, R. (2018). Dynamic Modeling and Advanced Control of Post-combustion $\mathrm{CO}_{2}$ Capture Plants. Chemical Engineering Research and Design, 131, 430-439.

\section{Selected Presentations}

1. Wang, Y., Bhattacharyya, D., Turton, R. Optimal Load-Following Operation of NGCC Power Plants with Quantified Uncertainty of Equipment Health. 2020 AIChE Annual Meeting, San Francisco, CA, November 15-20, 2020

2. Wang, Y., Bhattacharyya, D., Turton, R. Dynamic Optimization of an NGCC Power Plant for LoadFollowing Operation. 2019 AIChE Annual Meeting, Orlando, FL, November 10-15, 2019

3. Wang, Y., Bhattacharyya, D., Turton, R. Dynamic Modeling and Control of an NGCC Power Plant for Load-following Operation. 2019 FOCAPD Conference, Copper Mountain, CO, July14-18, 2019

4. Wang, Y., Bhattacharyya, D., Turton, R. Dynamic Modeling and Control of an NGCC Power Plant with a Damage Model. 2018 AIChE Annual Meeting, Pittsburgh, PA, October 28 - November 2, 2018

5. Wang, Y., Bhattacharyya, D., Turton, R. Design and Optimization of an NGCC Power Plant with $\mathrm{CO}_{2}$ Capture for Optimal Load-Following. 2017 ISA POWID Symposium, Cleveland, OH, June 27-29, 2017 


\section{References}

Alobaid, F., Postler, R., Ströhle, J., Epple, B., \& Kim, H. G. (2008). Modeling and investigation start-up procedures of a combined cycle power plant. Applied Energy, 85(12), 1173-1189.

Alobaid, F., Ströhle, J., Epple, B., \& Kim, H. G. (2009). Dynamic simulation of a supercritical once-through heat recovery steam generator during load changes and start-up procedures. Applied Energy, 86(7-8), 1274-1282.

Alobaid, F., Karner, K., Belz, J., Epple, B., \& Kim, H. G. (2014). Numerical and experimental study of a heat recovery steam generator during start-up procedure. Energy, 64, 1057-1070.

Antoulas, A. C. (1999). Approximation of linear dynamical systems. Wiley Encyclopedia of Electrical and Electronics Engineering, 11, 403-422.

Antoulas, A. C., \& Sorensen, D. C. (2001). Approximation of large-scale dynamical systems: An overview.

Apan-Ortiz, J. I., Sanchez-Fernández, E., \& González-Díaz, A. (2018). Use of steam jet booster as an integration strategy to operate a natural gas combined cycle with post-combustion $\mathrm{CO} 2$ capture at part-load. Energy, 165, 126-139.

Bergman, T. L., Incropera, F. P., Lavine, A. S., \& DeWitt, D. P. (2011). Introduction to heat transfer. John Wiley \& Sons.

Benato, A., Stoppato, A., \& Mirandola, A. (2015). Dynamic behaviour analysis of a three pressure level heat recovery steam generator during transient operation. Energy, 90, 1595-1605.

Benato, A., Bracco, S., Stoppato, A., \& Mirandola, A. L. T. E. (2016). LTE: A procedure to predict power plants dynamic behaviour and components lifetime reduction during transient operation. Applied energy, 162, 880-891.

Bendick, W., Cipolla, L., Gabrel, J., \& Hald, J. (2010). New ECCC assessment of creep rupture strength for steel grade X10CrMoVNb9-1 (Grade 91). International Journal of Pressure Vessels and Piping, 87(6), 304-309.

Bhattacharyya, D., and Rengaswamy, R. (2010). Dimensional optimization of a tubular solid oxide fuel cell. Computers \& Chemical Engineering, 34(11), 1789-1802. 
Brevus, V., Yasniy, O., \& Lapusta, Y. (2014). Structural integrity assessment of thermal power plant superheater collector. Procedia materials science, 3, 1394-1399.

Chaibakhsh, A., \& Ghaffari, A. (2008). Steam turbine model. Simulation Modelling Practice and Theory, 16(9), 1145-1162.

Chen, K. L., Deardorf, A. F., Copeland, J. F., Pflasterer, R., \& Beckerdite, G. (1993). Creep-fatigue monitoring system for header ligaments of fossil power plants. In Fracture mechanics: Applications and new materials.

Collier, J. G., \& Thome, J. R. (1994). Convective boiling and condensation. Clarendon Press. Oxford, England, UK

Cooke, D. H. (1983, November). Modeling of off-design multistage turbine pressures by Stodola's ellipse. In Energy Incorporated PEPSE User's Group Meeting, Richmond, VA, 2-3.

Dong-mei, J., Jia-qi, S., Quan, S., Heng-Chao, G., Jian-Xing, R., and Quan-jun, Z. (2018). Optimization of start-up scheduling and life assessment for a steam turbine. Energy, 160, 19-32.

Dittus, F. W. and Boelter, L. M. K. (1930). Heat transfer in automobile radiators of the tubular type. University of California Publications in Engineering, 2,443-461.

Dzierwa, P. (2016). Optimum heating of pressure components of steam boilers with regard to thermal stresses. Journal of Thermal Stresses, 39(7), 874-886.

Dzierwa, P., and Taler, J. (2015). Optimum heating of pressure vessels with holes. Journal of pressure vessel technology, 137(1).

DOE/OE, What is the Smart Grid? https://www.smartgrid.gov/the_smart_grid/smart_grid.html

ECCC (European Creep Collaborative Committee). Data sheet. Robertson DG, editor. ERA Technology Ltd; 2005.

EIA, Electricity in the United States is produced with diverse energy sources and technologies. https://www.eia.gov/energyexplained/index.php?page=electricity_in_the_united_states\#t $\underline{a b 1}$

EPRI, Investigation of Cracking in Fossil Boiler Drums: Finite-Element Stress and Fracture Mechanics Analyses. EPRI, Palo Alto, CA: 2005. 1011916. 
EPRI, Investigation of Cracking in a Fossil Natural Circulation Boiler Drum: Finite Element Stress and Fracture Mechanics Analyses. Palo Alto, CA: 2006. 1013268.

European Committee For Standardization. EN 13445 part 3 unfired pressure vessels, clause 17; simplified assessment of fatigue life, and clause 18; detailed assessment of fatigue life; 2002.

Franco, A., \& Giannini, N. (2006). A general method for the optimum design of heat recovery steam generators. Energy, 31(15), 3342-3361.

Fontaine, P., and Golopin, J. F. (2007, October). HRSG Optimization for cycling duty based on Euro Norm EN 12952-3. In ETD Conference on Cyclic Operation of Power Plant (Vol. 5, No. 1, pp. 1-14).

German Boiler Regulations. TRD 301 annex 1 calculation for cyclic loading due to pulsating internal pressure or combined changes of internal pressure and temperature; 2001.

Glover, K. (1984). All optimal Hankel-norm approximations of linear multivariable systems and

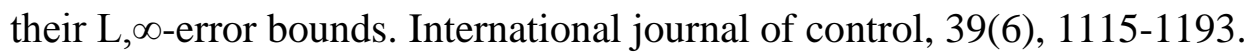

Gnielinski, V. (1976). New equations for heat and mass transfer in turbulent pipe and channel flow. Int. Chem. Eng., 16(2), 359-368.

González-Gómez, P. A., Gómez-Hernández, J., Ferruzza, D., Haglind, F., and Santana, D. (2019). Dynamic performance and stress analysis of the steam generator of parabolic trough solar power plants. Applied Thermal Engineering, 147, 804-818.

González-Gómez, P. A., Gómez-Hernández, J., Briongos, J. V., \& Santana, D. (2018). Transient thermo-mechanical analysis of steam generators for solar tower plants. Applied energy, 212, 1051-1068.

Gray, D. (2001). Correlating cycle duty with cost at fossil fuel power plants (p. 64). Tech. rep. 1004010. EPRI, Palo Alto, CA. 2002.

He, X., \& Lima, F. V. (2019). Development and implementation of advanced control strategies for power plant cycling with carbon capture. Computers \& Chemical Engineering, 121, 497509. 
Hentschel, J., Zindler, H., \& Spliethoff, H. (2017). Modelling and transient simulation of a supercritical coal-fired power plant: Dynamic response to extended secondary control power output. Energy, 137, 927-940.

Hetnarski, R. B., Eslami, M. R., and Gladwell, G. M. L. (2009). Thermal stresses: advanced theory and applications. Springer Netherlands.

Horkeby, K. (2012). Simulation of heat recovery steam generator in a combined cycle power plant. Linkopings, Sveden: Linköpings Universitet.

Hübel, M., Meinke, S., Andrén, M. T., Wedding, C., Nocke, J., Gierow, C., ... and Funkquist, J. (2017). Modelling and simulation of a coal-fired power plant for start-up optimisation. Applied Energy, 208, 319-331.

Khan, W. A., Culham, R. J., \& Yovanovich, M. M. (2006). Analytical model for convection heat transfer from tube banks. Journal of Thermophysics and Heat transfer, 20(4), 720-727.

Kim, R., Wang, Y., Vudata, S. P., Bhattacharyya, D., Lima, F. V., \& Turton, R. (2020). Dynamic Optimal Dispatch of Energy Systems with Intermittent Renewables and Damage Model. Mathematics, 8(6), 868.

Kim, T. S., Lee, D. K., and Ro, S. T. (2000). Analysis of thermal stress evolution in the steam drum during start-up of a heat recovery steam generator. Applied Thermal Engineering, 20(11), 977-992.

Kumar, N., Besuner, P., Lefton, S., Agan, D., \& Hilleman, D. (2012). Power plant cycling costs (No. NREL/SR-5500-55433). National Renewable Energy Lab. (NREL), Golden, CO (United States).

Kwon, O., Myers, M., Karstensen, A. D., \& Knowles, D. (2006). The effect of the steam temperature fluctuations during steady state operation on the remnant life of the superheater header. International journal of pressure vessels and piping, 83(5), 349-358.

Jackson, P. S., Fabricius, A., \& Wholey, A. (2019, July). Failure Analysis of SA-213 T91 HRSG Superheater Tube Weld. In ASME Power Conference (Vol. 59100, p. V001T03A002). American Society of Mechanical Engineers. 
Jiang, Y., Liese, E., Zitney, S. E., \& Bhattacharyya, D. (2018). Optimal design of microtube recuperators for an indirect supercritical carbon dioxide recompression closed Brayton cycle. Applied energy, 216, 634-648.

Jiang, Y., Liese, E., Zitney, S. E., \& Bhattacharyya, D. (2018). Design and dynamic modeling of printed circuit heat exchangers for supercritical carbon dioxide Brayton power cycles. Applied energy, 231, 1019-1032.

JianPing, J., Guang, M., Yi, S., and SongBo, X. (2003). An effective continuum damage mechanics model for creep-fatigue life assessment of a steam turbine rotor. International Journal of Pressure Vessels and Piping, 80(6), 389-396.

Johansen, T. A., \& FOSS, B. (1993). Constructing NARMAX models using ARMAX models. International journal of control, 58(5), 1125-115

Jordal, K., Ystad, P. A. M., Anantharaman, R., Chikukwa, A., \& Bolland, O. (2012). Design-point and part-load considerations for natural gas combined cycle plants with post combustion capture. International Journal of Greenhouse Gas Control, 11, 271-282.

Lawal, A., Wang, M., Stephenson, P., \& Obi, O. (2012). Demonstrating full-scale post-combustion $\mathrm{CO}_{2}$ capture for coal-fired power plants through dynamic modelling and simulation. Fuel, 101, 115-128.

Lefton, S. A., \& Besuner, P. (2006). The cost of cycling coal fired power plants. Coal Power Magazine, 2006, 16-20.

Lefton, S. (2004). Profitable operation requires knowing how much it costs to cycle your unit. Combined Cycle Journal, 49-52.

Lefton, S. A., \& Hilleman, D. (2011). Make your plant ready for cycling operations. Power, 155(8), 58-58.

Lefton, S. A., Besuner, P. M., \& Agan, D. D. (2006). The real cost of on/off cycling. Modern power systems, (OCT), 11-13.

Liese, E. (2014). Modeling of a steam turbine including partial arc admission for use in a process simulation software environment. Journal of Engineering for Gas Turbines and Power, 136(11), 112605. 
Liese, E., \& Zitney, S. E. (2018). Using Dynamic Simulation to Evaluate Attemperator Operation in a Natural Gas Combined Cycle With Duct Burners in the Heat Recovery Steam Generator. Journal of Engineering for Gas Turbines and Power, 140(1), 011801.

Lozza, G. (1990). Bottoming steam cycles for combined gas steam power plants: a theoretical estimation of steam turbine performance and cycle analysis. In Proceedings of the 1990 ASME Cogen Turbo, New Orleans, LA, August, 27-29.

Madejski, P., \& Taler, D. (2013). Analysis of temperature and stress distribution of superheater tubes after attemperation or sootblower activation. Energy conversion and management, 71, 131-137.

Miettinen, K. M. (2002). Nonlinear multiobjective optimization. Massachusetts, USA: Kluwer Academic Publishers.

Modliński, N., Szczepanek, K., Nabagło, D., Madejski, P., \& Modliński, Z. (2019). Mathematical procedure for predicting tube metal temperature in the second stage reheater of the operating flexibly steam boiler. Applied Thermal Engineering, 146, 854-865.

Moelling, D., Jackson, P., Malloy, J. (2015) Protecting steam cycle components during low-load operation of combined cycle gas turbine plants. Power, 159 (3), 42-45.

Montañés, R. M., GarĐarsdóttir, S. Ó, Normann, F., Johnsson, F., \& Nord, L. O. (2017). Demonstrating load-change transient performance of a commercial-scale natural gas combined cycle power plant with post-combustion CO 2 capture. International Journal of Greenhouse Gas Control, 63, 158-174.

Mukhopadhyay, N. K., Dutta, B. K., \& Kushwaha, H. S. (2001). On-line fatigue-creep monitoring system for high-temperature components of power plants. International Journal of Fatigue, 23(6), 549-560.

Oko, E., \& Wang, M. (2014). Dynamic modelling, validation and analysis of coal-fired subcritical power plant. Fuel, 135, 292-300.

Paul, P., Bhattacharyya, D., Turton, R., and Zitney, S. E. (2017). Nonlinear Dynamic Model-Based Multiobjective Sensor Network Design Algorithm for a Plant with an Estimator-Based Control System. Industrial \& Engineering Chemistry Research, 56(26), 7478-7490. 
Platt, J. (2002). Determining the Cost of Cycling and Varied Load Operation: Methodology. Tech. Rep. 1004412, EPRI, Palo Alto, CA. 2002.

Pilkey, W. D., and Pilkey, D. F. (2008). Peterson's stress concentration factors. John Wiley and Sons.

Pletl, C. (2005). Experiments and numerical simulation on th dynamic behaviour of a waste heat boiler with once-through cycle; Experimente und numerische Simulation zum dynamischen Verhalten eines Abhitzedampferzeugers mit Zwangdurchlauf.

Prasad, G., Swidenbank, E., \& Hogg, B. W. (1998). A local model networks based multivariable long-range predictive control strategy for thermal power plants. Automatica, 34(10), 11851204.

Rodilla, P., Cerisola, S., \& Batlle, C. (2013). Modeling the major overhaul cost of gas-fired plants in the unit commitment problem. IEEE Transactions on Power Systems, 29(3), 1001-1011.

Rosario, D. A., Riccardella, P. C., Bisbee, L. H., Luttrell, M. E., Nelson, S., Eastman, A. D., \& Rogers, M. D. (1995). Remaining life assessment of a secondary superheater outlet header (No. CONF-950740-). American Society of Mechanical Engineers, New York, NY (United States).

Rúa, J., Agromayor, R., Hillestad, M., and Nord, L. O. (2020). Optimal Dynamic Operation of Natural Gas Combined Cycles Accounting for Stresses in Thick-Walled Components. Applied Thermal Engineering, 114858

Rúa, J., and Nord, L. O. (2020). Optimal control of flexible natural gas combined cycles with stress monitoring: Linear vs nonlinear model predictive control. Applied Energy, 265, 114820.

Sarda, P., Hedrick, E., Reynolds, K., Bhattacharyya, D., Zitney, S. E., \& Omell, B. (2018). Development of a Dynamic Model and Control System for Load-Following Studies of Supercritical Pulverized Coal Power Plants. Processes, 6(11), 226.

Shankar, V., Valsan, M., Rao, K. B. S., Kannan, R., Mannan, S. L., and Pathak, S. D. (2006). Low cycle fatigue behavior and microstructural evolution of modified $9 \mathrm{Cr}-1 \mathrm{Mo}$ ferritic steel. Materials Science and Engineering: A, 437(2), 413-422. 
Sorge, J., Taft, C., Boohaker, C., Seachman, S. (2017, June). HRSG Damage Reduction through Improved Controls - Phase 1 and 2 Findings. In 60th Annual ISA POWID Symposium, Cleveland, $\mathrm{OH}$.

Starkloff, R., Alobaid, F., Karner, K., Epple, B., Schmitz, M., \& Boehm, F. (2015). Development and validation of a dynamic simulation model for a large coal-fired power plant. Applied Thermal Engineering, 91, 496-506.

Taler, J., Węglowski, B., Taler, D., Sobota, T., Dzierwa, P., Trojan, M., Madejski, P. and Pilarczyk, M., (2015). Determination of start-up curves for a boiler with natural circulation based on the analysis of stress distribution in critical pressure components. Energy, 92, 153-159.

Taler, J., Taler, D., Kaczmarski, K., Dzierwa, P., Trojan, M., and Sobota, T. (2018). Monitoring of thermal stresses in pressure components based on the wall temperature measurement. Energy, 160, 500-519.

Troy, N., Flynn, D., Milligan, M., \& O'Malley, M. (2012). Unit commitment with dynamic cycling costs. IEEE Transactions on Power Systems, 27(4), 2196-2205.

UNI - Ente Nazionale di Normazione. UNI EN 12952-5:2011. Water-tube Boilers Standards; 2011.

Van den Bergh, K., \& Delarue, E. (2015). Cycling of conventional power plants: technical limits and actual costs. Energy Conversion and Management, 97, 70-77.

Viswanathan, R., Paterson, S. R., Grunloh, H., \& Gehl, S. (1994). Life assessment of superheater/reheater tubes in fossil boilers.

Wang, W., \& Safonov, M. G. (1990). A tighter relative-error bound for balanced stochastic truncation. Systems \& Control Letters, 14(4), 307-317.

Wang, Y., Bhattacharyya, D., \& Turton, R. (2019). Dynamic Modeling and Control of a Natural Gas Combined Cycle Power Plant for Load-Following Operation. In Computer Aided Chemical Engineering (Vol. 47, pp. 101-106). Elsevier.

Wang, Y., Bhattacharyya, D., Turton, R. (2020). Evaluation of Novel Configurations of Natural Gas Combined Cycle (NGCC) Power Plants for Load-Following Operation using Dynamic Modeling and Optimization. Energy \& Fuel, 34(1), 1053-1070. 
Willcox, K., \& Peraire, J. (2002). Balanced model reduction via the proper orthogonal decomposition. AIAA journal, 40(11), 2323-2330.

Yan, H., Li, X., Liu, M., Chong, D., \& Yan, J. (2020). Performance analysis of a solar-aided coalfired power plant in off-design working conditions and dynamic process. Energy Conversion and Management, 220, 113059.

Yasniy, O., Pyndus, Y., Brevus, V., Iasnii, V., \& Lapusta, Y. (2016). Lifetime estimation of superheater header. Procedia Structural Integrity, 2, 840-846.

Yasniy, O., Pyndus, Y., Iasnii, V., \& Lapusta, Y. (2017). Residual lifetime assessment of thermal power plant superheater header. Engineering Failure Analysis, 82, 390-403.

Zhang, Q., Turton, R., \& Bhattacharyya, D. (2016). Development of model and model-predictive control of an MEA-based postcombustion $\mathrm{CO}_{2}$ capture process. Industrial \& Engineering Chemistry Research, 55(5), 1292-1308.

Zhang, Q., Turton, R., \& Bhattacharyya, D. (2018). Nonlinear model predictive control and Hळ robust control for a post-combustion $\mathrm{CO}_{2}$ capture process. International Journal of Greenhouse Gas Control, 70, 105-116.

Zoelle, A., Keairns, D., Pinkerton, L. L., Turner, M. J., Woods, M., Kuehn, N. \& Chou, V. (2015). Cost and Performance Baseline for Fossil Energy Plants Volume 1a: Bituminous Coal (PC) and Natural Gas to Electricity Revision 3 (No. DOE/NETL-2015/1723). NETL 